\title{
Supplementary material for: A high-resolution spatial assessment of the impacts of drought variability on vegetation activity in Spain from 1981 to 2015
}

Sergio M. Vicente-Serrano ${ }^{1,}{ }^{*}$, Cesar Azorin-Molina ${ }^{2}$, Marina Peña-Gallardo ${ }^{1}$, Miquel TomasBurguera $^{3}$, Fernando Domínguez-Castro ${ }^{1}$, Natalia Martín-Hernández ${ }^{1}$, Santiago Beguería ${ }^{3}$, Ahmed $\underline{\text { El Kenawy }}^{4}$, Iván Noguera ${ }^{1}$, Mónica García $^{5}$

Family names (or surnames) are underlined

${ }^{1}$ Instituto Pirenaico de Ecología, Spanish National Research Council (IPE-CSIC), Campus de Aula Dei, P.O. Box 13034, E-50059 Zaragoza, Spain; ${ }^{2}$ Regional Climate Group, Department of Earth Sciences, University of Gothenburg, Gothenburg, Sweden; ${ }^{3}$ Estación Experimental de Aula Dei, Spanish National Research Council (EEAD-CSIC), Zaragoza, Spain; ${ }^{4}$ Department of Geography, Mansoura University, 35516, Mansoura, Egypt; ${ }^{5}$ Department of Environmental Engineering, Technical University of Denmark, Lyngby, Denmark.

* Corresponding author: Sergio M. Vicente-Serrano (e-mail: svicen@ipe.csic.es) 

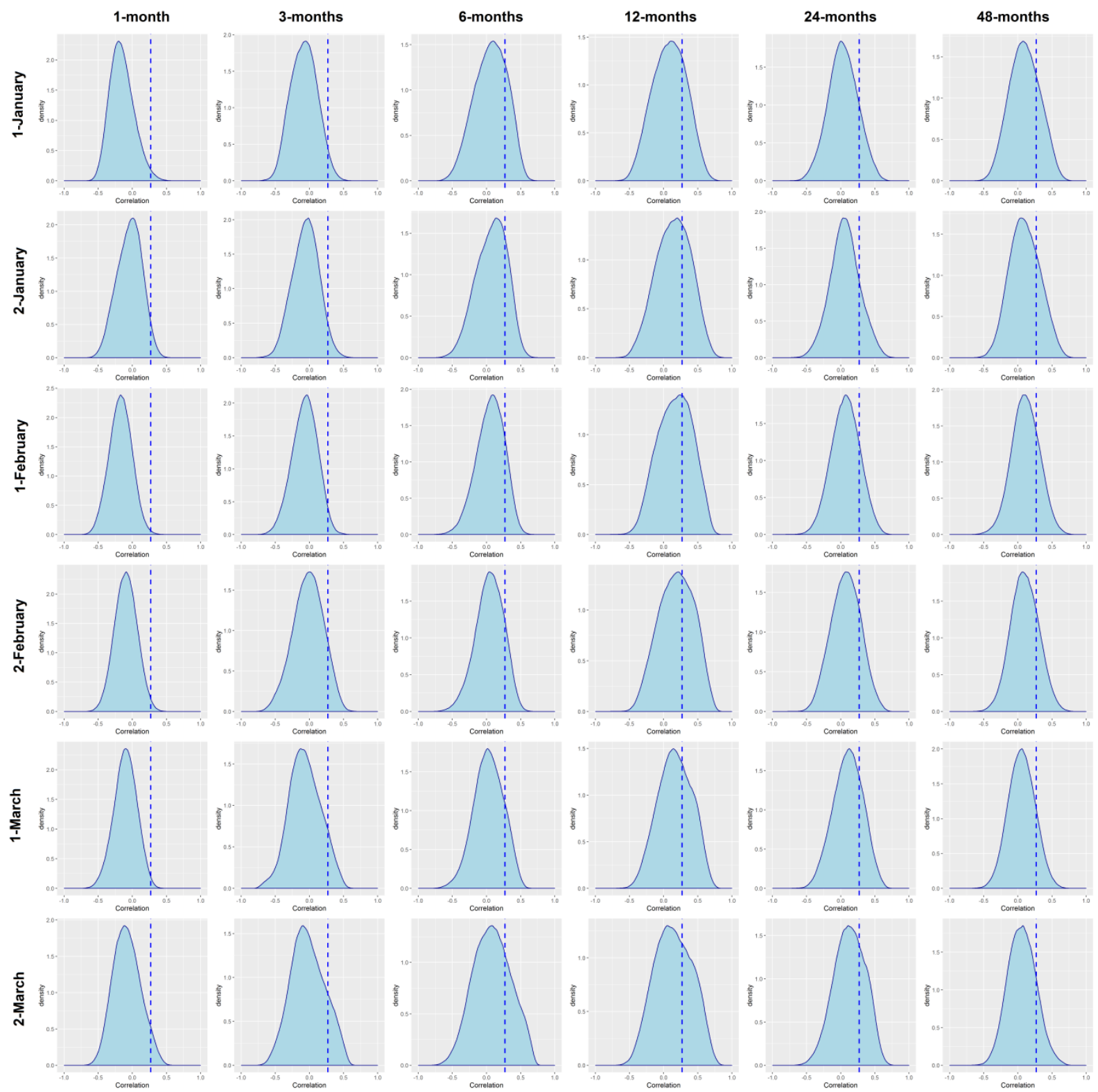

Supplementary Figure 1: Density plots summarizing the maximum correlations found between the sNDVI and the SPEI (January-March). Vertical dashed line represents the threshold for significant correlations $(\mathrm{p}<0.05)$. 

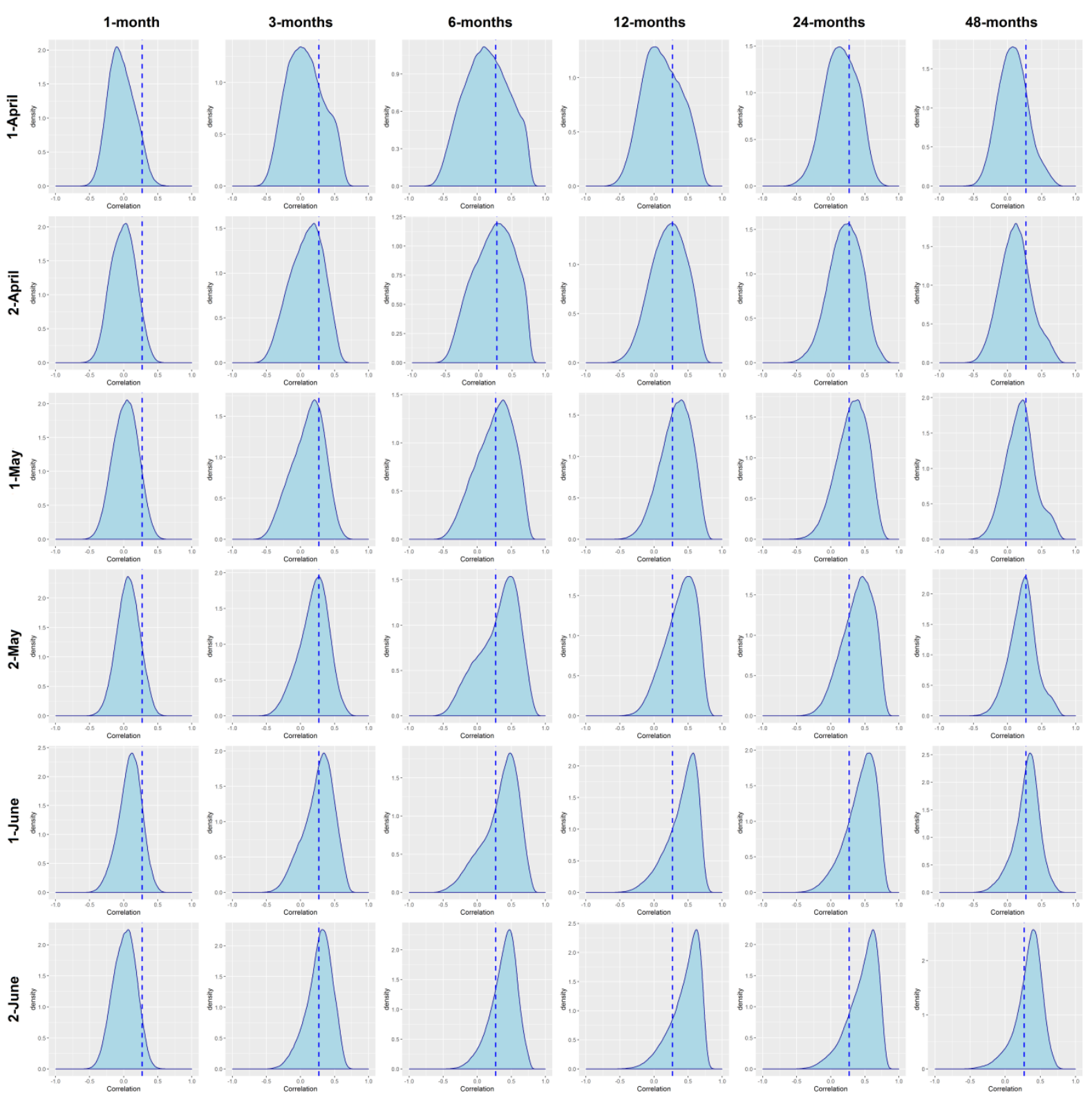

Supplementary Figure 2: Density plots summarizing the maximum correlations found between the sNDVI and the SPEI (April-June). Vertical dashed line represents the threshold for significant correlations $(\mathrm{p}<0.05)$. 

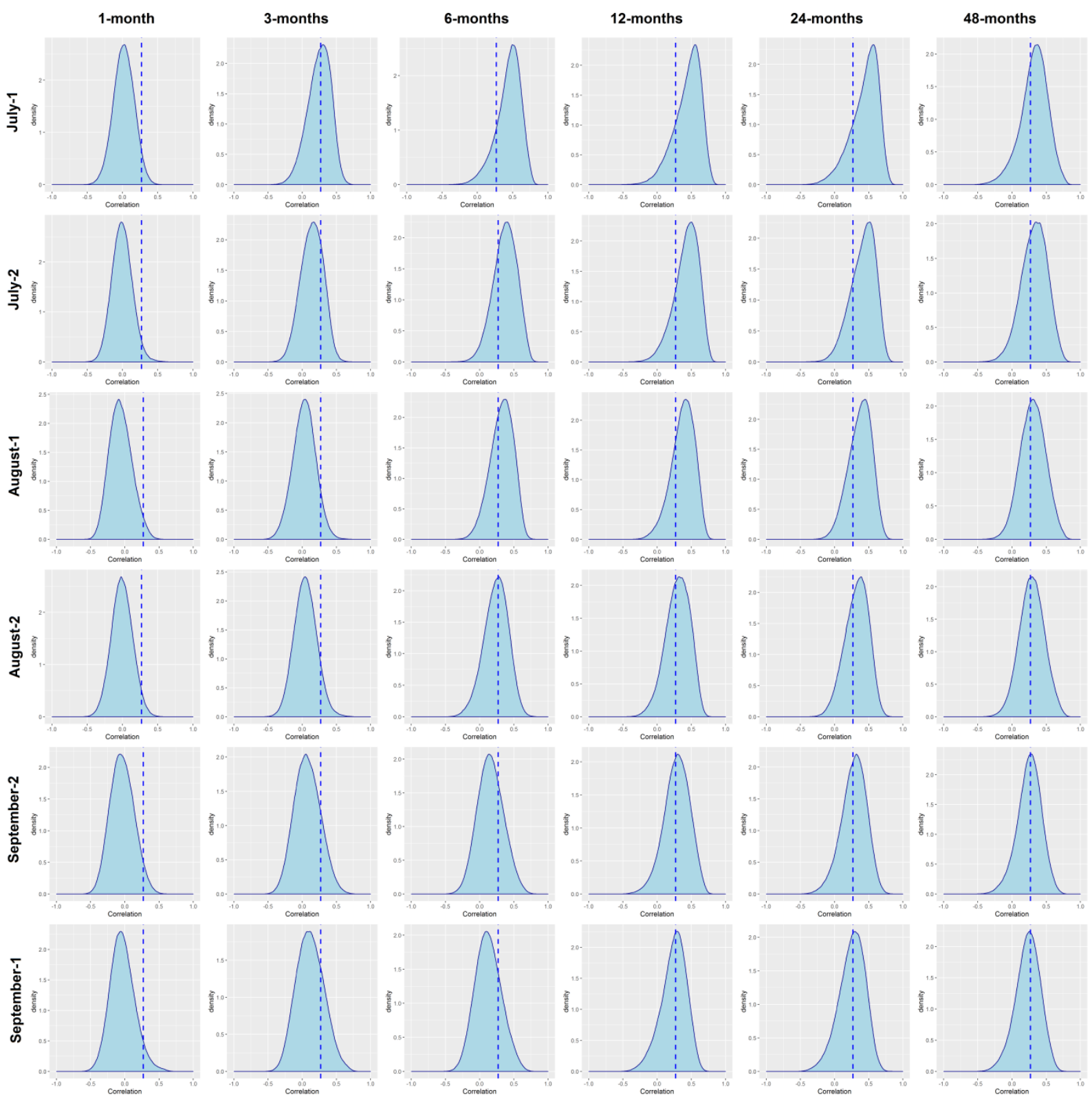

Supplementary Figure 3: Density plots summarizing the maximum correlations found between the SNDVI and the SPEI (July-September). Vertical dashed line represents the threshold for significant correlations $(\mathrm{p}<0.05)$. 

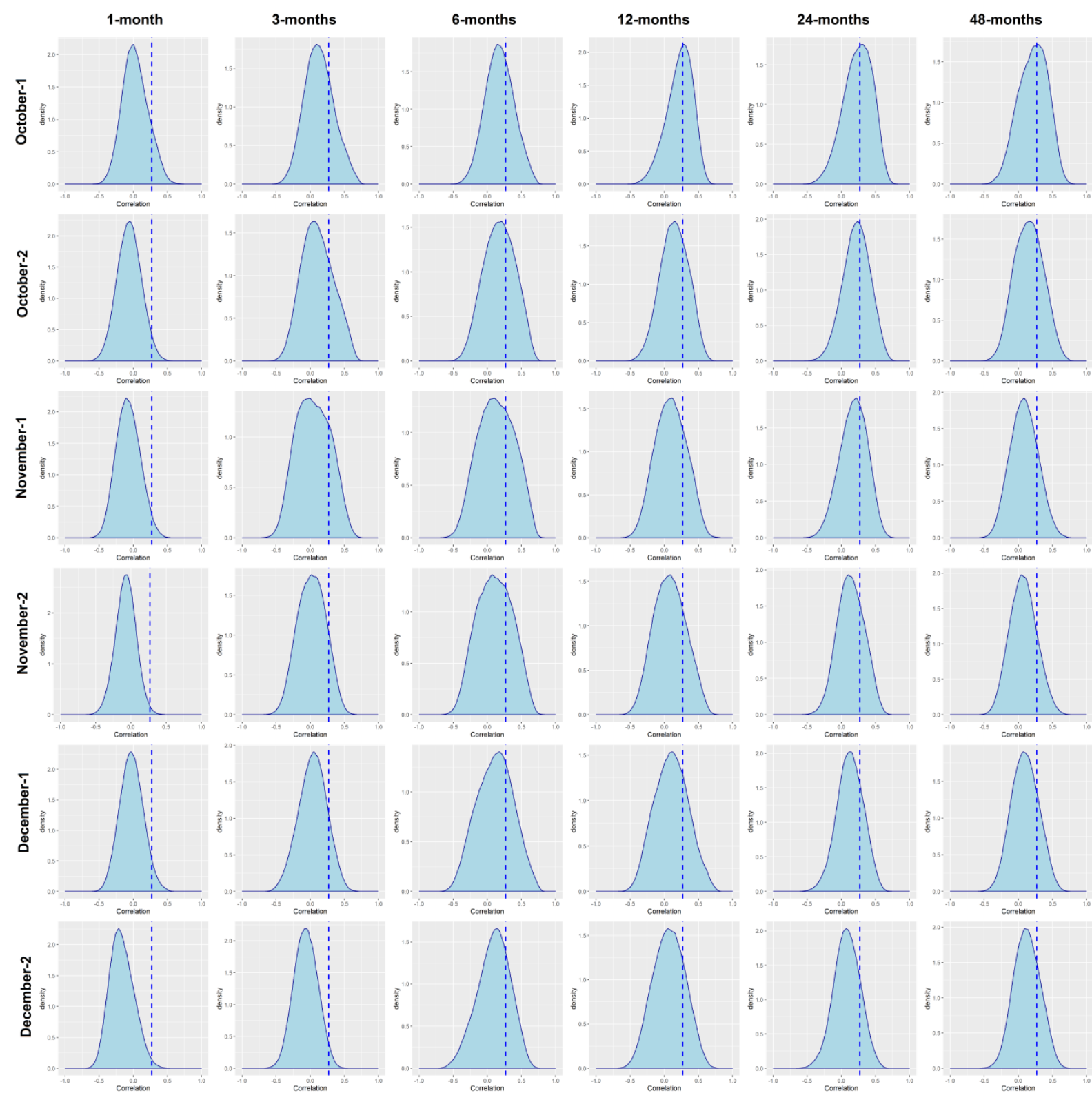

Supplementary Figure 4: Density plots summarizing the maximum correlations found between the sNDVI and the SPEI (October-December). Vertical dashed line represents the threshold for significant correlations $(\mathrm{p}<0.05)$. 

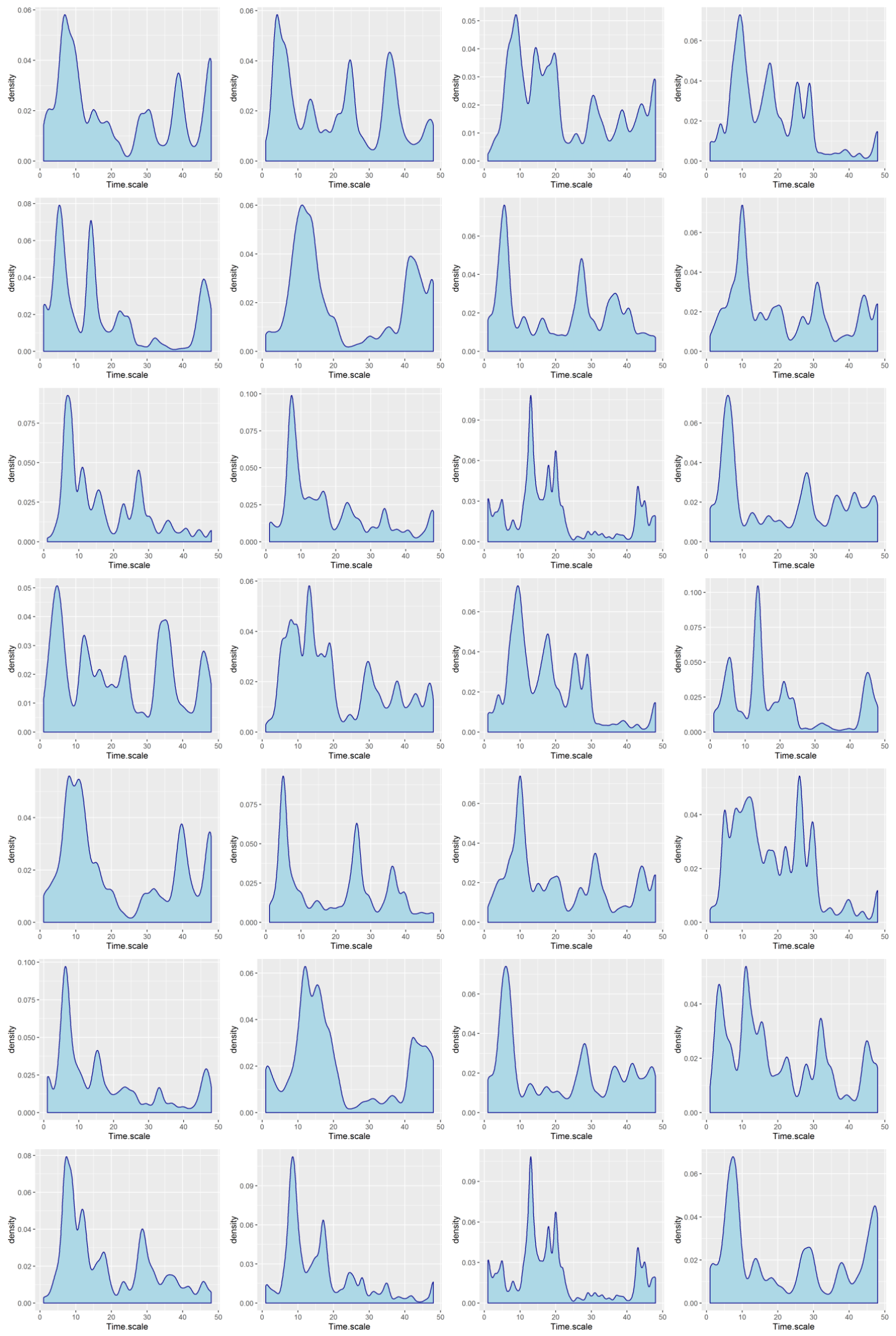

Supplementary Figure 5: Density plots showing the SPEI time scale at which the maximum correlation between SNDVI and SPEI is recorded for the different 24 semi-monthly periods. 


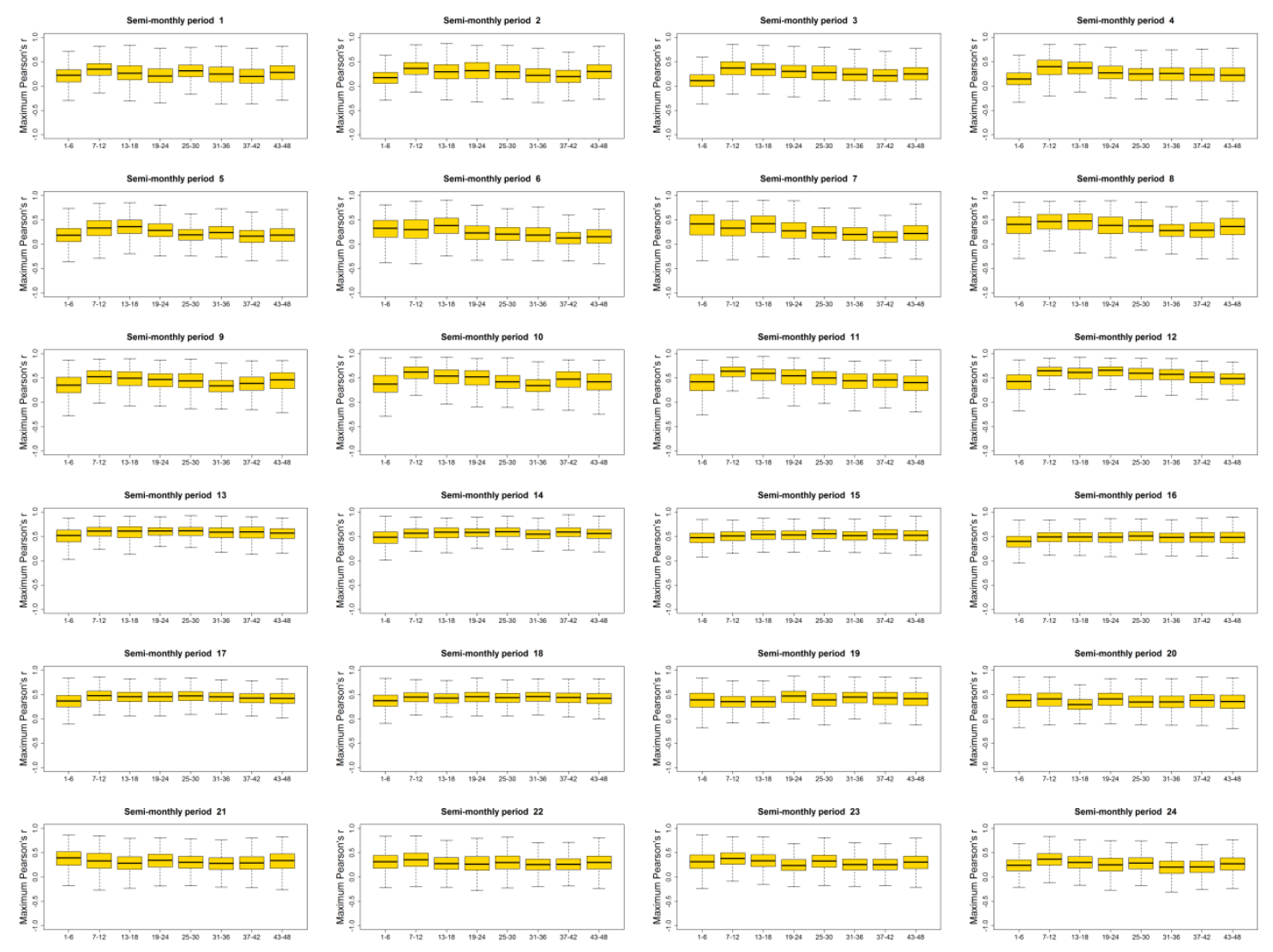

Supplementary Figure 6: Boxplots showing the maximum sNDVI vs. SPEI correlation as a function of the different SPEI time-scales. 

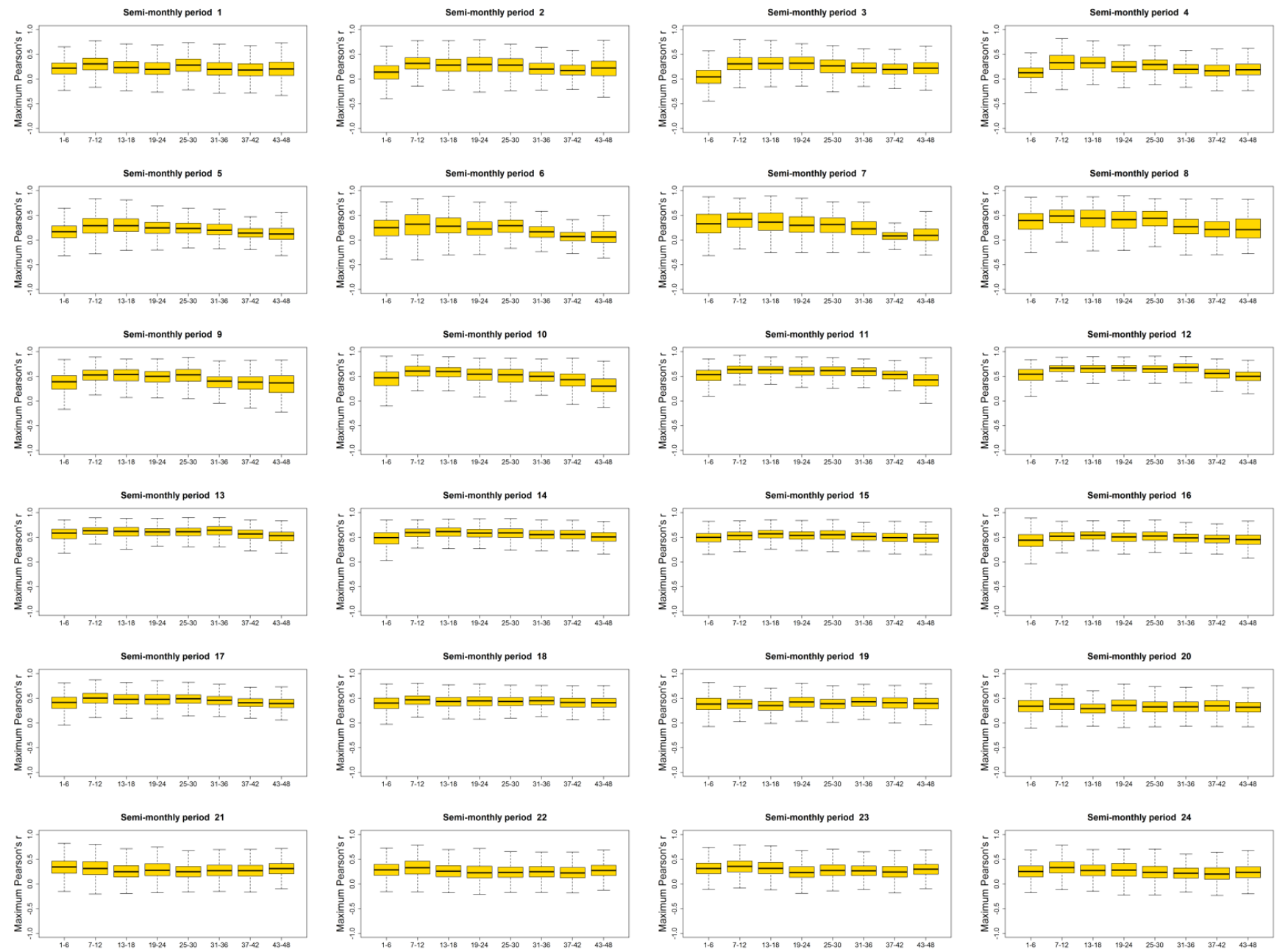

Supplementary Figure 7: Boxplots showing the maximum sNDVI vs. SPEI correlation as a function of the different SPEI time-scales. Non-irrigated arable lands 

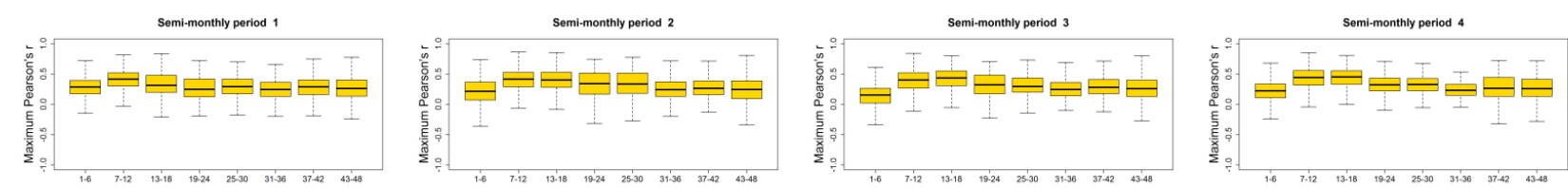

Semi-monthly period 5
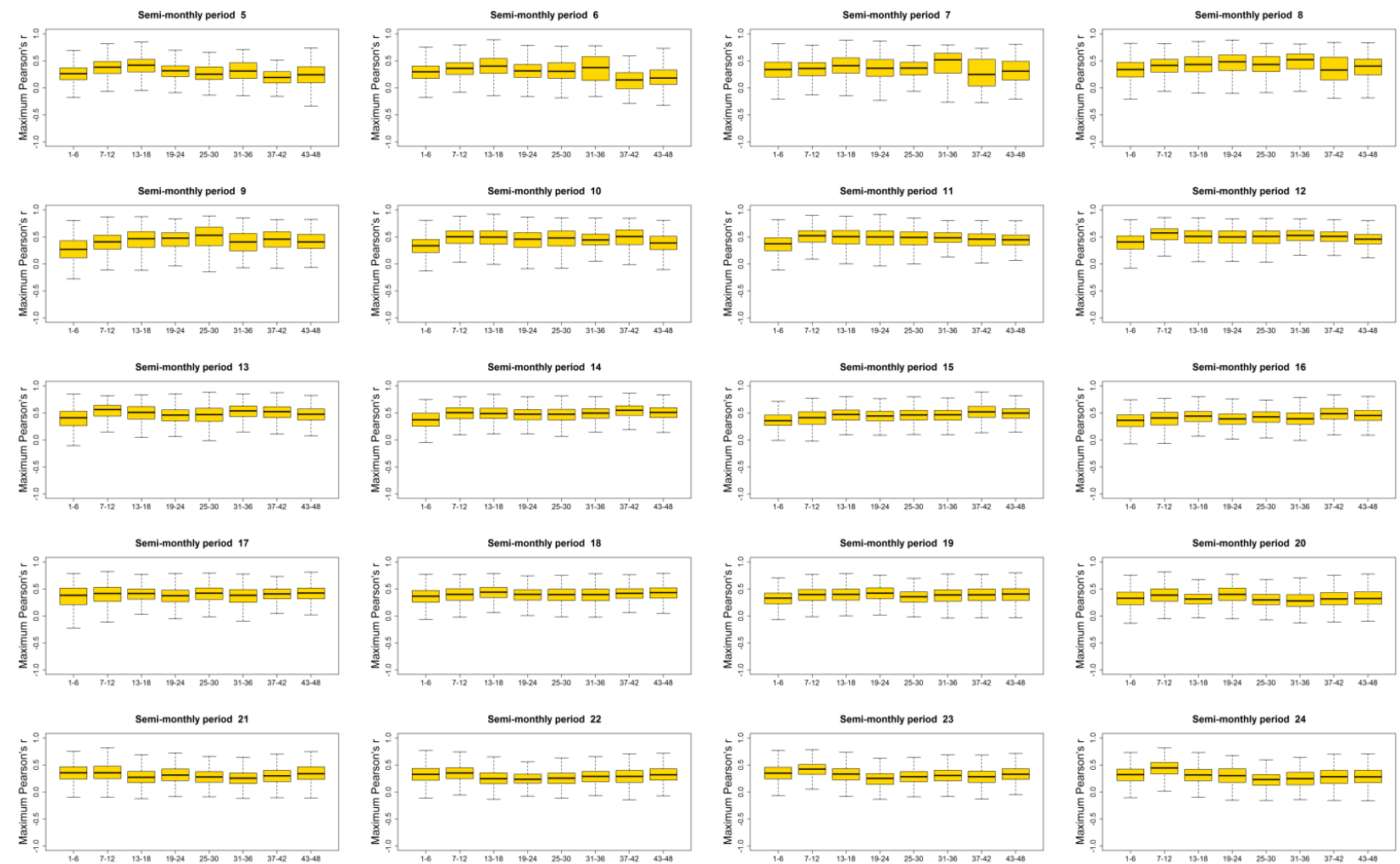

Supplementary Figure 8: Boxplots showing the maximum sNDVI vs. SPEI correlation as a function of the different SPEI time-scales. Irrigated lands 

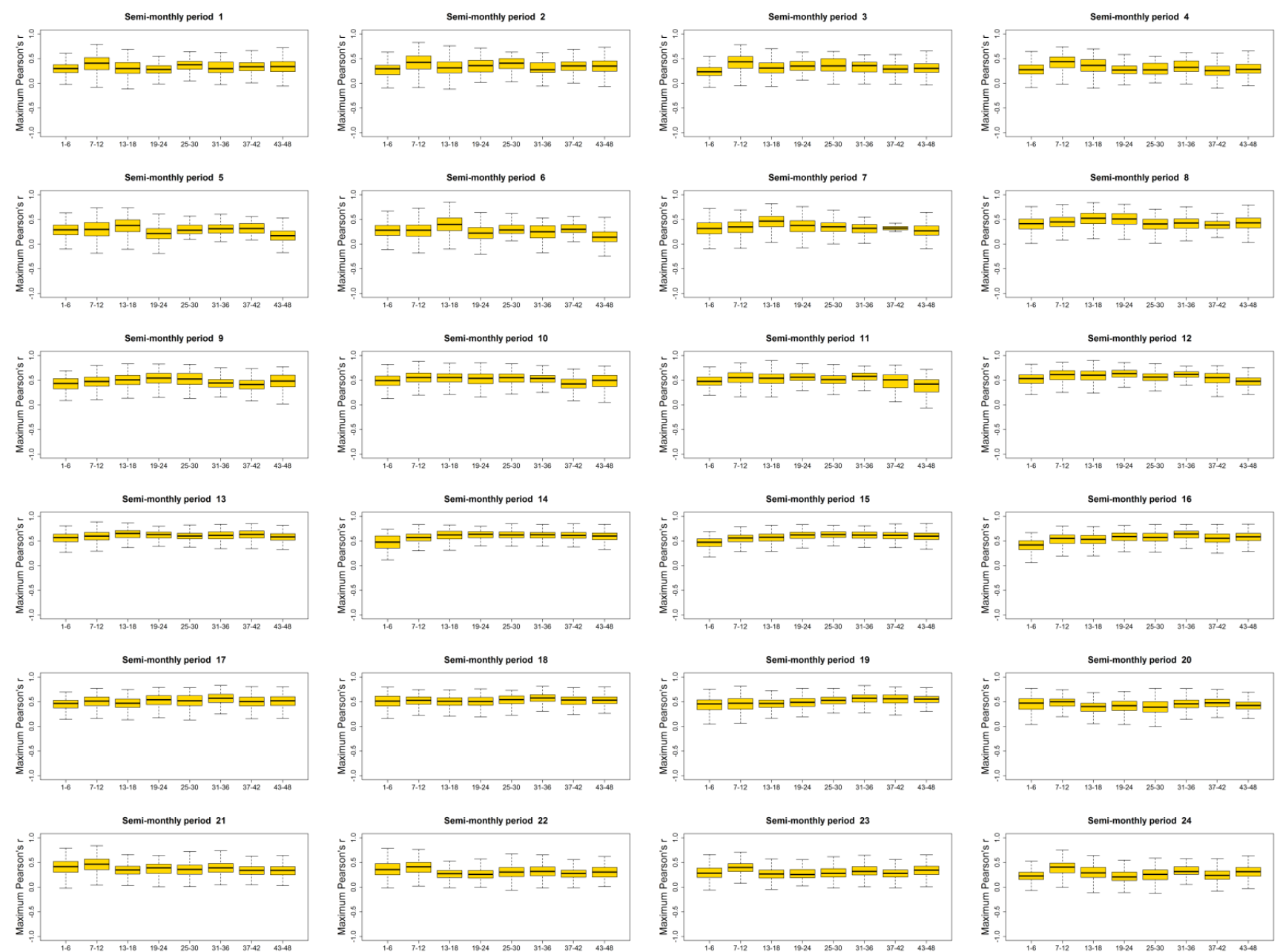

Supplementary Figure 9: Boxplots showing the maximum sNDVI vs. SPEI correlation as a function of the different SPEI time-scales. Vineyards 


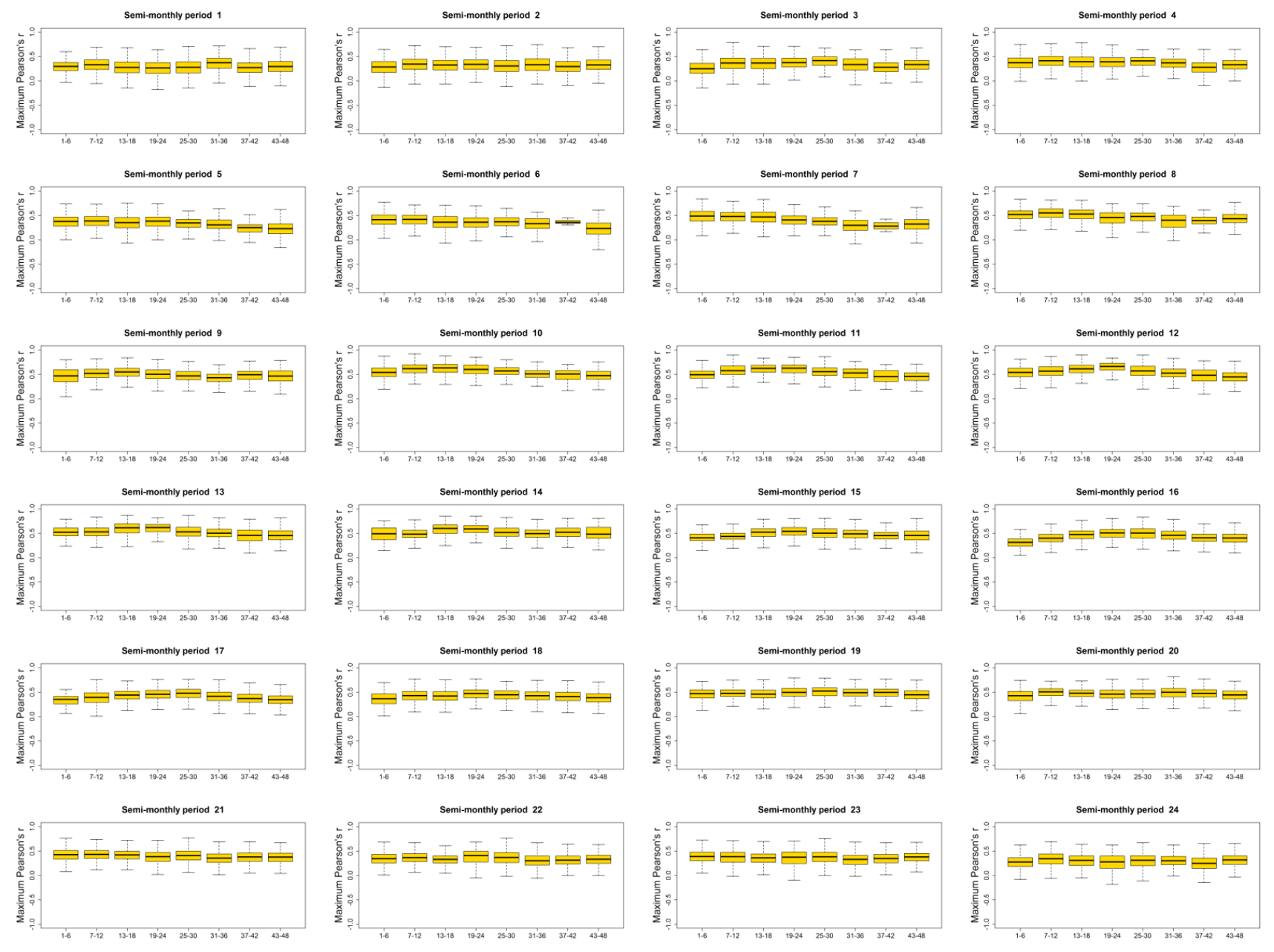

Supplementary Figure 10: Boxplots showing the maximum sNDVI vs. SPEI correlation as a function of the different SPEI time-scales. Olive groves. 


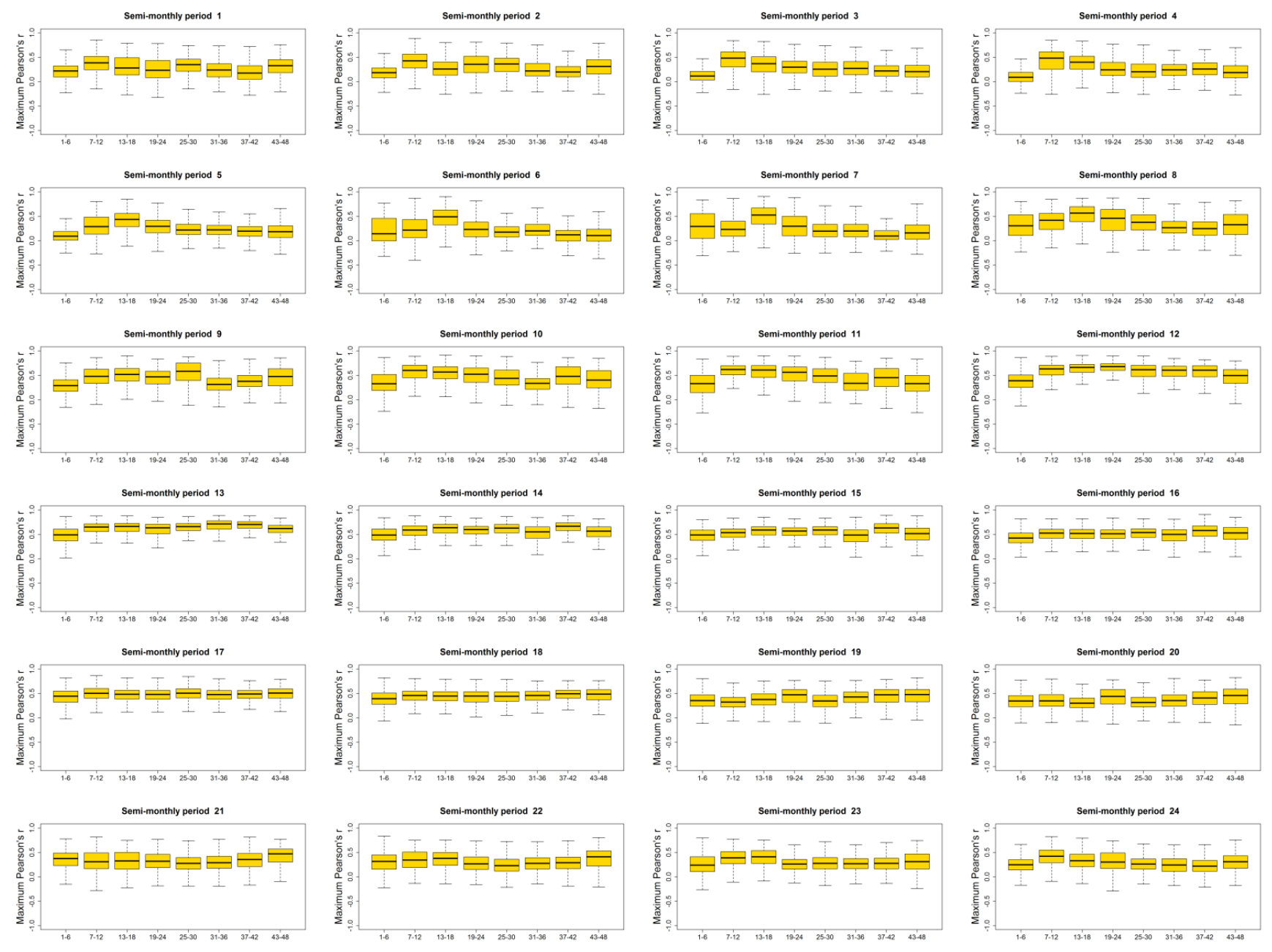

Supplementary Figure 11: Boxplots showing the maximum sNDVI vs. SPEI correlation as a function of the different SPEI time-scales. Mixed agriculture/natural vegetation 


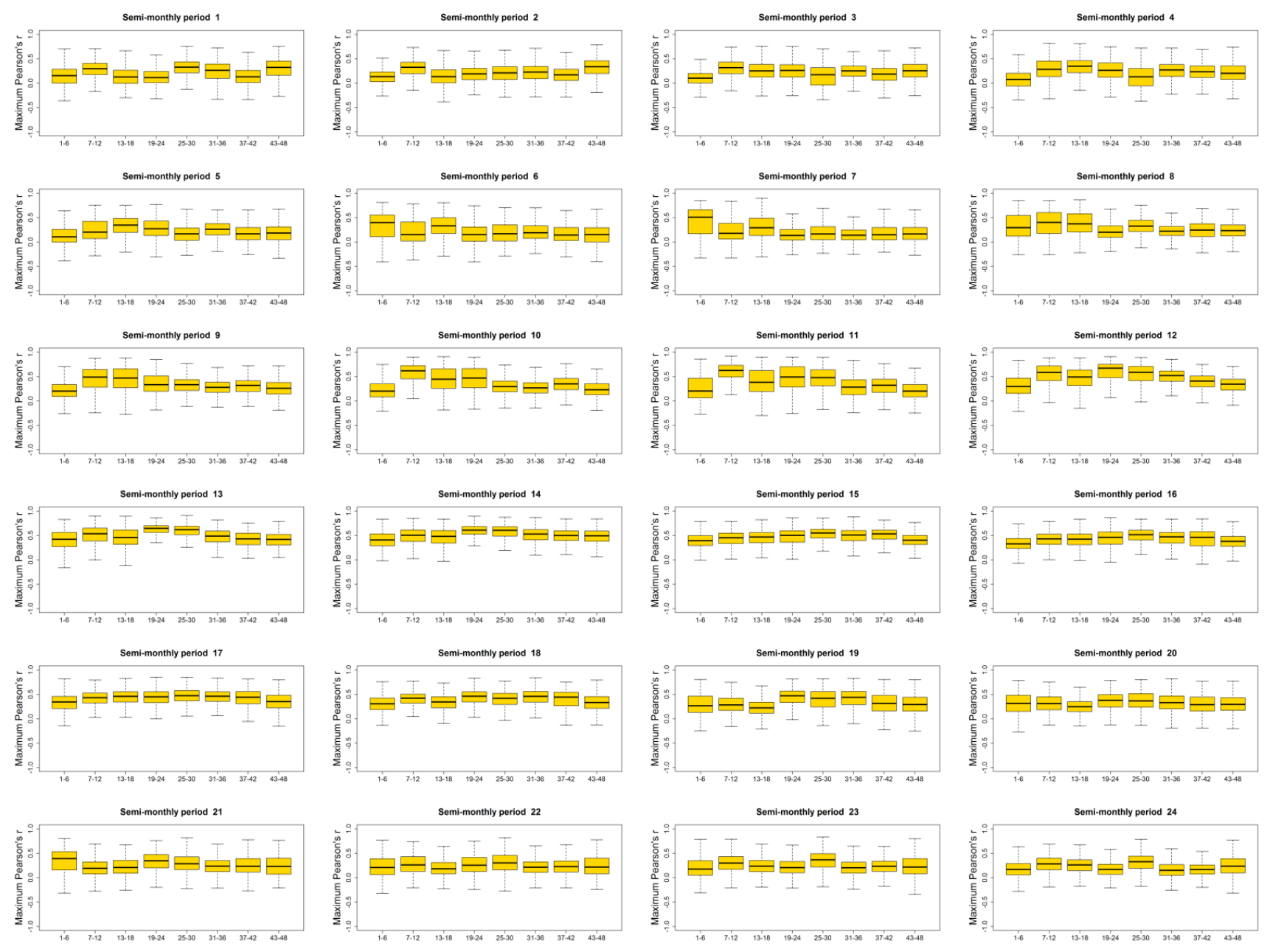

Supplementary Figure 12: Boxplots showing the maximum sNDVI vs. SPEI correlation as a function of the different SPEI time-scales. Broad-leaved forests 


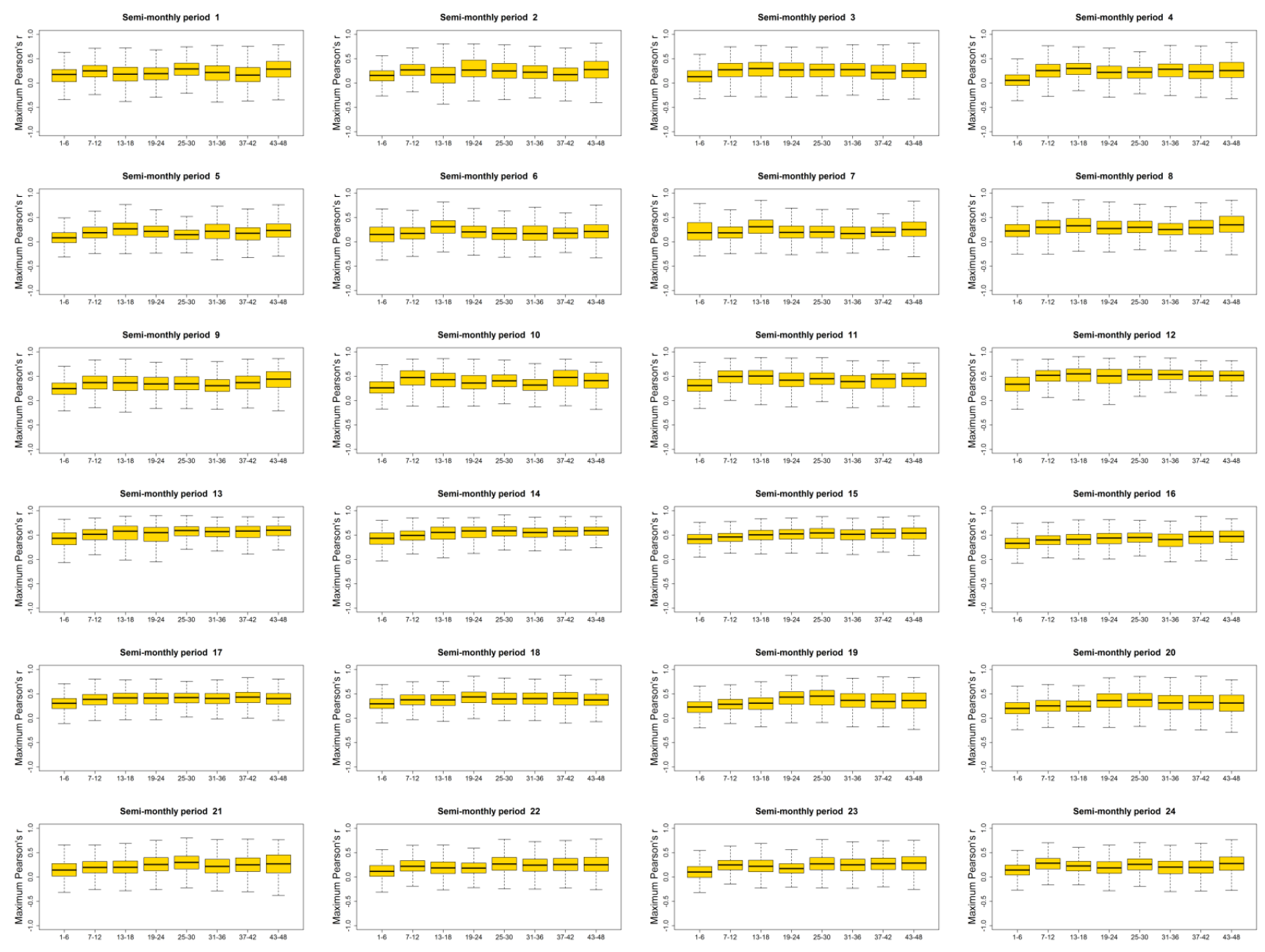

Supplementary Figure 13: Boxplots showing the maximum sNDVI vs. SPEI correlation as a function of the different SPEI time-scales. Coniferous forests 


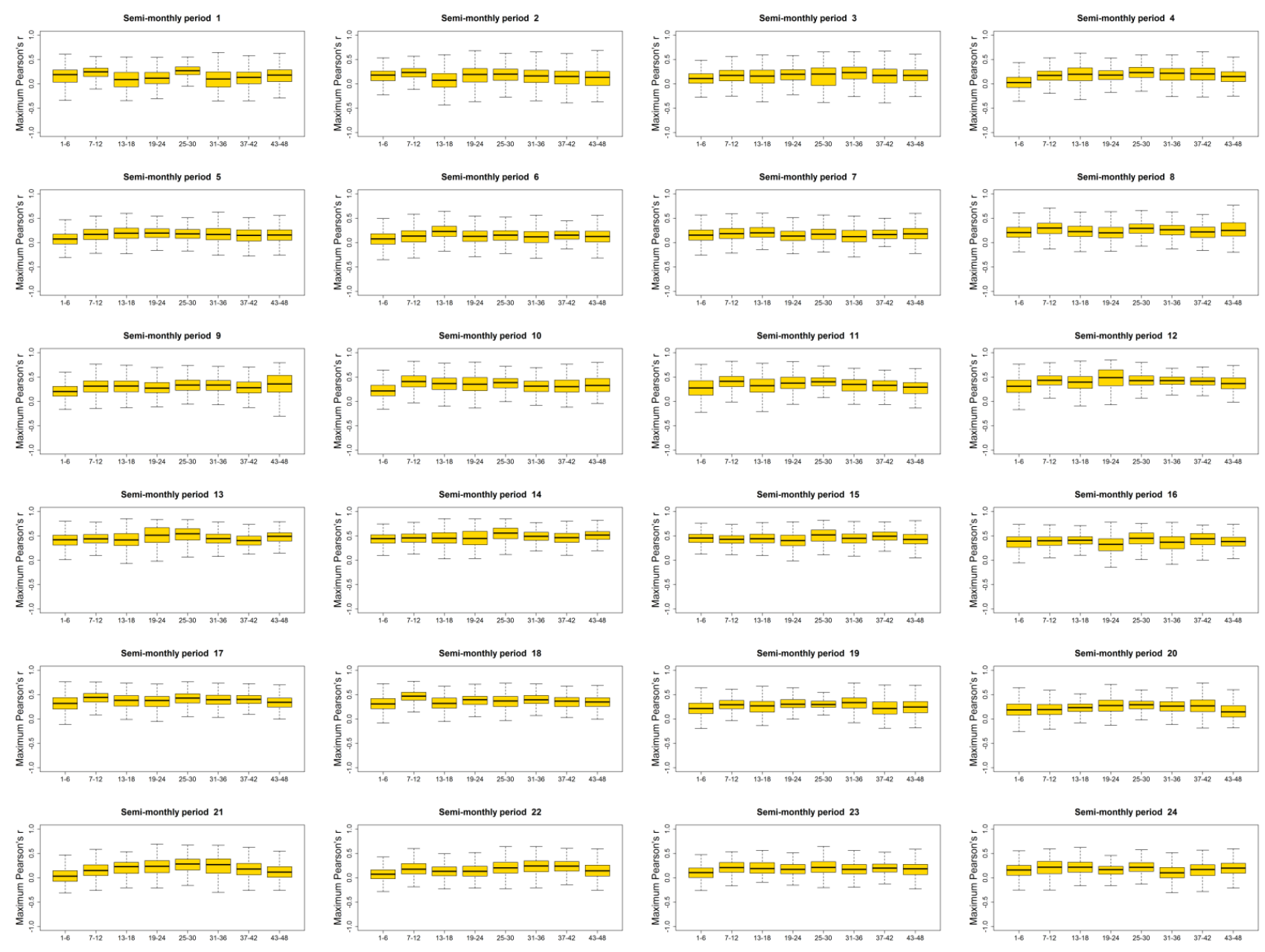

Supplementary Figure 14: Boxplots showing the maximum sNDVI vs. SPEI correlation as a function of the different SPEI time-scales. Mixed forests 


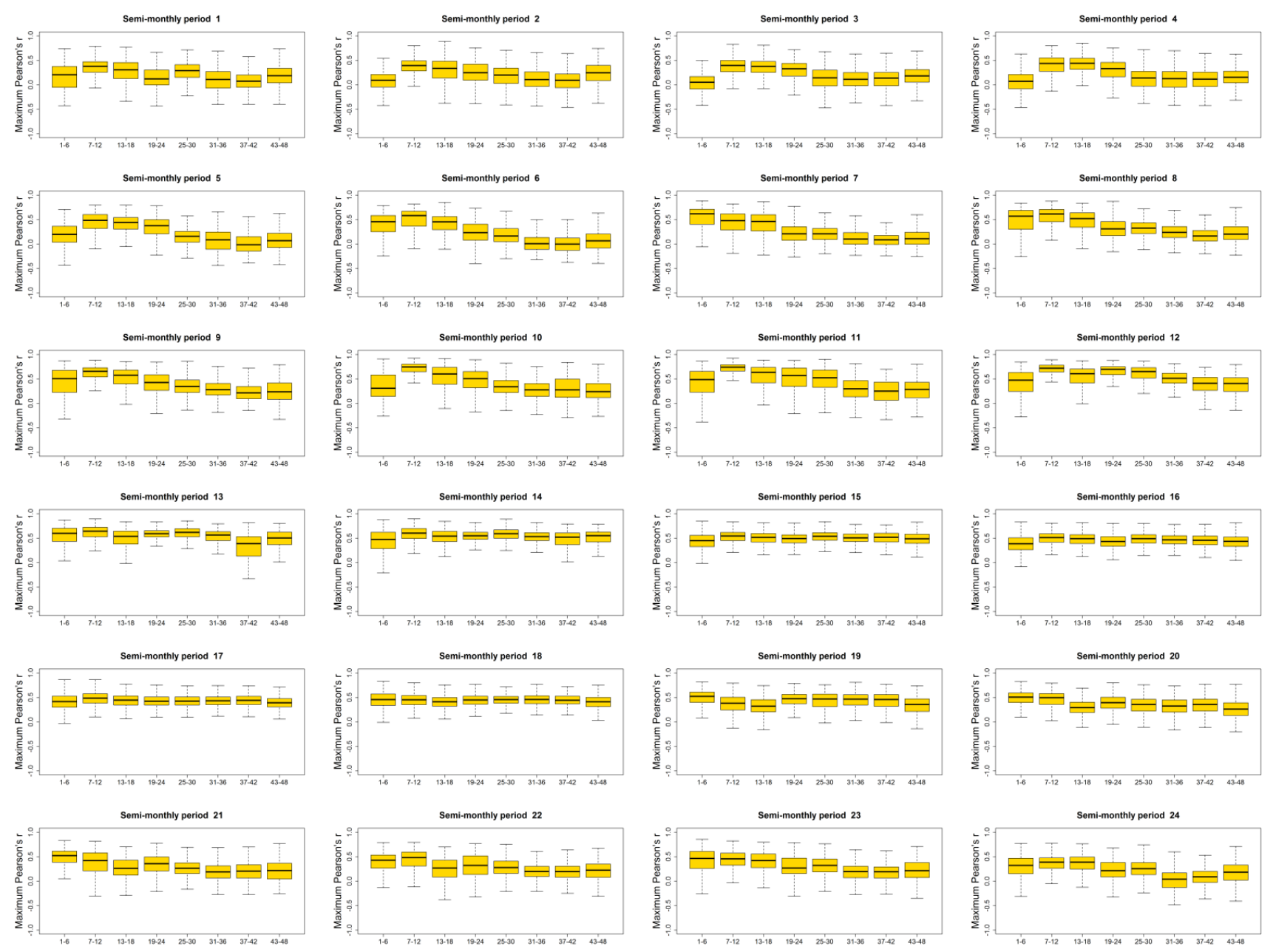

Supplementary Figure 15: Boxplots showing the maximum sNDVI vs. SPEI correlation as a function of the different SPEI time-scales. Natural grassland 

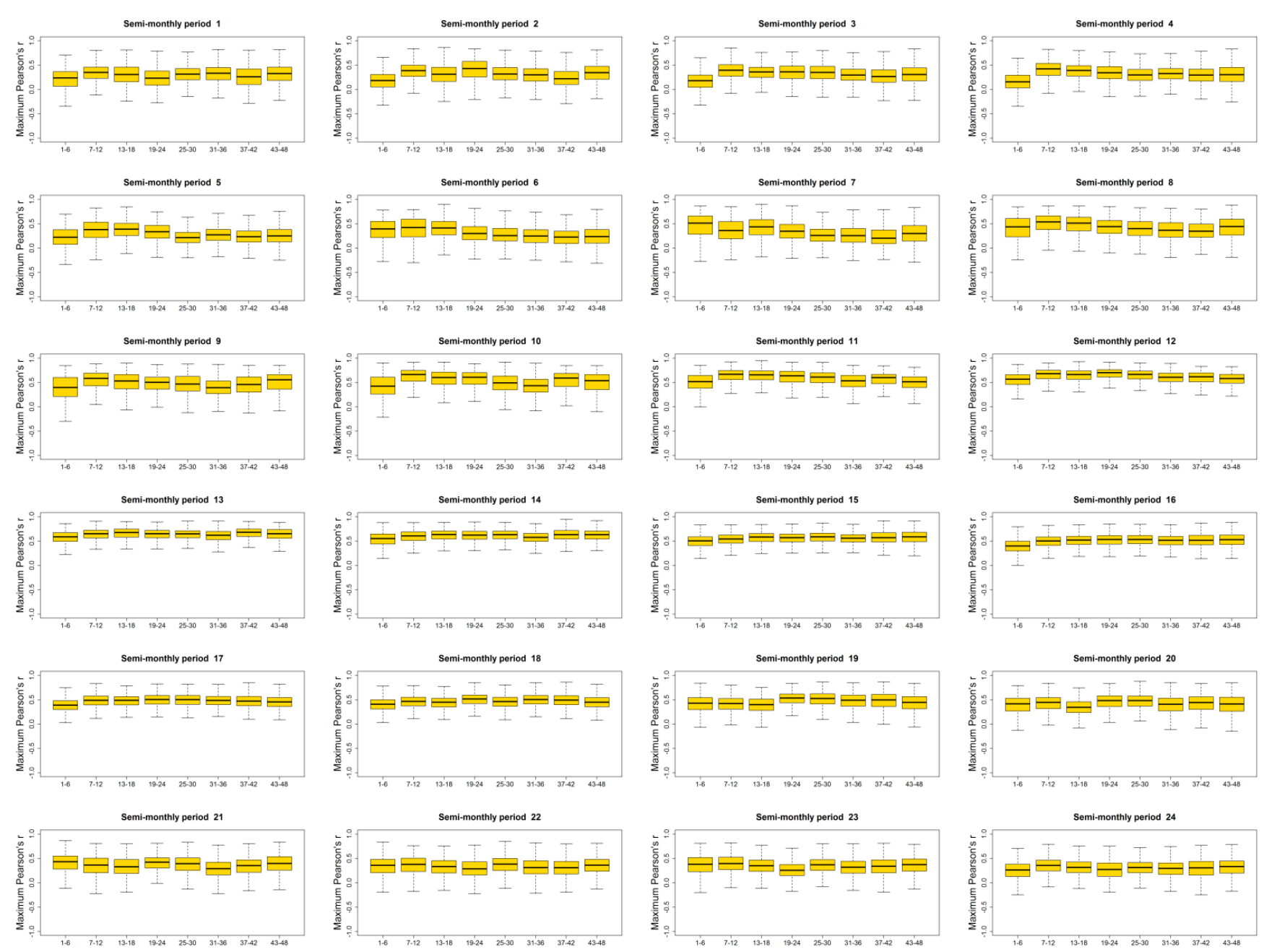

Supplementary Figure 16: Boxplots showing the maximum sNDVI vs. SPEI correlation as a function of the different SPEI time-scales. Sclerophillous vegetation 


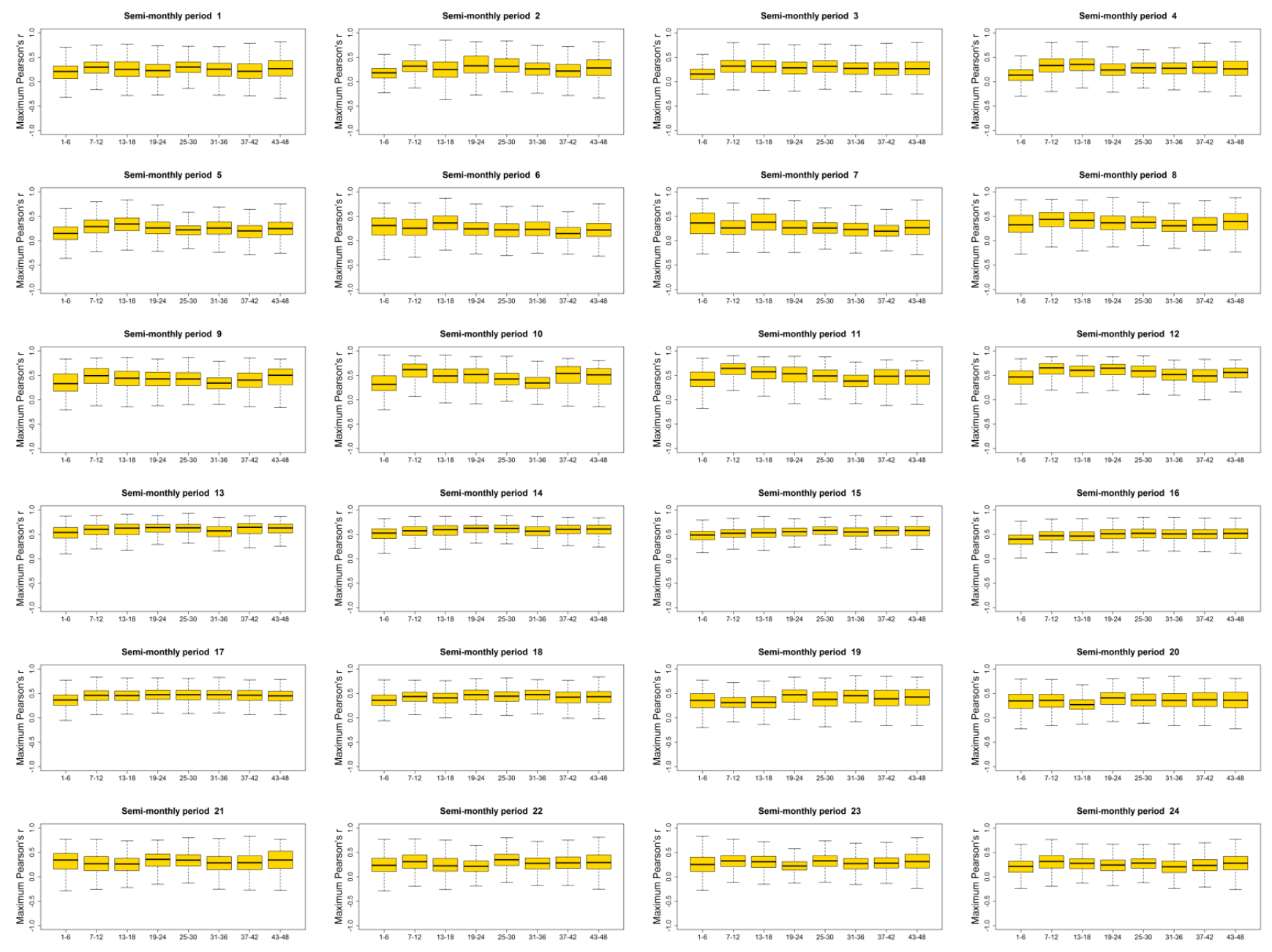

Supplementary Figure 17: Boxplots showing the maximum sNDVI vs. SPEI correlation as a function of the different SPEI time-scales. Transition wood-scrub. 


\begin{tabular}{|l|r|r|r|r|}
\hline & $\begin{array}{l}\text { Negative } \\
(\mathrm{p}<0.05)\end{array}$ & $\begin{array}{l}\text { Negative } \\
(\mathrm{p}>0.05)\end{array}$ & $\begin{array}{l}\text { Positive }(\mathrm{p} \\
>0.05)\end{array}$ & $\begin{array}{l}\text { Positive }(\mathrm{p} \\
<0.05)\end{array}$ \\
\hline 1st Jan & 0.1 & 7.9 & 47.1 & 44.9 \\
\hline 2nd Jan & 0.5 & 7.8 & 43.6 & 48.2 \\
\hline 1st Feb & 0.2 & 7.3 & 43.2 & 49.3 \\
\hline 2sd Feb & 0.0 & 6.1 & 45.2 & 48.6 \\
\hline 1st Mar & 0.0 & 9.5 & 48.2 & 42.2 \\
\hline 2sd Mar & 0.3 & 13.0 & 44.0 & 42.7 \\
\hline 1st Apr & 0.0 & 8.6 & 35.5 & 55.9 \\
\hline 2sd Apr & 0.0 & 4.7 & 25.3 & 69.9 \\
\hline 1st May & 0.0 & 1.0 & 13.7 & 85.3 \\
\hline 2sd May & 0.0 & 0.3 & 7.2 & 92.5 \\
\hline 1st Jun & 0.0 & 0.1 & 2.4 & 97.5 \\
\hline 2sd Jun & 0.0 & 0.0 & 1.3 & 98.7 \\
\hline 1st Jul & 0.0 & 0.0 & 1.8 & 98.2 \\
\hline 2sd Jul & 0.0 & 0.0 & 2.3 & 97.7 \\
\hline 1st Aug & 0.0 & 0.0 & 3.5 & 96.4 \\
\hline 2sd Aug & 0.0 & 0.1 & 5.6 & 94.2 \\
\hline 1st Sep & 0.0 & 0.2 & 9.7 & 90.1 \\
\hline 2sd Sep & 0.0 & 0.2 & 12.7 & 87.1 \\
\hline 1st Oct & 0.0 & 0.5 & 22.0 & 77.5 \\
\hline 2sd Oct & 0.0 & 1.1 & 35.9 & 63.1 \\
\hline 1st Nov & 0.0 & 3.1 & 42.7 & 54.2 \\
\hline 2sd Nov & 0.0 & 3.5 & 48.5 & 47.9 \\
\hline 1st Dec & 0.0 & 1.9 & 40.6 & 57.5 \\
\hline 2sd Dec & 0.0 & 4.1 & 45.8 & 50.1 \\
\hline
\end{tabular}

Supplementary Table 1: Percentage of the total surface area in Spain showing positive or negative, significant or non-significant Pearson's r correlations between the SNDVI and the SPEI. Nonirrigated arable lands. 


\begin{tabular}{|l|r|r|r|r|}
\hline & $\begin{array}{l}\text { Negative } \\
(\mathrm{p}<0.05)\end{array}$ & $\begin{array}{l}\text { Negative } \\
(\mathrm{p}>0.05)\end{array}$ & $\begin{array}{l}\text { Positive }(\mathrm{p} \\
>0.05)\end{array}$ & $\begin{array}{l}\text { Positive (p } \\
<0.05)\end{array}$ \\
\hline 1st Jan & 0.0 & 4.0 & 32.5 & 63.5 \\
\hline 2nd Jan & 0.2 & 5.1 & 28.0 & 66.7 \\
\hline 1st Feb & 0.3 & 4.4 & 27.1 & 68.2 \\
\hline 2sd Feb & 0.1 & 2.8 & 26.1 & 71.0 \\
\hline 1st Mar & 0.0 & 3.3 & 31.7 & 65.0 \\
\hline 2sd Mar & 0.0 & 4.4 & 32.8 & 62.8 \\
\hline 1st Apr & 0.0 & 3.5 & 30.7 & 65.8 \\
\hline 2sd Apr & 0.0 & 3.0 & 26.3 & 70.7 \\
\hline 1st May & 0.0 & 2.6 & 24.7 & 72.7 \\
\hline 2sd May & 0.0 & 1.6 & 16.9 & 81.5 \\
\hline 1st Jun & 0.0 & 1.0 & 14.4 & 84.7 \\
\hline 2sd Jun & 0.0 & 0.3 & 11.0 & 88.7 \\
\hline 1st Jul & 0.0 & 0.3 & 12.0 & 87.6 \\
\hline 2sd Jul & 0.0 & 0.1 & 9.8 & 90.1 \\
\hline 1st Aug & 0.0 & 0.2 & 11.6 & 88.2 \\
\hline 2sd Aug & 0.0 & 0.7 & 17.2 & 82.1 \\
\hline 1st Sep & 0.0 & 1.1 & 22.1 & 76.7 \\
\hline 2sd Sep & 0.0 & 0.5 & 20.8 & 78.7 \\
\hline 1st Oct & 0.0 & 0.8 & 25.8 & 73.4 \\
\hline 2sd Oct & 0.0 & 2.3 & 35.5 & 62.2 \\
\hline 1st Nov & 0.0 & 1.8 & 37.0 & 61.2 \\
\hline 2sd Nov & 0.0 & 2.0 & 40.6 & 57.3 \\
\hline 1st Dec & 0.0 & 1.1 & 30.6 & 68.3 \\
\hline 2sd Dec & 0.0 & 2.2 & 32.3 & 65.4 \\
\hline
\end{tabular}

Supplementary Table 2: Percentage of the total surface area in Spain showing positive or negative, significant or non-significant Pearson's $r$ correlations between the sNDVI and the SPEI. Irrigated lands 


\begin{tabular}{|l|r|r|r|r|}
\hline & $\begin{array}{l}\text { Negative } \\
(\mathrm{p}<0.05)\end{array}$ & $\begin{array}{l}\text { Negative } \\
(\mathrm{p}>0.05)\end{array}$ & $\begin{array}{l}\text { Positive }(\mathrm{p} \\
>0.05)\end{array}$ & $\begin{array}{l}\text { Positive }(\mathrm{p} \\
<0.05)\end{array}$ \\
\hline 1st Jan & 0.0 & 1.6 & 32.4 & 66.1 \\
\hline 2nd Jan & 0.0 & 1.2 & 29.3 & 69.4 \\
\hline 1st Feb & 0.0 & 1.1 & 35.4 & 63.5 \\
\hline 2sd Feb & 0.0 & 0.9 & 37.0 & 62.1 \\
\hline 1st Mar & 0.0 & 3.8 & 44.8 & 51.4 \\
\hline 2sd Mar & 0.0 & 6.3 & 41.2 & 52.4 \\
\hline 1st Apr & 0.0 & 1.0 & 33.1 & 65.9 \\
\hline 2sd Apr & 0.0 & 0.2 & 14.1 & 85.7 \\
\hline 1st May & 0.0 & 0.1 & 9.0 & 90.9 \\
\hline 2sd May & 0.0 & 0.1 & 4.4 & 95.5 \\
\hline 1st Jun & 0.0 & 0.1 & 5.3 & 94.6 \\
\hline 2sd Jun & 0.0 & 0.0 & 1.7 & 98.3 \\
\hline 1st Jul & 0.0 & 0.0 & 0.9 & 99.1 \\
\hline 2sd Jul & 0.0 & 0.0 & 0.6 & 99.4 \\
\hline 1st Aug & 0.0 & 0.0 & 0.8 & 99.2 \\
\hline 2sd Aug & 0.0 & 0.0 & 1.9 & 98.1 \\
\hline 1st Sep & 0.0 & 0.0 & 4.1 & 95.9 \\
\hline 2sd Sep & 0.0 & 0.0 & 2.7 & 97.3 \\
\hline 1st Oct & 0.0 & 0.1 & 5.0 & 94.9 \\
\hline 2sd Oct & 0.0 & 0.2 & 11.3 & 88.5 \\
\hline 1st Nov & 0.0 & 0.2 & 22.7 & 77.1 \\
\hline 2sd Nov & 0.0 & 0.4 & 40.3 & 59.4 \\
\hline 1st Dec & 0.0 & 0.5 & 40.1 & 59.3 \\
\hline 2sd Dec & 0.0 & 1.8 & 45.3 & 52.9 \\
\hline
\end{tabular}

Supplementary Table 3: Percentage of the total surface area in Spain showing positive or negative, significant or non-significant Pearson's r correlations between the sNDVI and the SPEI. Vineyards 


\begin{tabular}{|l|r|r|r|r|}
\hline & $\begin{array}{l}\text { Negative } \\
(\mathrm{p}<0.05)\end{array}$ & $\begin{array}{l}\text { Negative } \\
(\mathrm{p}>0.05)\end{array}$ & $\begin{array}{l}\text { Positive }(\mathrm{p} \\
>0.05)\end{array}$ & $\begin{array}{l}\text { Positive (p } \\
<0.05)\end{array}$ \\
\hline 1st Jan & 0.0 & 2.9 & 43.1 & 54.0 \\
\hline 2nd Jan & 0.0 & 1.6 & 36.4 & 61.9 \\
\hline 1st Feb & 0.0 & 1.5 & 31.7 & 66.8 \\
\hline 2sd Feb & 0.0 & 0.6 & 24.2 & 75.2 \\
\hline 1st Mar & 0.0 & 1.5 & 28.0 & 70.5 \\
\hline 2sd Mar & 0.0 & 1.5 & 23.0 & 75.5 \\
\hline 1st Apr & 0.0 & 0.6 & 11.9 & 87.5 \\
\hline 2sd Apr & 0.0 & 0.2 & 5.7 & 94.2 \\
\hline 1st May & 0.0 & 0.1 & 4.6 & 95.3 \\
\hline 2sd May & 0.0 & 0.0 & 1.2 & 98.8 \\
\hline 1st Jun & 0.0 & 0.0 & 0.9 & 99.1 \\
\hline 2sd Jun & 0.0 & 0.0 & 1.7 & 98.3 \\
\hline 1st Jul & 0.0 & 0.0 & 2.7 & 97.3 \\
\hline 2sd Jul & 0.0 & 0.0 & 2.6 & 97.4 \\
\hline 1st Aug & 0.0 & 0.0 & 4.7 & 95.2 \\
\hline 2sd Aug & 0.0 & 0.1 & 10.9 & 89.1 \\
\hline 1st Sep & 0.0 & 0.1 & 20.2 & 79.7 \\
\hline 2sd Sep & 0.0 & 0.0 & 12.6 & 87.4 \\
\hline 1st Oct & 0.0 & 0.0 & 4.5 & 95.5 \\
\hline 2sd Oct & 0.0 & 0.1 & 6.8 & 93.1 \\
\hline 1st Nov & 0.0 & 0.2 & 16.4 & 83.4 \\
\hline 2sd Nov & 0.0 & 0.5 & 31.2 & 68.3 \\
\hline 1st Dec & 0.0 & 0.5 & 23.4 & 76.1 \\
\hline 2sd Dec & 0.0 & 1.8 & 39.6 & 58.6 \\
\hline
\end{tabular}

Supplementary Table 4: Percentage of the total surface area in Spain showing positive or negative, significant or non-significant Pearson's r correlations between the sNDVI and the SPEI. Olive groves. 


\begin{tabular}{|l|r|r|r|r|}
\hline & $\begin{array}{l}\text { Negative } \\
(\mathrm{p}<0.05)\end{array}$ & $\begin{array}{l}\text { Negative } \\
(\mathrm{p}>0.05)\end{array}$ & $\begin{array}{l}\text { Positive }(\mathrm{p} \\
>0.05)\end{array}$ & $\begin{array}{l}\text { Positive }(\mathrm{p} \\
<0.05)\end{array}$ \\
\hline 1st Jan & 0.0 & 7.7 & 39.1 & 53.1 \\
\hline 2nd Jan & 0.0 & 5.7 & 39.7 & 54.6 \\
\hline 1st Feb & 0.0 & 5.6 & 39.0 & 55.3 \\
\hline 2sd Feb & 0.0 & 6.6 & 37.4 & 55.9 \\
\hline 1st Mar & 0.0 & 6.9 & 38.7 & 54.4 \\
\hline 2sd Mar & 0.1 & 12.3 & 34.4 & 53.1 \\
\hline 1st Apr & 0.0 & 9.6 & 34.1 & 56.3 \\
\hline 2sd Apr & 0.0 & 4.0 & 28.9 & 67.0 \\
\hline 1st May & 0.0 & 0.9 & 20.5 & 78.5 \\
\hline 2sd May & 0.0 & 0.8 & 15.8 & 83.4 \\
\hline 1st Jun & 0.0 & 1.6 & 15.1 & 83.3 \\
\hline 2sd Jun & 0.0 & 0.6 & 9.5 & 89.9 \\
\hline 1st Jul & 0.0 & 0.1 & 5.4 & 94.5 \\
\hline 2sd Jul & 0.0 & 0.0 & 4.2 & 95.8 \\
\hline 1st Aug & 0.0 & 0.0 & 5.4 & 94.6 \\
\hline 2sd Aug & 0.0 & 0.1 & 8.8 & 91.1 \\
\hline 1st Sep & 0.0 & 0.6 & 9.4 & 89.9 \\
\hline 2sd Sep & 0.0 & 0.4 & 15.6 & 83.9 \\
\hline 1st Oct & 0.0 & 1.0 & 26.4 & 72.5 \\
\hline 2sd Oct & 0.0 & 1.3 & 32.1 & 66.6 \\
\hline 1st Nov & 0.0 & 4.5 & 37.6 & 57.9 \\
\hline 2sd Nov & 0.0 & 4.9 & 42.2 & 52.9 \\
\hline 1st Dec & 0.0 & 4.1 & 41.0 & 54.9 \\
\hline 2sd Dec & 0.0 & 4.1 & 39.9 & 56.0 \\
\hline
\end{tabular}

Supplementary Table 5: Percentage of the total surface area in Spain showing positive or negative, significant or non-significant Pearson's r correlations between the SNDVI and the SPEI. Mixed agriculture/natural vegetation 


\begin{tabular}{|l|r|r|r|r|}
\hline & $\begin{array}{l}\text { Negative } \\
(\mathrm{p}<0.05)\end{array}$ & $\begin{array}{l}\text { Negative } \\
(\mathrm{p}>0.05)\end{array}$ & $\begin{array}{l}\text { Positive }(\mathrm{p} \\
>0.05)\end{array}$ & $\begin{array}{l}\text { Positive }(\mathrm{p} \\
<0.05)\end{array}$ \\
\hline 1st Jan & 0.2 & 15.9 & 45.5 & 38.4 \\
\hline 2nd Jan & 0.2 & 12.3 & 49.5 & 38.0 \\
\hline 1st Feb & 0.2 & 11.3 & 47.5 & 41.0 \\
\hline 2sd Feb & 0.1 & 13.2 & 44.3 & 42.3 \\
\hline 1st Mar & 0.1 & 13.6 & 46.7 & 39.7 \\
\hline 2sd Mar & 0.2 & 17.9 & 41.8 & 40.1 \\
\hline 1st Apr & 0.0 & 12.6 & 45.3 & 42.0 \\
\hline 2sd Apr & 0.0 & 5.8 & 42.5 & 51.7 \\
\hline 1st May & 0.0 & 3.3 & 33.1 & 63.5 \\
\hline 2sd May & 0.0 & 2.6 & 29.1 & 68.3 \\
\hline 1st Jun & 0.0 & 4.7 & 25.2 & 70.2 \\
\hline 2sd Jun & 0.0 & 1.9 & 18.9 & 79.2 \\
\hline 1st Jul & 0.0 & 1.0 & 13.5 & 85.5 \\
\hline 2sd Jul & 0.0 & 0.2 & 11.5 & 88.4 \\
\hline 1st Aug & 0.0 & 0.1 & 14.1 & 85.8 \\
\hline 2sd Aug & 0.0 & 0.4 & 21.0 & 78.6 \\
\hline 1st Sep & 0.0 & 1.6 & 20.9 & 77.5 \\
\hline 2sd Sep & 0.0 & 1.7 & 28.9 & 69.5 \\
\hline 1st Oct & 0.0 & 4.4 & 37.2 & 58.3 \\
\hline 2sd Oct & 0.0 & 2.9 & 39.2 & 57.9 \\
\hline 1st Nov & 0.0 & 7.0 & 43.6 & 49.4 \\
\hline 2sd Nov & 0.0 & 8.1 & 47.7 & 44.2 \\
\hline 1st Dec & 0.0 & 9.0 & 46.0 & 45.0 \\
\hline 2sd Dec & 0.1 & 8.8 & 51.0 & 40.1 \\
\hline
\end{tabular}

Supplementary Table 6: Percentage of the total surface area in Spain showing positive or negative, significant or non-significant Pearson's r correlations between the sNDVI and the SPEI. Broadleaved forests 


\begin{tabular}{|l|r|r|r|r|}
\hline & $\begin{array}{l}\text { Negative } \\
(\mathrm{p}<0.05)\end{array}$ & $\begin{array}{l}\text { Negative } \\
(\mathrm{p}>0.05)\end{array}$ & $\begin{array}{l}\text { Positive }(\mathrm{p} \\
>0.05)\end{array}$ & $\begin{array}{l}\text { Positive }(\mathrm{p} \\
<0.05)\end{array}$ \\
\hline 1st Jan & 0.4 & 15.9 & 46.0 & 37.7 \\
\hline 2nd Jan & 0.6 & 15.1 & 47.0 & 37.3 \\
\hline 1st Feb & 0.3 & 11.3 & 45.2 & 43.3 \\
\hline 2sd Feb & 0.2 & 12.1 & 45.5 & 42.2 \\
\hline 1st Mar & 0.3 & 14.2 & 51.1 & 34.5 \\
\hline 2sd Mar & 0.2 & 14.0 & 48.4 & 37.3 \\
\hline 1st Apr & 0.0 & 10.2 & 48.7 & 41.1 \\
\hline 2sd Apr & 0.0 & 4.8 & 42.2 & 53.0 \\
\hline 1st May & 0.0 & 2.9 & 32.7 & 64.4 \\
\hline 2sd May & 0.0 & 1.4 & 27.2 & 71.4 \\
\hline 1st Jun & 0.0 & 1.5 & 19.9 & 78.6 \\
\hline 2sd Jun & 0.0 & 0.8 & 13.6 & 85.6 \\
\hline 1st Jul & 0.0 & 0.3 & 9.6 & 90.0 \\
\hline 2sd Jul & 0.0 & 0.1 & 7.2 & 92.7 \\
\hline 1st Aug & 0.0 & 0.1 & 8.2 & 91.7 \\
\hline 2sd Aug & 0.0 & 0.5 & 20.3 & 79.2 \\
\hline 1st Sep & 0.0 & 1.6 & 26.4 & 72.0 \\
\hline 2sd Sep & 0.0 & 0.9 & 31.3 & 67.8 \\
\hline 1st Oct & 0.0 & 3.7 & 37.9 & 58.3 \\
\hline 2sd Oct & 0.0 & 5.6 & 42.8 & 51.7 \\
\hline 1st Nov & 0.1 & 10.8 & 47.3 & 41.8 \\
\hline 2sd Nov & 0.1 & 9.5 & 51.2 & 39.2 \\
\hline 1st Dec & 0.1 & 9.5 & 48.0 & 42.3 \\
\hline 2sd Dec & 0.3 & 10.8 & 49.2 & 39.8 \\
\hline
\end{tabular}

Supplementary Table 7: Percentage of the total surface area in Spain showing positive or negative, significant or non-significant Pearson's $r$ correlations between the SNDVI and the SPEI. Coniferous forests 


\begin{tabular}{|l|r|r|r|r|}
\hline & $\begin{array}{l}\text { Negative } \\
(\mathrm{p}<0.05)\end{array}$ & $\begin{array}{l}\text { Negative } \\
(\mathrm{p}>0.05)\end{array}$ & $\begin{array}{l}\text { Positive }(\mathrm{p} \\
>0.05)\end{array}$ & $\begin{array}{l}\text { Positive }(\mathrm{p} \\
<0.05)\end{array}$ \\
\hline 1st Jan & 0.9 & 19.6 & 53.6 & 25.9 \\
\hline 2nd Jan & 1.8 & 18.4 & 55.6 & 24.2 \\
\hline 1st Feb & 1.5 & 17.2 & 55.5 & 25.8 \\
\hline 2sd Feb & 0.1 & 17.8 & 59.8 & 22.2 \\
\hline 1st Mar & 0.1 & 16.4 & 62.9 & 20.7 \\
\hline 2sd Mar & 0.8 & 20.8 & 60.1 & 18.3 \\
\hline 1st Apr & 0.0 & 12.7 & 62.7 & 24.6 \\
\hline 2sd Apr & 0.0 & 5.4 & 50.4 & 44.2 \\
\hline 1st May & 0.0 & 3.5 & 39.4 & 57.0 \\
\hline 2sd May & 0.0 & 1.7 & 31.3 & 66.9 \\
\hline 1st Jun & 0.0 & 2.8 & 26.0 & 71.2 \\
\hline 2sd Jun & 0.0 & 1.9 & 20.5 & 77.6 \\
\hline 1st Jul & 0.0 & 0.4 & 14.4 & 85.1 \\
\hline 2sd Jul & 0.0 & 0.0 & 9.7 & 90.2 \\
\hline 1st Aug & 0.0 & 0.1 & 10.6 & 89.2 \\
\hline 2sd Aug & 0.0 & 0.8 & 21.5 & 77.6 \\
\hline 1st Sep & 0.0 & 0.9 & 24.8 & 74.3 \\
\hline 2sd Sep & 0.0 & 0.9 & 27.4 & 71.7 \\
\hline 1st Oct & 0.0 & 4.1 & 47.2 & 48.6 \\
\hline 2sd Oct & 0.0 & 6.0 & 52.8 & 41.2 \\
\hline 1st Nov & 0.1 & 13.4 & 47.3 & 39.1 \\
\hline 2sd Nov & 0.1 & 12.4 & 57.6 & 29.9 \\
\hline 1st Dec & 0.1 & 11.9 & 64.8 & 23.2 \\
\hline 2sd Dec & 0.2 & 13.4 & 61.4 & 25.0 \\
\hline
\end{tabular}

Supplementary Table 8: Percentage of the total surface area in Spain showing positive or negative, significant or non-significant Pearson's r correlations between the SNDVI and the SPEI. Mixed forests 


\begin{tabular}{|l|r|r|r|r|}
\hline & $\begin{array}{l}\text { Negative } \\
(\mathrm{p}<0.05)\end{array}$ & $\begin{array}{l}\text { Negative } \\
(\mathrm{p}>0.05)\end{array}$ & $\begin{array}{l}\text { Positive }(\mathrm{p} \\
>0.05)\end{array}$ & $\begin{array}{l}\text { Positive }(\mathrm{p} \\
<0.05)\end{array}$ \\
\hline 1st Jan & 1.7 & 16.2 & 34.3 & 47.8 \\
\hline 2nd Jan & 2.0 & 13.1 & 33.2 & 51.7 \\
\hline 1st Feb & 1.2 & 11.5 & 33.4 & 54.0 \\
\hline 2sd Feb & 1.0 & 11.8 & 29.5 & 57.7 \\
\hline 1st Mar & 1.4 & 12.2 & 27.6 & 58.8 \\
\hline 2sd Mar & 0.5 & 13.3 & 26.5 & 59.7 \\
\hline 1st Apr & 0.0 & 9.1 & 25.7 & 65.2 \\
\hline 2sd Apr & 0.0 & 2.7 & 23.2 & 74.1 \\
\hline 1st May & 0.0 & 2.2 & 16.5 & 81.3 \\
\hline 2sd May & 0.0 & 1.8 & 13.7 & 84.4 \\
\hline 1st Jun & 0.0 & 2.5 & 10.7 & 86.7 \\
\hline 2sd Jun & 0.0 & 1.8 & 7.8 & 90.4 \\
\hline 1st Jul & 0.1 & 1.4 & 6.5 & 92.0 \\
\hline 2sd Jul & 0.0 & 0.8 & 6.0 & 93.1 \\
\hline 1st Aug & 0.0 & 0.1 & 6.8 & 93.1 \\
\hline 2sd Aug & 0.0 & 0.2 & 10.8 & 88.9 \\
\hline 1st Sep & 0.0 & 0.2 & 12.4 & 87.3 \\
\hline 2sd Sep & 0.0 & 0.2 & 13.7 & 86.0 \\
\hline 1st Oct & 0.0 & 1.4 & 18.9 & 79.7 \\
\hline 2sd Oct & 0.0 & 1.7 & 22.4 & 75.9 \\
\hline 1st Nov & 0.0 & 6.5 & 26.7 & 66.8 \\
\hline 2sd Nov & 0.2 & 6.7 & 32.0 & 61.1 \\
\hline 1st Dec & 0.3 & 7.6 & 28.7 & 63.4 \\
\hline 2sd Dec & 1.3 & 10.8 & 36.2 & 51.8 \\
\hline
\end{tabular}

Supplementary Table 9: Percentage of the total surface area in Spain showing positive or negative, significant or non-significant Pearson's $r$ correlations between the sNDVI and the SPEI. Natural grassland 


\begin{tabular}{|l|r|r|r|r|}
\hline & $\begin{array}{l}\text { Negative } \\
(\mathrm{p}<0.05)\end{array}$ & $\begin{array}{l}\text { Negative } \\
(\mathrm{p}>0.05)\end{array}$ & $\begin{array}{l}\text { Positive }(\mathrm{p} \\
>0.05)\end{array}$ & $\begin{array}{l}\text { Positive }(\mathrm{p} \\
<0.05)\end{array}$ \\
\hline 1st Jan & 0.1 & 7.8 & 37.4 & 54.7 \\
\hline 2nd Jan & 0.1 & 6.2 & 36.9 & 56.8 \\
\hline 1st Feb & 0.1 & 4.3 & 35.6 & 60.0 \\
\hline 2sd Feb & 0.0 & 4.0 & 33.1 & 62.9 \\
\hline 1st Mar & 0.1 & 5.0 & 37.8 & 57.2 \\
\hline 2sd Mar & 0.1 & 5.7 & 34.2 & 60.0 \\
\hline 1st Apr & 0.0 & 5.0 & 29.8 & 65.1 \\
\hline 2sd Apr & 0.0 & 1.8 & 21.5 & 76.7 \\
\hline 1st May & 0.0 & 1.1 & 15.1 & 83.8 \\
\hline 2sd May & 0.0 & 0.4 & 9.4 & 90.2 \\
\hline 1st Jun & 0.0 & 0.1 & 4.0 & 95.9 \\
\hline 2sd Jun & 0.0 & 0.0 & 1.8 & 98.1 \\
\hline 1st Jul & 0.0 & 0.0 & 1.2 & 98.8 \\
\hline 2sd Jul & 0.0 & 0.0 & 1.2 & 98.8 \\
\hline 1st Aug & 0.0 & 0.0 & 2.2 & 97.8 \\
\hline 2sd Aug & 0.0 & 0.1 & 5.7 & 94.2 \\
\hline 1st Sep & 0.0 & 0.2 & 8.8 & 91.1 \\
\hline 2sd Sep & 0.0 & 0.2 & 10.7 & 89.2 \\
\hline 1st Oct & 0.0 & 0.6 & 15.8 & 83.6 \\
\hline 2sd Oct & 0.0 & 0.9 & 21.4 & 77.8 \\
\hline 1st Nov & 0.0 & 3.1 & 28.6 & 68.3 \\
\hline 2sd Nov & 0.0 & 3.2 & 33.7 & 63.2 \\
\hline 1st Dec & 0.0 & 2.8 & 31.5 & 65.8 \\
\hline 2sd Dec & 0.0 & 4.7 & 37.4 & 57.8 \\
\hline
\end{tabular}

Supplementary Table 10: Percentage of the total surface area in Spain showing positive or negative, significant or non-significant Pearson's $r$ correlations between the sNDVI and the SPEI. 


\begin{tabular}{|l|r|r|r|r|}
\hline & $\begin{array}{l}\text { Negative } \\
(\mathrm{p}<0.05)\end{array}$ & $\begin{array}{l}\text { Negative } \\
(\mathrm{p}>0.05)\end{array}$ & $\begin{array}{l}\text { Positive }(\mathrm{p} \\
>0.05)\end{array}$ & $\begin{array}{l}\text { Positive }(\mathrm{p} \\
<0.05)\end{array}$ \\
\hline 1st Jan & 0.1 & 11.7 & 44.0 & 44.1 \\
\hline 2nd Jan & 0.2 & 9.9 & 44.1 & 45.9 \\
\hline 1st Feb & 0.1 & 6.8 & 43.4 & 49.6 \\
\hline 2sd Feb & 0.1 & 6.5 & 42.6 & 50.8 \\
\hline 1st Mar & 0.1 & 8.1 & 45.0 & 46.9 \\
\hline 2sd Mar & 0.2 & 10.1 & 42.9 & 46.8 \\
\hline 1st Apr & 0.0 & 7.7 & 40.2 & 52.1 \\
\hline 2sd Apr & 0.0 & 2.9 & 30.3 & 66.8 \\
\hline 1st May & 0.0 & 1.9 & 23.1 & 75.0 \\
\hline 2sd May & 0.0 & 0.9 & 17.4 & 81.7 \\
\hline 1st Jun & 0.0 & 0.8 & 11.7 & 87.5 \\
\hline 2sd Jun & 0.0 & 0.5 & 7.3 & 92.2 \\
\hline 1st Jul & 0.0 & 0.1 & 3.7 & 96.2 \\
\hline 2sd Jul & 0.0 & 0.0 & 2.6 & 97.3 \\
\hline 1st Aug & 0.0 & 0.0 & 3.9 & 96.1 \\
\hline 2sd Aug & 0.0 & 0.1 & 8.9 & 91.0 \\
\hline 1st Sep & 0.0 & 0.3 & 13.4 & 86.3 \\
\hline 2sd Sep & 0.0 & 0.2 & 18.9 & 80.9 \\
\hline 1st Oct & 0.0 & 1.5 & 28.5 & 70.0 \\
\hline 2sd Oct & 0.0 & 2.5 & 33.0 & 64.5 \\
\hline 1st Nov & 0.0 & 5.3 & 37.1 & 57.6 \\
\hline 2sd Nov & 0.0 & 4.7 & 43.3 & 52.0 \\
\hline 1st Dec & 0.0 & 4.5 & 42.8 & 52.7 \\
\hline 2sd Dec & 0.1 & 7.0 & 46.8 & 46.1 \\
\hline
\end{tabular}

Supplementary Table 11: Percentage of the total surface area in Spain showing positive or negative, significant or non-significant Pearson's $r$ correlations between the sNDVI and the SPEI. Transition wood-scrub. 

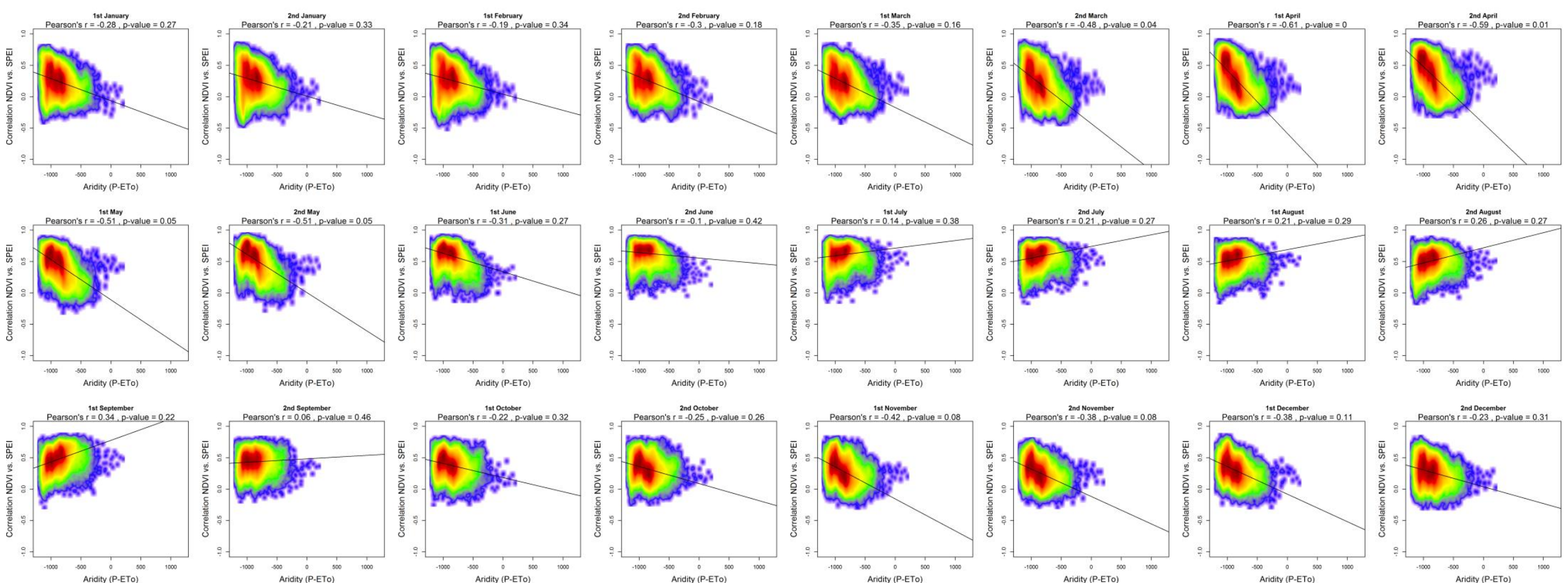

Supplementary Figure 18: Relationship between the average aridity (P-AED) and the maximum correlations obtained between NDVI and the SPEI during the 24 semi-monthly periods of the year. Non Irrigated arable lands. Given the high number of points the signification of correlation was obtained by means of 1000 random samples of 30 cases from which correlations and p-values were obtained. The final signification was assessed by means of the average of the obtained p-values. 

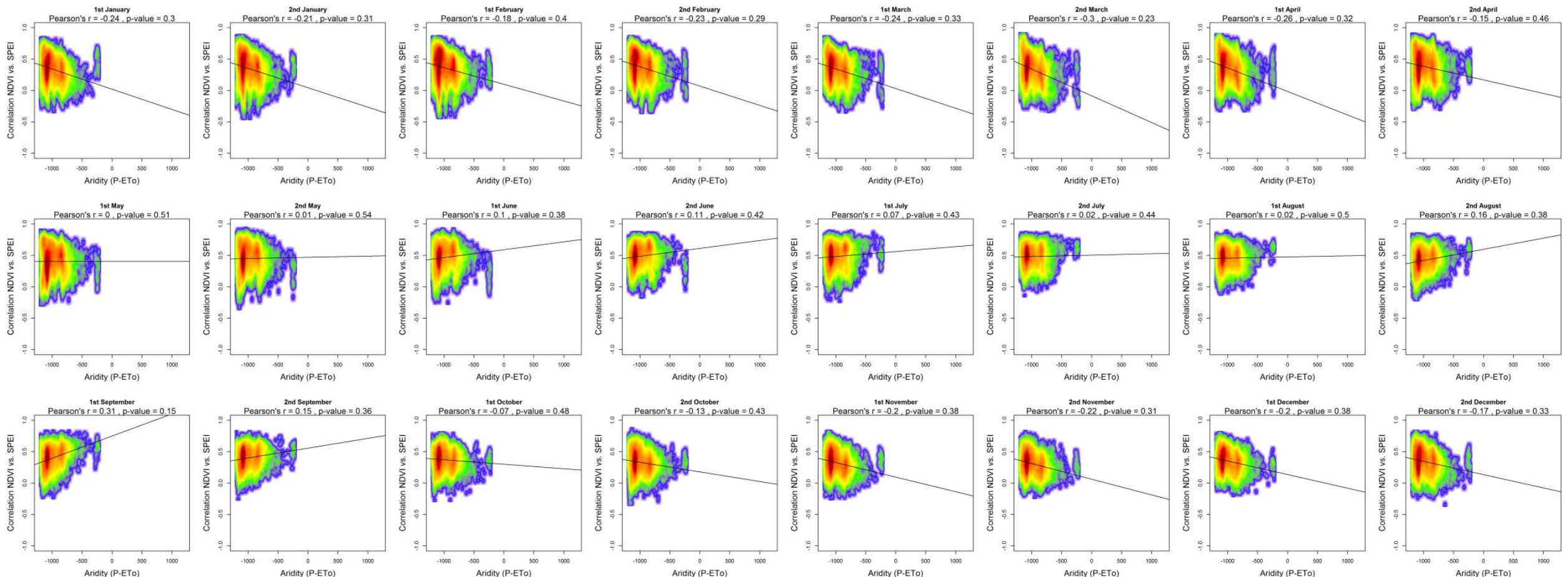

Supplementary Figure 19: Relationship between the average aridity (P-AED) and the maximum correlations obtained between NDVI and the

SPEI during the 24 semi-monthly periods of the year. Irrigated lands. Given the high number of points the signification of correlation was obtained by means of 1000 random samples of 30 cases from which correlations and p-values were obtained. The final signification was assessed by means of the average of the obtained p-values. 

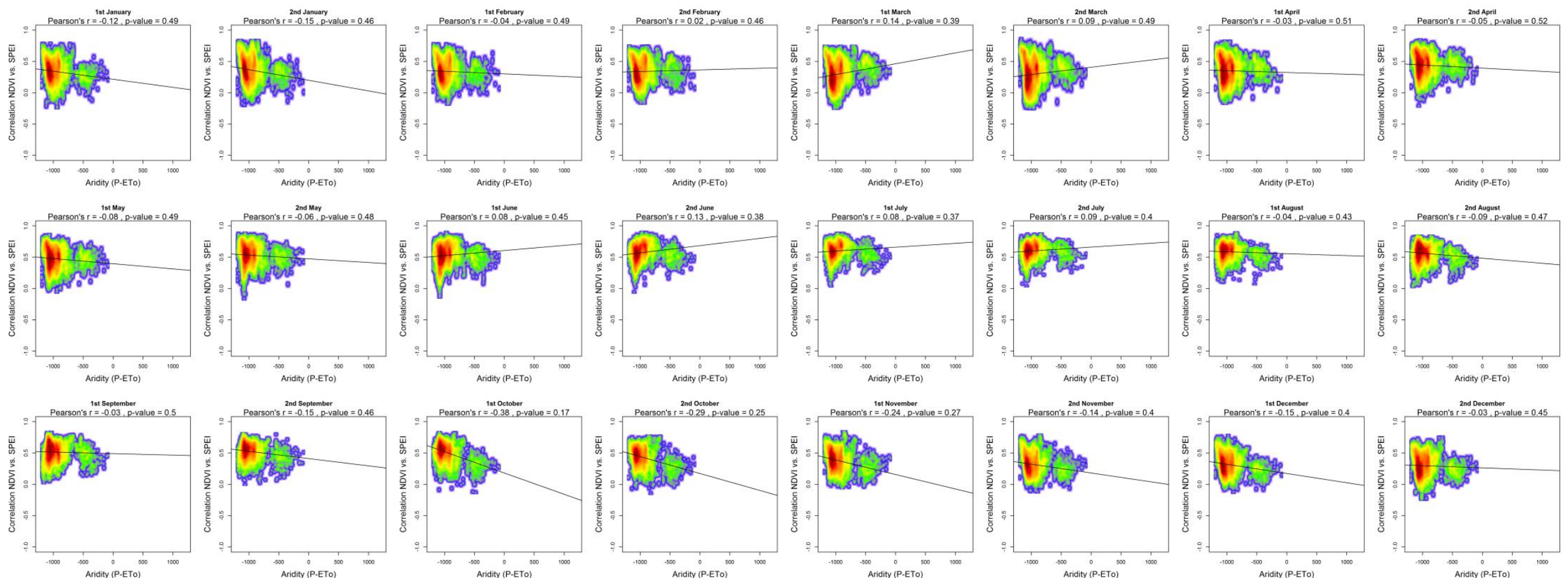

Supplementary Figure 20: Relationship between the average aridity (P-AED) and the maximum correlations obtained between NDVI and the SPEI during the 24 semi-monthly periods of the year. Vineyeards. Given the high number of points the signification of correlation was obtained by means of 1000 random samples of 30 cases from which correlations and p-values were obtained. The final signification was assessed by means of the average of the obtained p-values. 

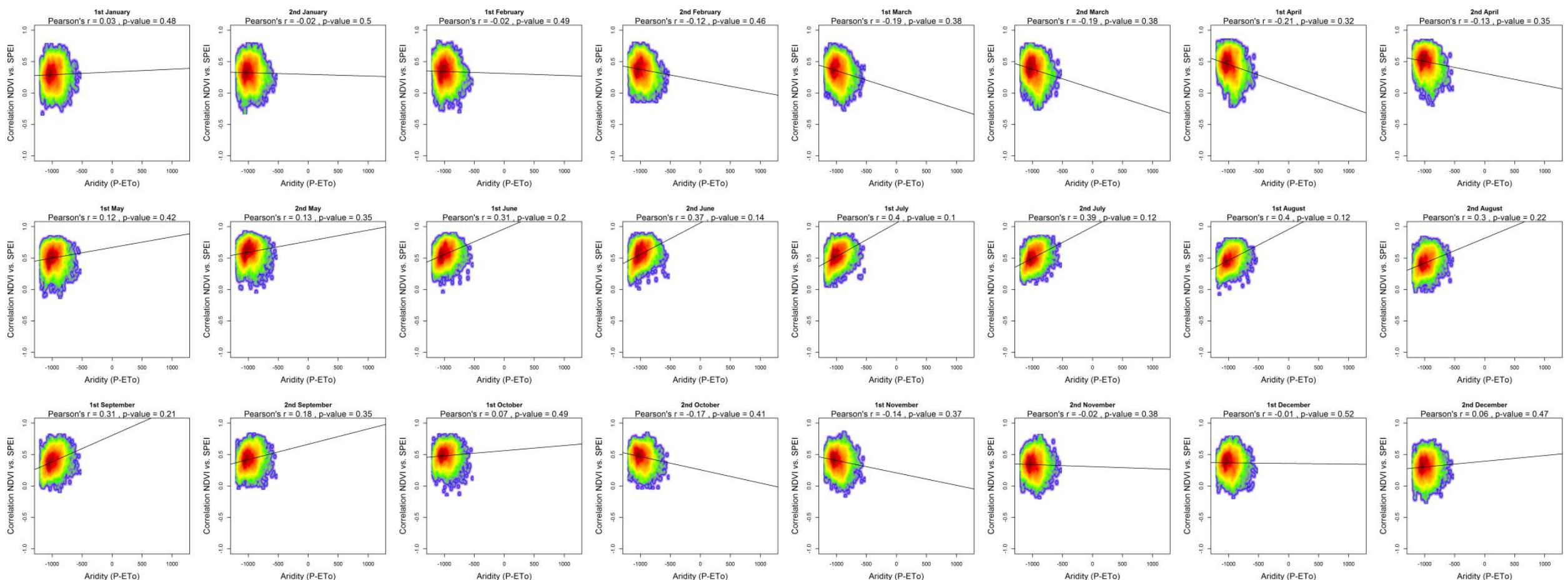

Supplementary Figure 21: Relationship between the average aridity (P-AED) and the maximum correlations obtained between NDVI and the SPEI during the 24 semi-monthly periods of the year. Olive groves. Given the high number of points the signification of correlation was obtained by means of 1000 random samples of 30 cases from which correlations and p-values were obtained. The final signification was assessed by means of the average of the obtained p-values. 

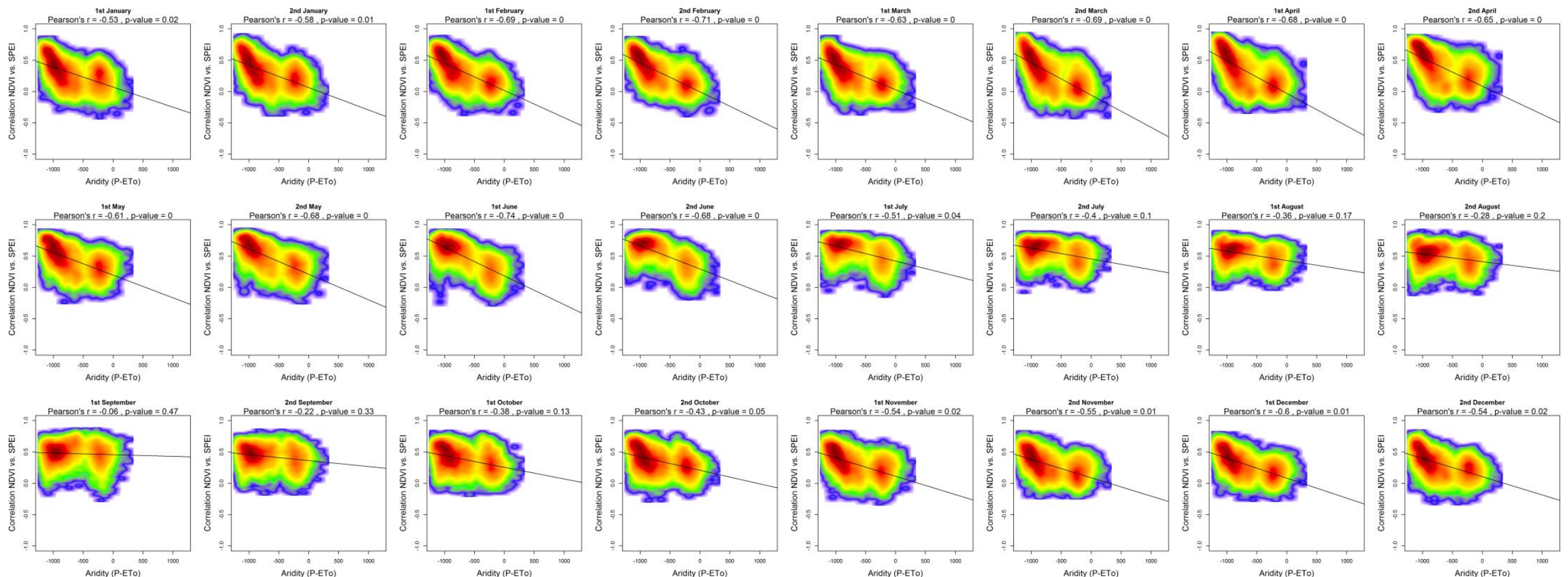

Supplementary Figure 22: Relationship between the average aridity (P-AED) and the maximum correlations obtained between NDVI and the SPEI during the 24 semi-monthly periods of the year. Mixed agriculture/natural vegetation. Given the high number of points the signification of correlation was obtained by means of 1000 random samples of 30 cases from which correlations and p-values were obtained. The final signification was assessed by means of the average of the obtained p-values. 

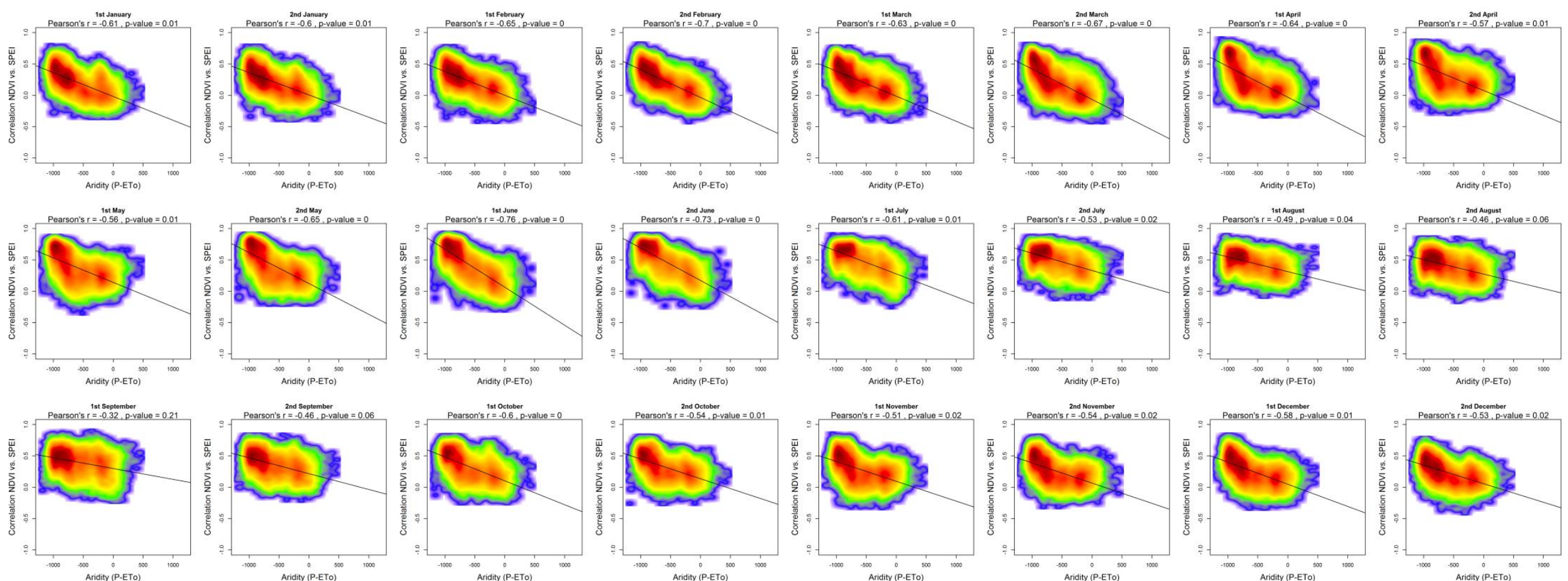

Supplementary Figure 23: Relationship between the average aridity (P-AED) and the maximum correlations obtained between NDVI and the SPEI during the 24 semi-monthly periods of the year. Broad-leaved forests. Given the high number of points the signification of correlation was obtained by means of 1000 random samples of 30 cases from which correlations and p-values were obtained. The final signification was assessed by means of the average of the obtained p-values. 

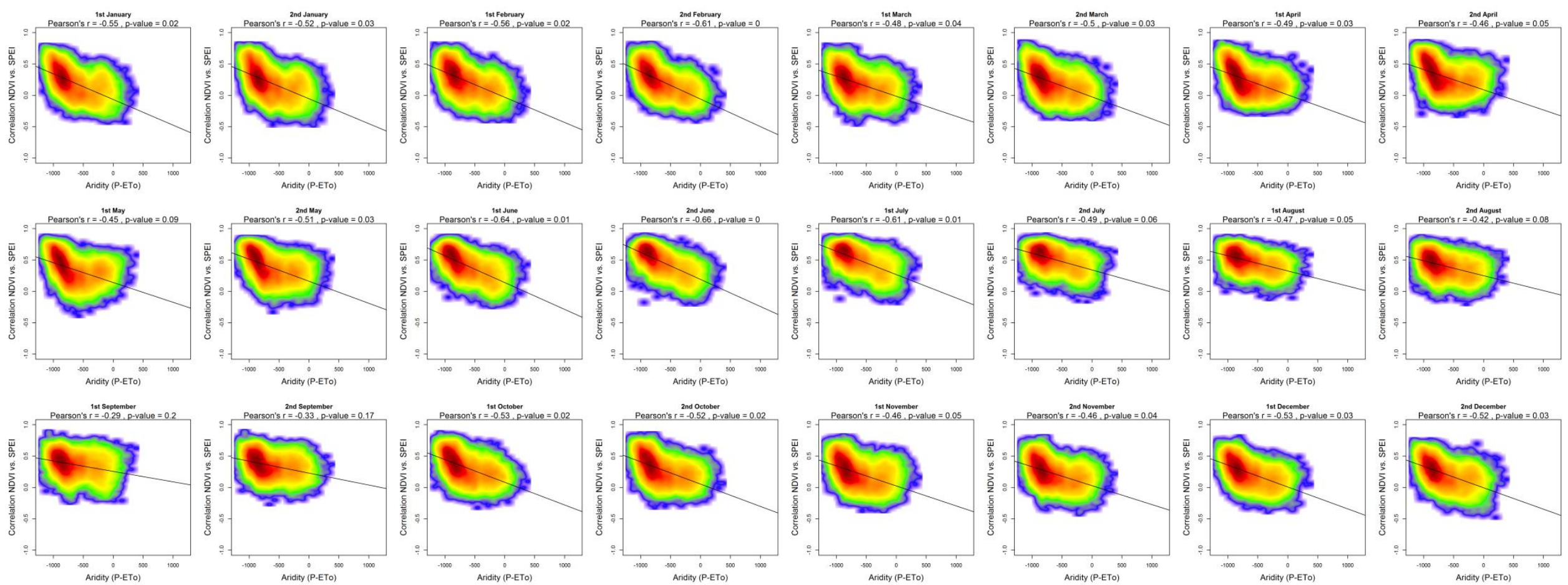

Supplementary Figure 24: Relationship between the average aridity (P-AED) and the maximum correlations obtained between NDVI and the SPEI during the 24 semi-monthly periods of the year. Coniferous forests. Given the high number of points the signification of correlation was obtained by means of 1000 random samples of 30 cases from which correlations and p-values were obtained. The final signification was assessed by means of the average of the obtained p-values. 

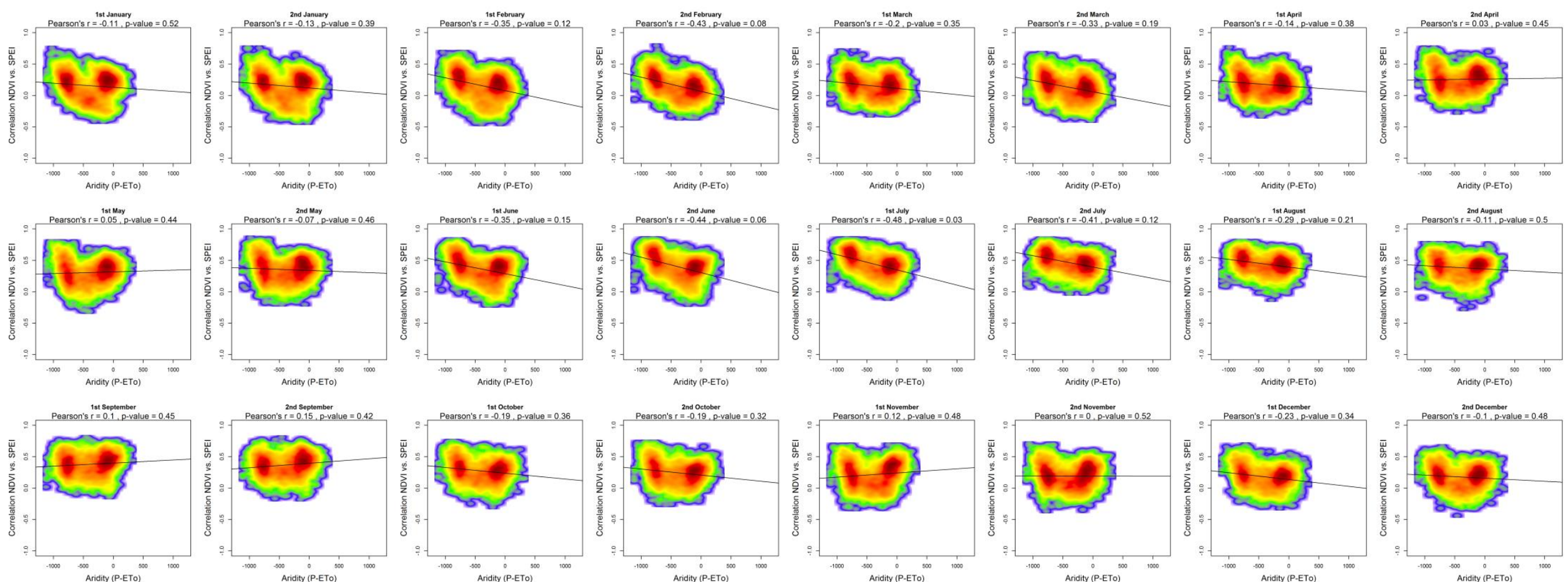

Supplementary Figure 25: Relationship between the average aridity (P-AED) and the maximum correlations obtained between NDVI and the SPEI during the 24 semi-monthly periods of the year. Mixed forests. Given the high number of points the signification of correlation was obtained by means of 1000 random samples of 30 cases from which correlations and p-values were obtained. The final signification was assessed by means of the average of the obtained p-values. 

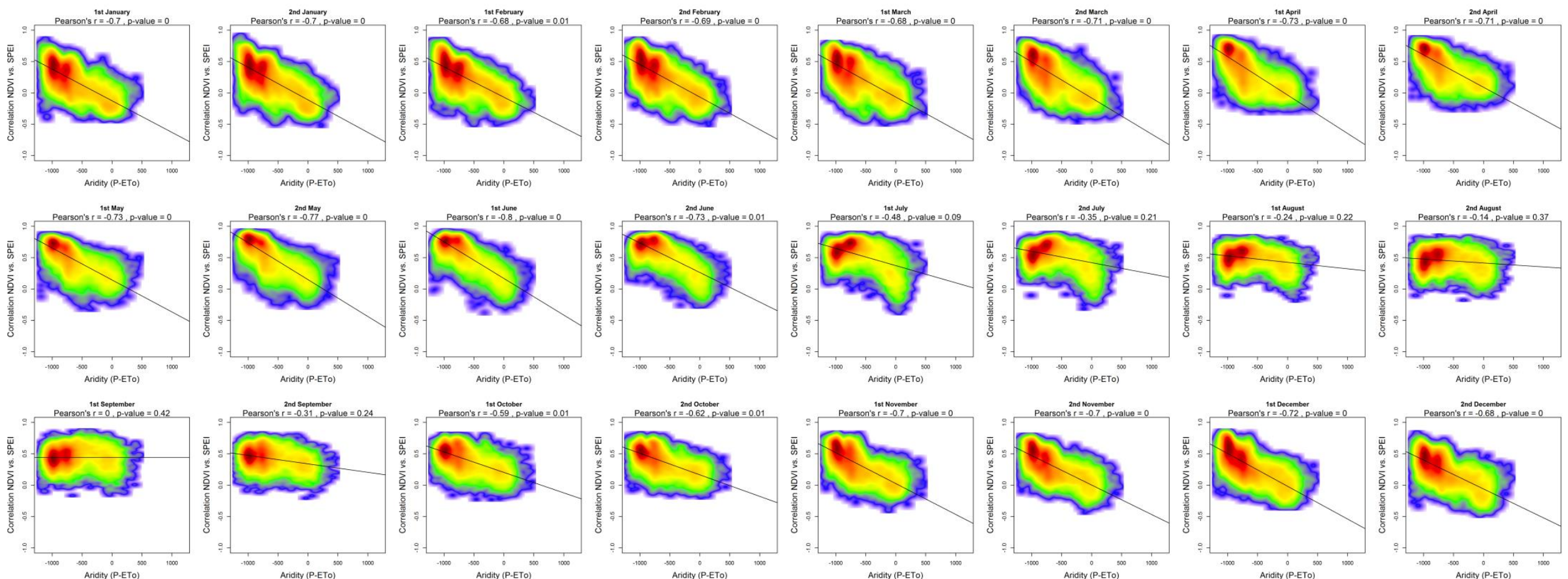

Supplementary Figure 26: Relationship between the average aridity (P-AED) and the maximum correlations obtained between NDVI and the SPEI during the 24 semi-monthly periods of the year. Natural grasslands. Given the high number of points the signification of correlation was obtained by means of 1000 random samples of 30 cases from which correlations and p-values were obtained. The final signification was assessed by means of the average of the obtained p-values. 

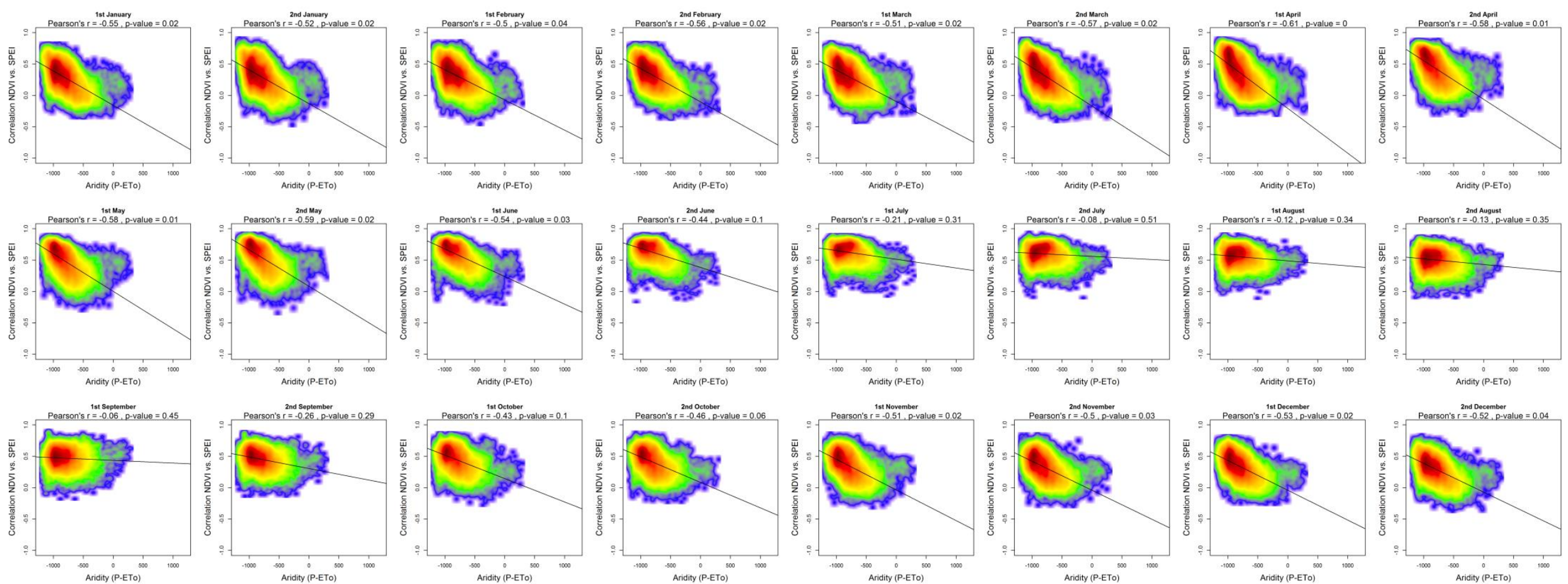

Supplementary Figure 27: Relationship between the average aridity (P-AED) and the maximum correlations obtained between NDVI and the SPEI during the 24 semi-monthly periods of the year. Sclerophillous vegetation. Given the high number of points the signification of correlation was obtained by means of 1000 random samples of 30 cases from which correlations and p-values were obtained. The final signification was assessed by means of the average of the obtained p-values. 

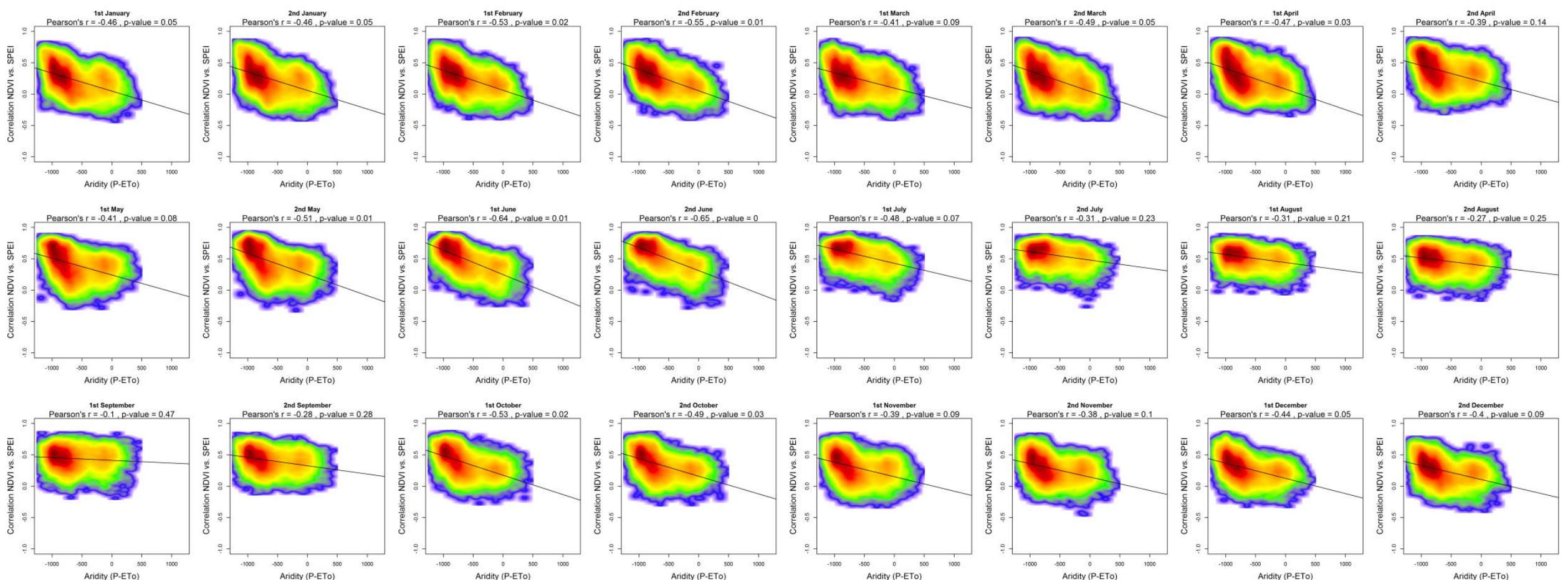

Supplementary Figure 28: Relationship between the average aridity (P-AED) and the maximum correlations obtained between NDVI and the SPEI during the 24 semi-monthly periods of the year. Transition wood-scrub. Given the high number of points the signification of correlation was obtained by means of 1000 random samples of 30 cases from which correlations and p-values were obtained. The final signification was assessed by means of the average of the obtained p-values. 

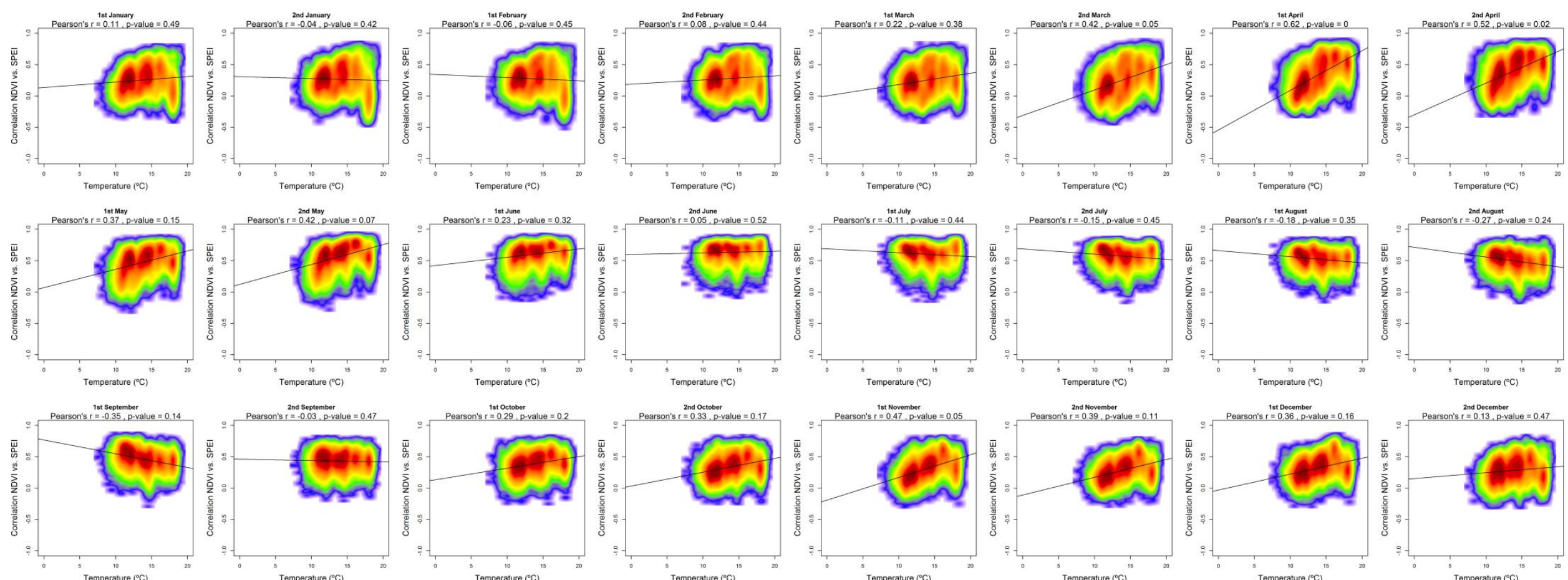

Supplementary Figure 29: Relationship between the average temperature and the maximum correlations obtained between NDVI and the SPEI during the 24 semi-monthly periods of the year. Non Irrigated arable lands. Given the high number of points the signification of correlation was obtained by means of 1000 random samples of 30 cases from which correlations and p-values were obtained. The final signification was assessed by means of the average of the obtained p-values. 

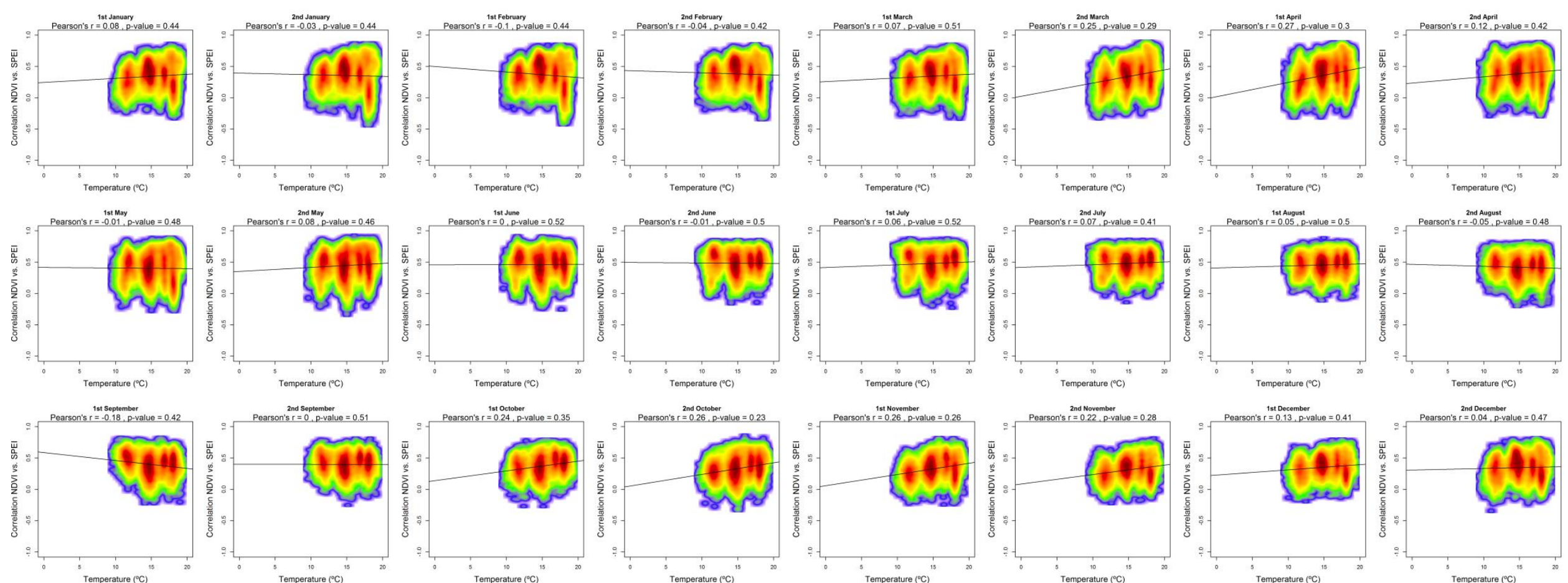

Supplementary Figure 30: Relationship between the average temperature and the maximum correlations obtained between NDVI and the SPEI during the 24 semi-monthly periods of the year. Irrigated lands. Given the high number of points the signification of correlation was obtained by means of 1000 random samples of 30 cases from which correlations and p-values were obtained. The final signification was assessed by means of the average of the obtained p-values. 

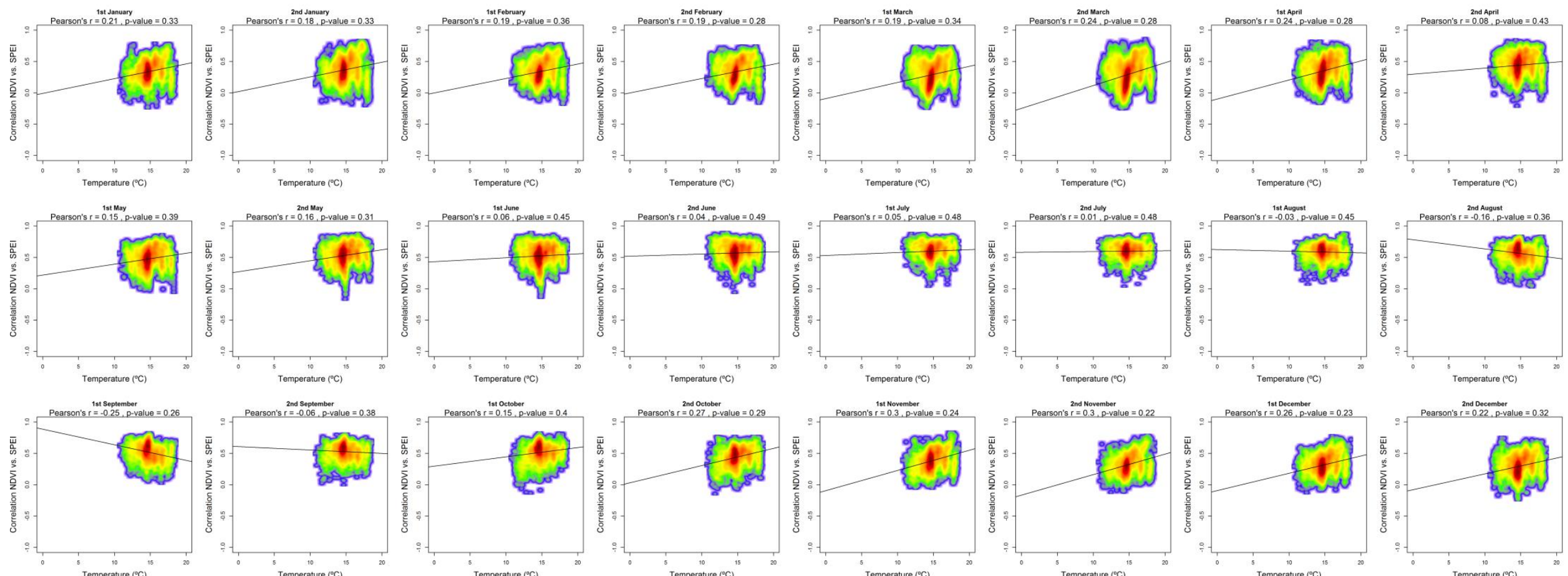

Supplementary Figure 31: Relationship between the average temperature and the maximum correlations obtained between NDVI and the SPEI during the 24 semi-monthly periods of the year. Vineyeards. Given the high number of points the signification of correlation was obtained by means of 1000 random samples of 30 cases from which correlations and p-values were obtained. The final signification was assessed by means of the average of the obtained p-values. 

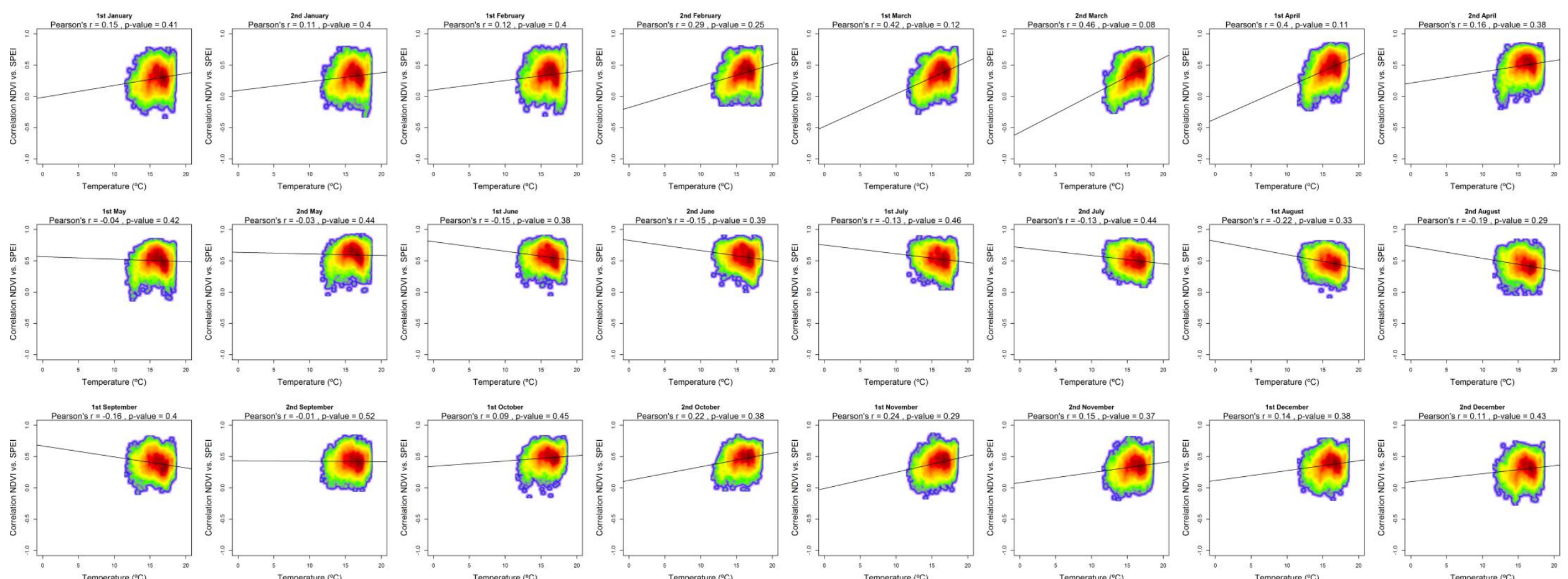

Supplementary Figure 32: Relationship between the average temperature and the maximum correlations obtained between NDVI and the SPEI during the 24 semi-monthly periods of the year. Olive groves. Given the high number of points the signification of correlation was obtained by means of 1000 random samples of 30 cases from which correlations and p-values were obtained. The final signification was assessed by means of the average of the obtained p-values. 

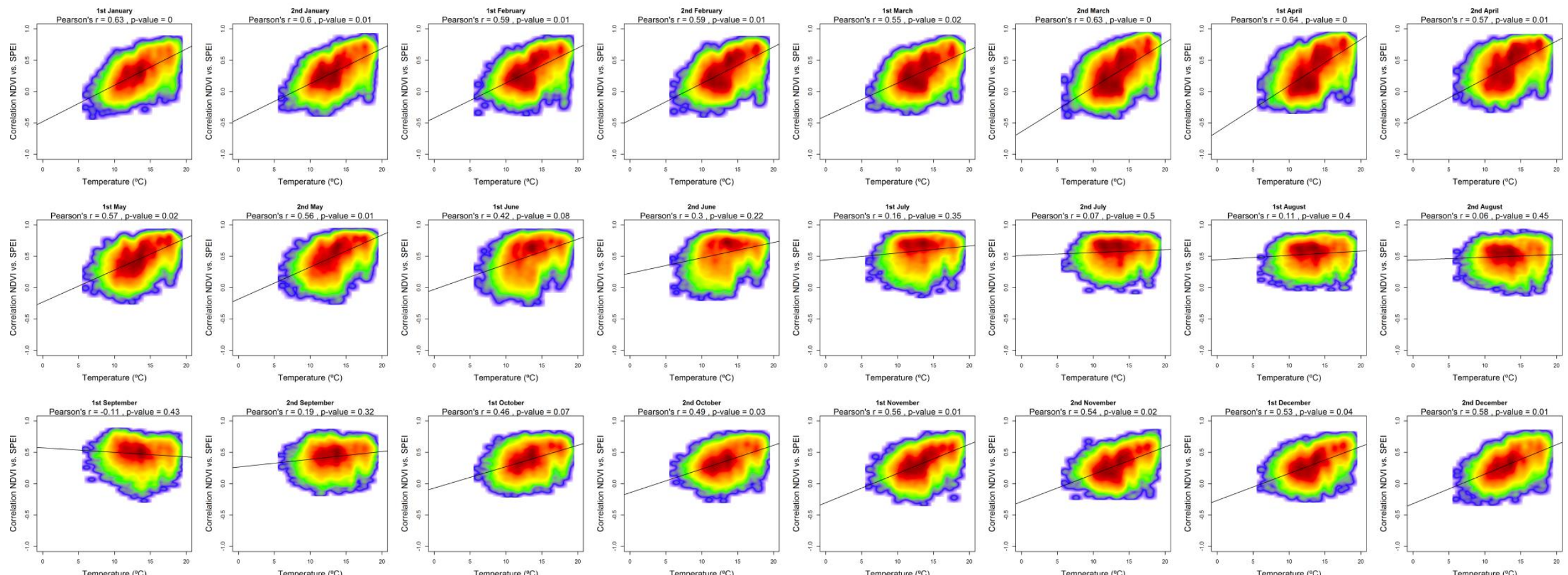

Supplementary Figure 33: Relationship between the average temperature and the maximum correlations obtained between NDVI and the SPEI during the 24 semi-monthly periods of the year. Mixed agriculture/natural vegetation. Given the high number of points the signification of correlation was obtained by means of 1000 random samples of 30 cases from which correlations and p-values were obtained. The final signification was assessed by means of the average of the obtained p-values. 

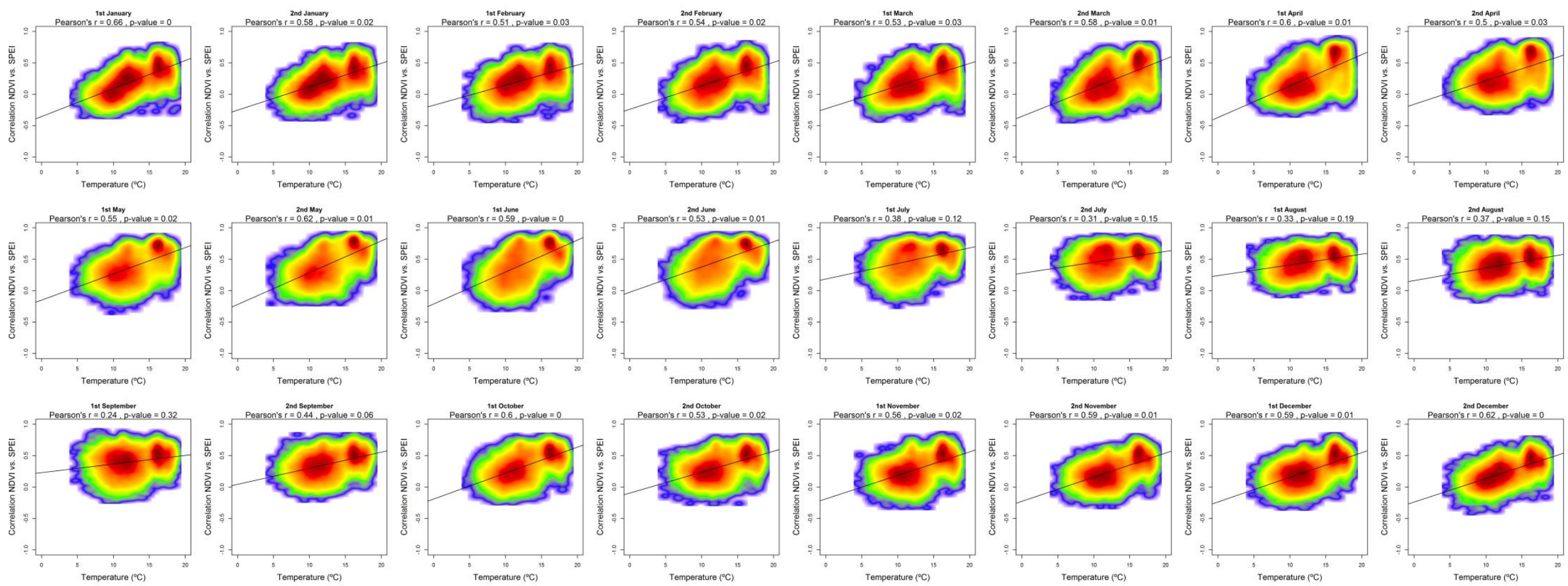

Supplementary Figure 34: Relationship between the average temperature and the maximum correlations obtained between NDVI and the SPEI during the 24 semi-monthly periods of the year. Broad-leaved forests. Given the high number of points the signification of correlation was obtained by means of 1000 random samples of 30 cases from which correlations and p-values were obtained. The final signification was assessed by means of the average of the obtained p-values. 

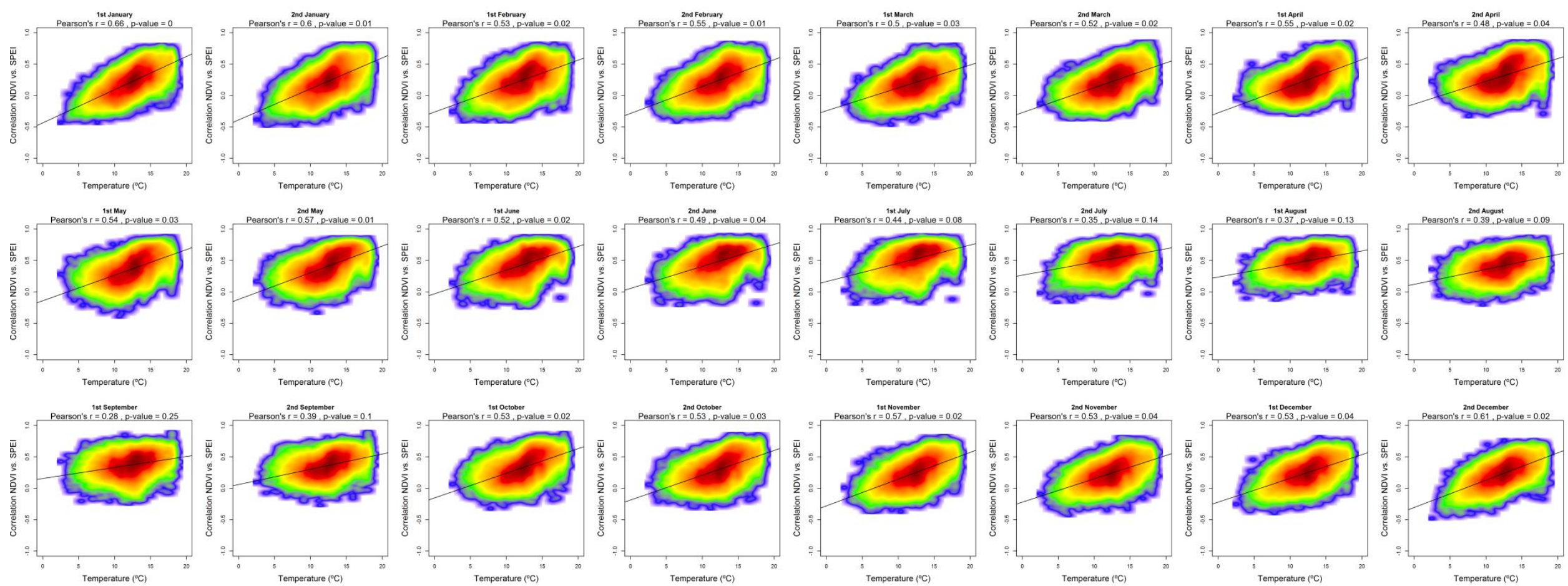

Supplementary Figure 35: Relationship between the average temperature and the maximum correlations obtained between NDVI and the SPEI during the 24 semi-monthly periods of the year. Coniferous forests. Given the high number of points the signification of correlation was obtained by means of 1000 random samples of 30 cases from which correlations and p-values were obtained. The final signification was assessed by means of the average of the obtained p-values. 

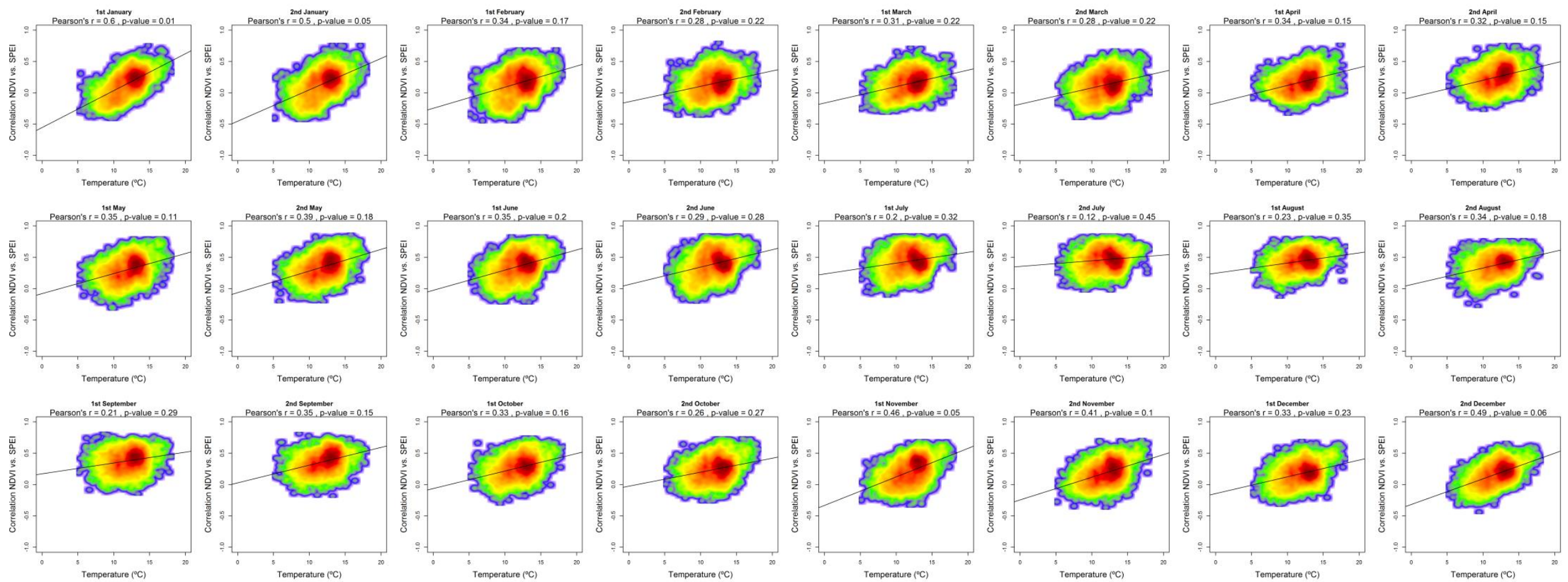

Supplementary Figure 36: Relationship between the average temperature and the maximum correlations obtained between NDVI and the SPEI during the 24 semi-monthly periods of the year. Mixed forests. Given the high number of points the signification of correlation was obtained by means of 1000 random samples of 30 cases from which correlations and p-values were obtained. The final signification was assessed by means of the average of the obtained p-values. 

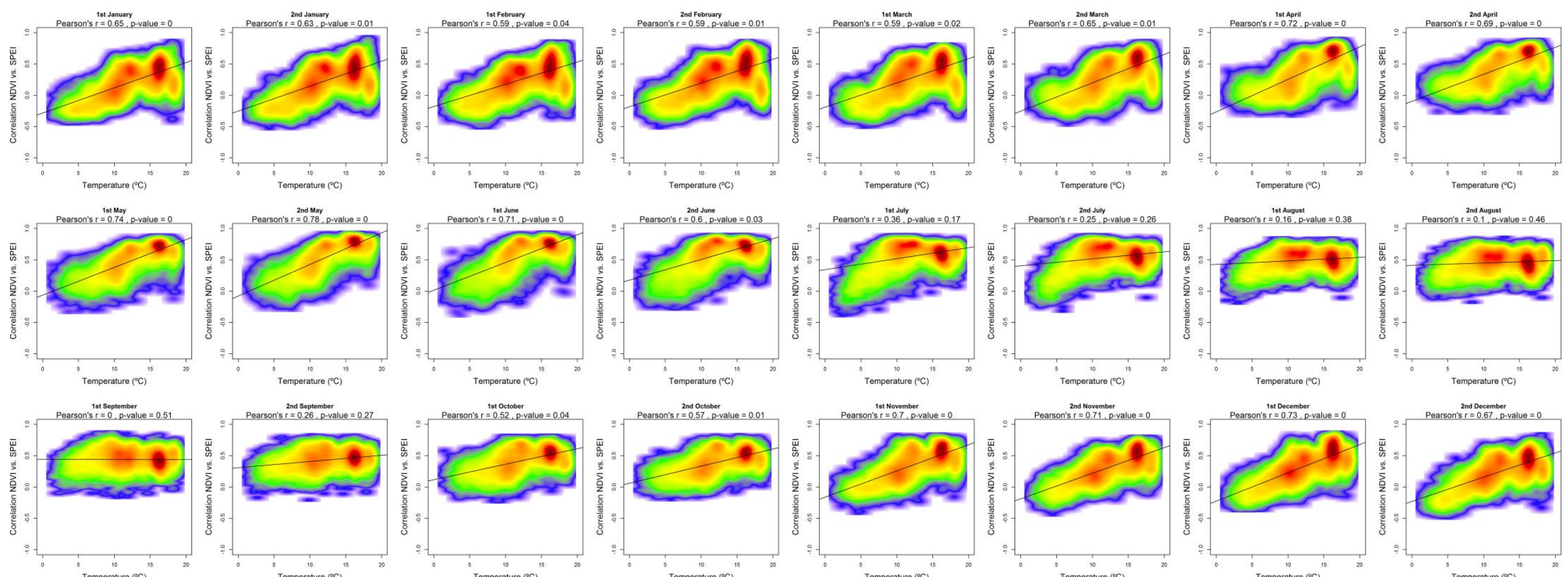

Supplementary Figure 37: Relationship between the average temperature and the maximum correlations obtained between NDVI and the SPEI during the 24 semi-monthly periods of the year. Natural grasslands. Given the high number of points the signification of correlation was obtained by means of 1000 random samples of 30 cases from which correlations and p-values were obtained. The final signification was assessed by means of the average of the obtained p-values. 

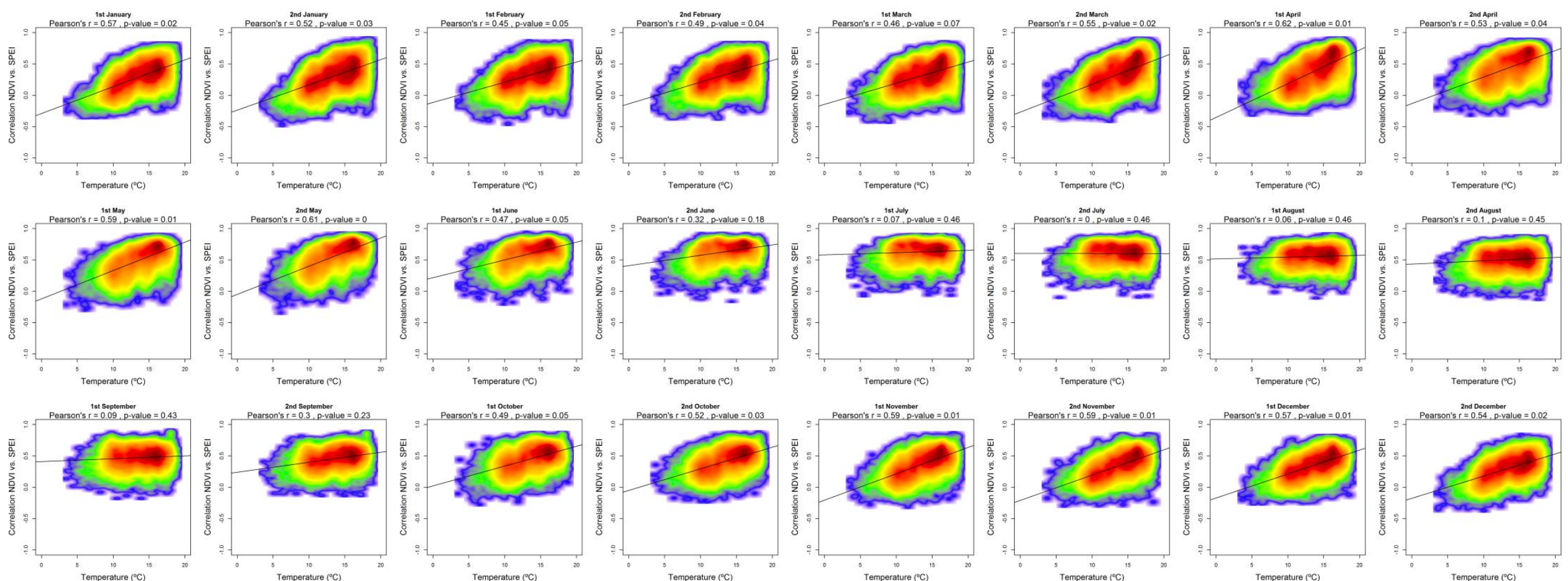

Supplementary Figure 38: Relationship between the average temperature and the maximum correlations obtained between NDVI and the SPEI during the 24 semi-monthly periods of the year. Sclerophillous vegetation. Given the high number of points the signification of correlation was obtained by means of 1000 random samples of 30 cases from which correlations and p-values were obtained. The final signification was assessed by means of the average of the obtained p-values. 

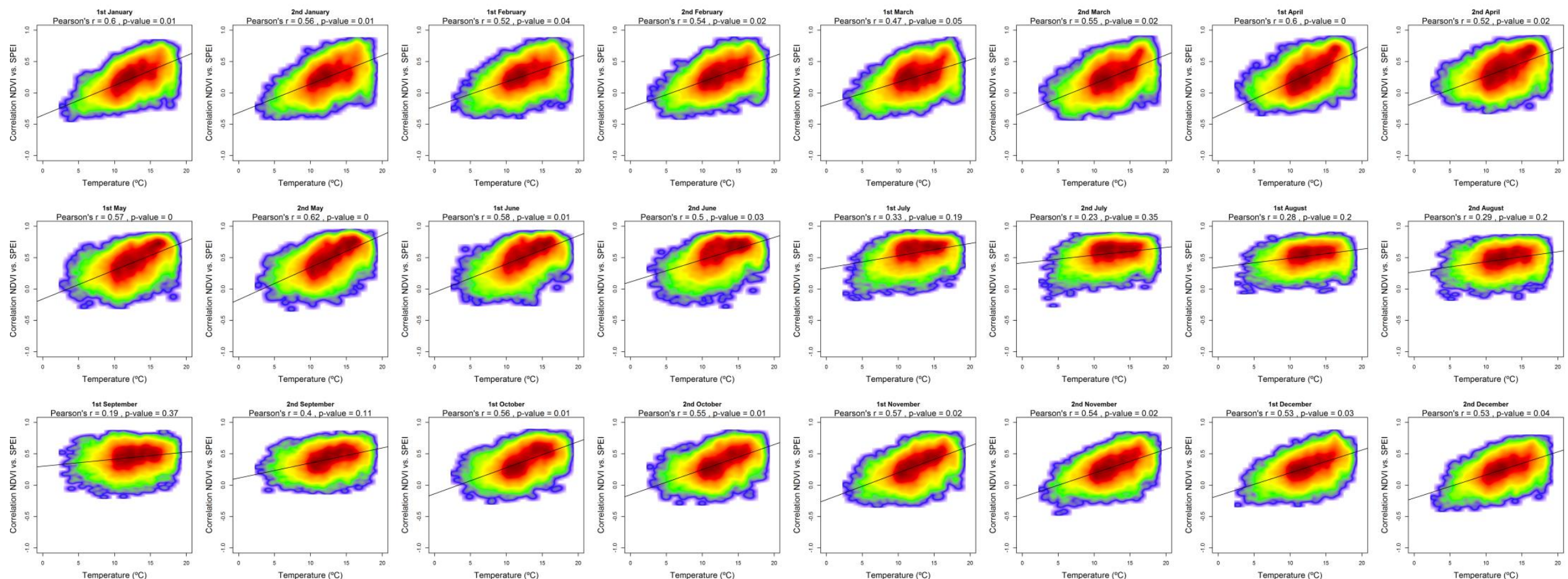

Supplementary Figure 39: Relationship between the average temperature and the maximum correlations obtained between NDVI and the SPEI during the 24 semi-monthly periods of the year. Transition wood-scrub. Given the high number of points the signification of correlation was obtained by means of 1000 random samples of 30 cases from which correlations and p-values were obtained. The final signification was assessed by means of the average of the obtained p-values. 

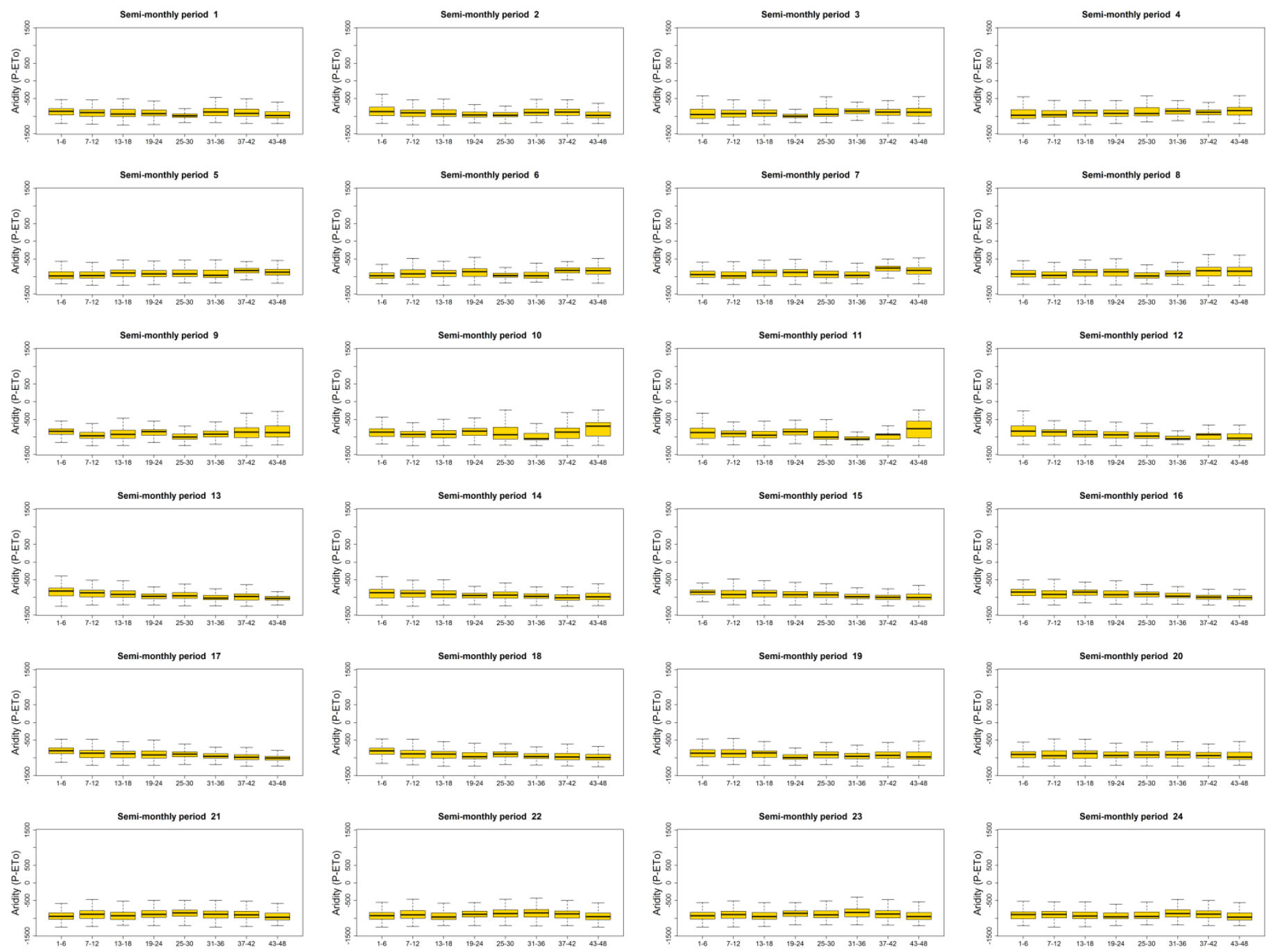

Supplementary Figure 40: Box-plots showing the values of aridity (P-AED) for areas showing maximum correlation between SPEI and sNDVI on different time scales. Non irrigated arable lands. 

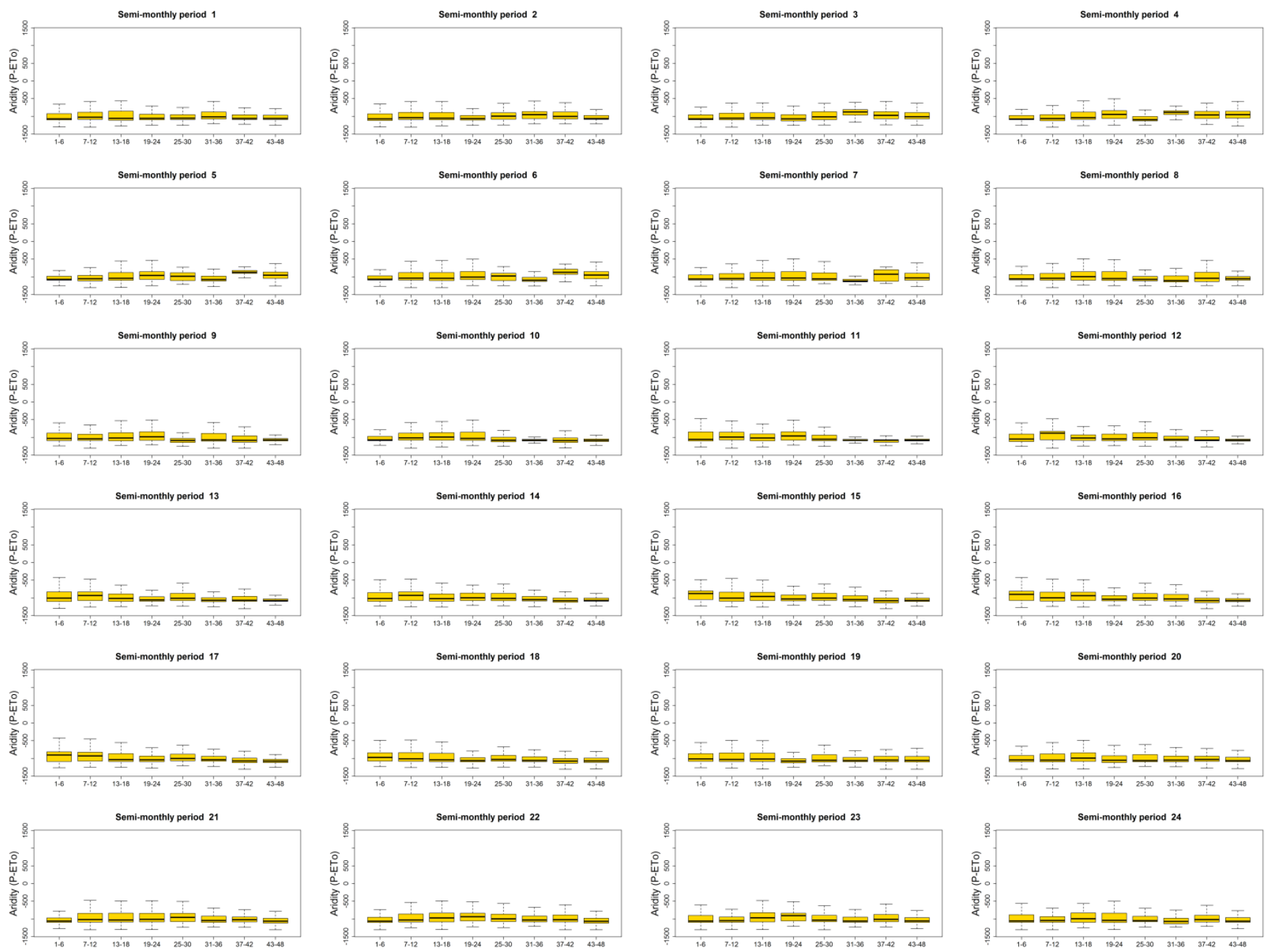

Supplementary Figure 41: Box-plots showing the values of aridity (P-AED) for areas showing maximum correlation between SPEI and sNDVI on different time scales. Irrigated lands. 

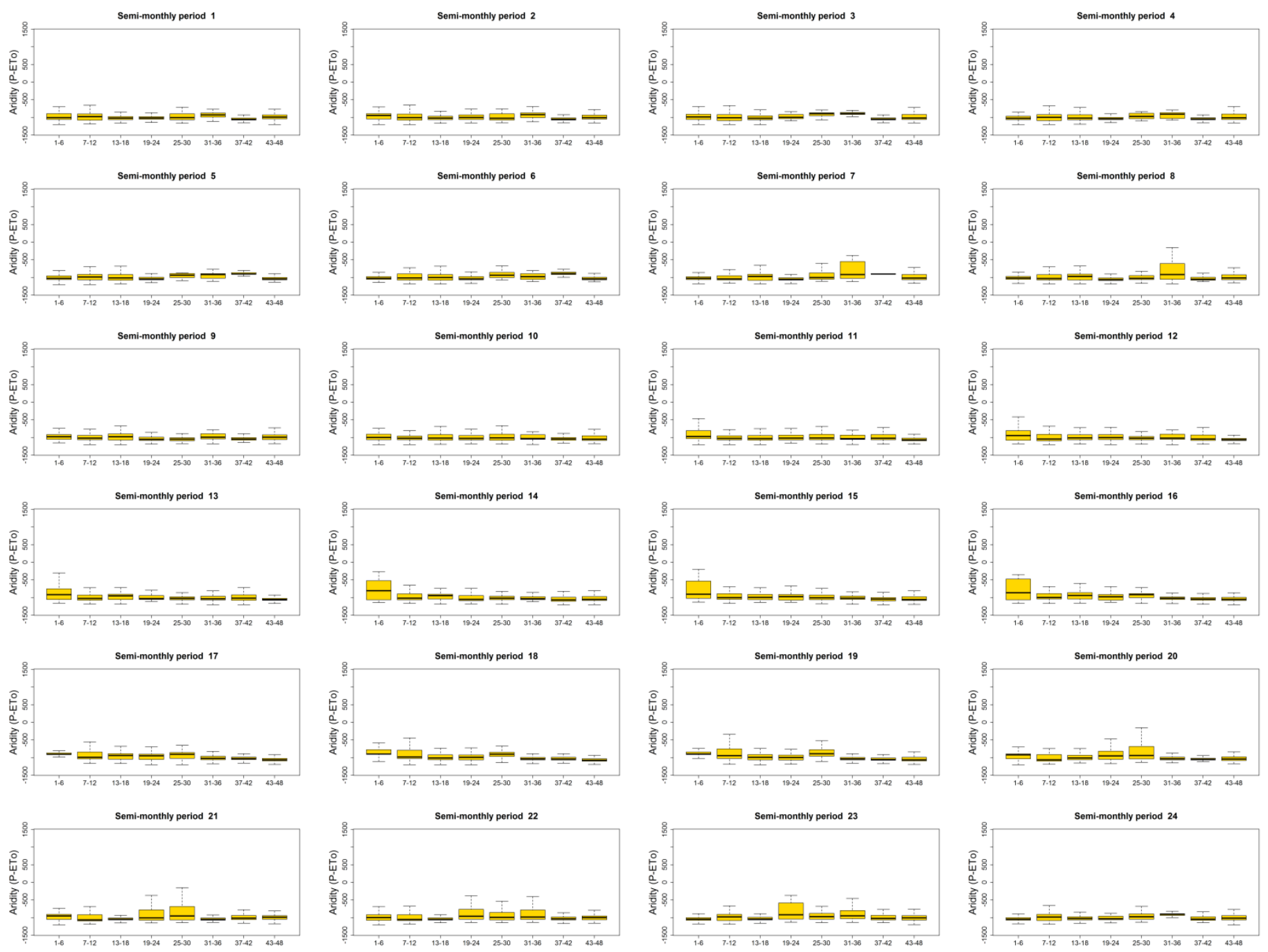

Supplementary Figure 42: Box-plots showing the values of aridity (P-AED) for areas showing maximum correlation between SPEI and sNDVI on different time scales. Vineyards. 

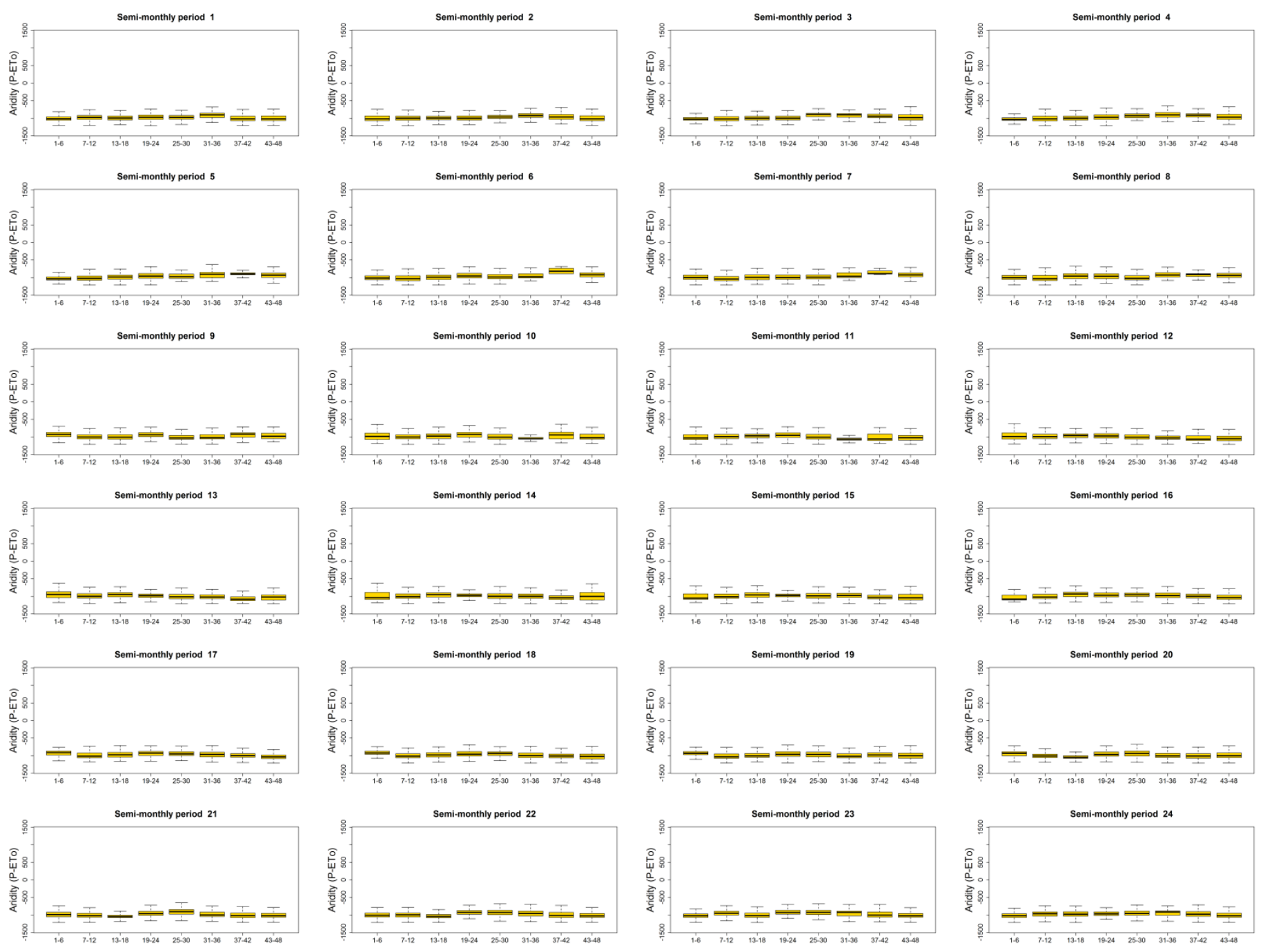

Supplementary Figure 43: Box-plots showing the values of aridity (P-AED) for areas showing maximum correlation between SPEI and sNDVI on different time scales. Olive groves. 

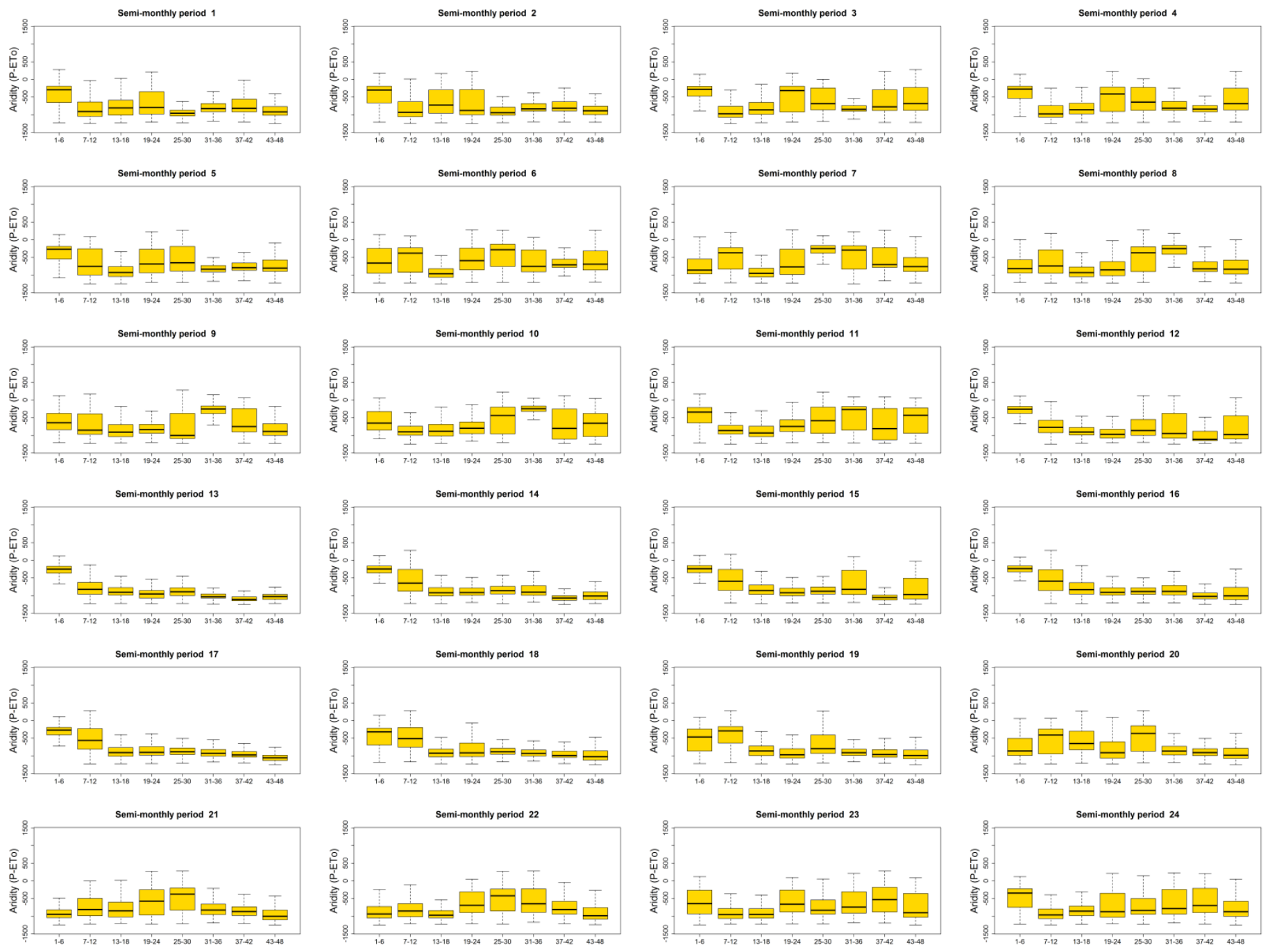

Supplementary Figure 44: Box-plots showing the values of aridity (P-AED) for areas showing maximum correlation between SPEI and sNDVI on different time scales. Mixed agriculture/natural vegetation. 

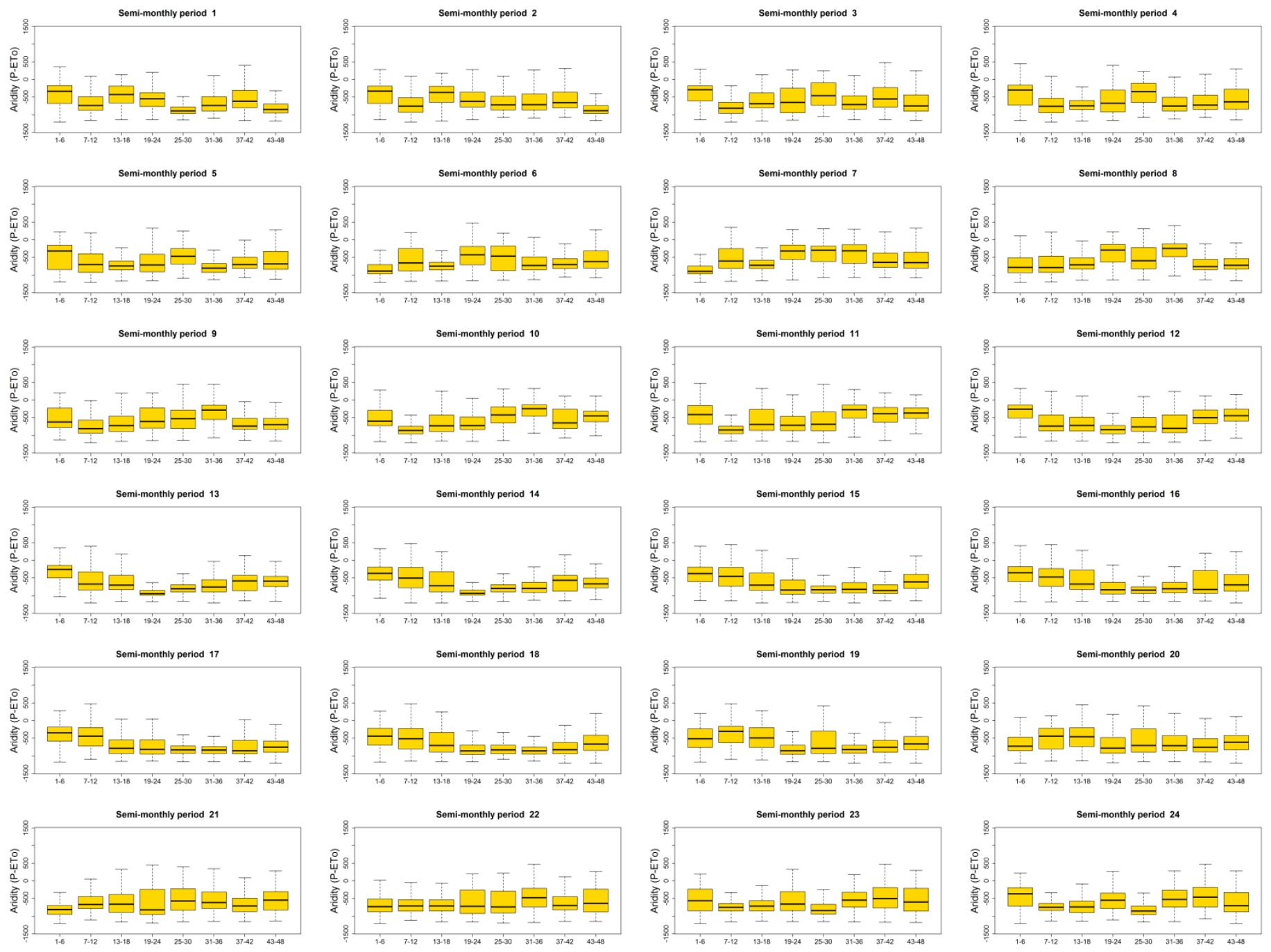

Supplementary Figure 45: Box-plots showing the values of aridity (P-AED) for areas showing maximum correlation between SPEI and sNDVI on different time scales. Broad-leaved forests. 

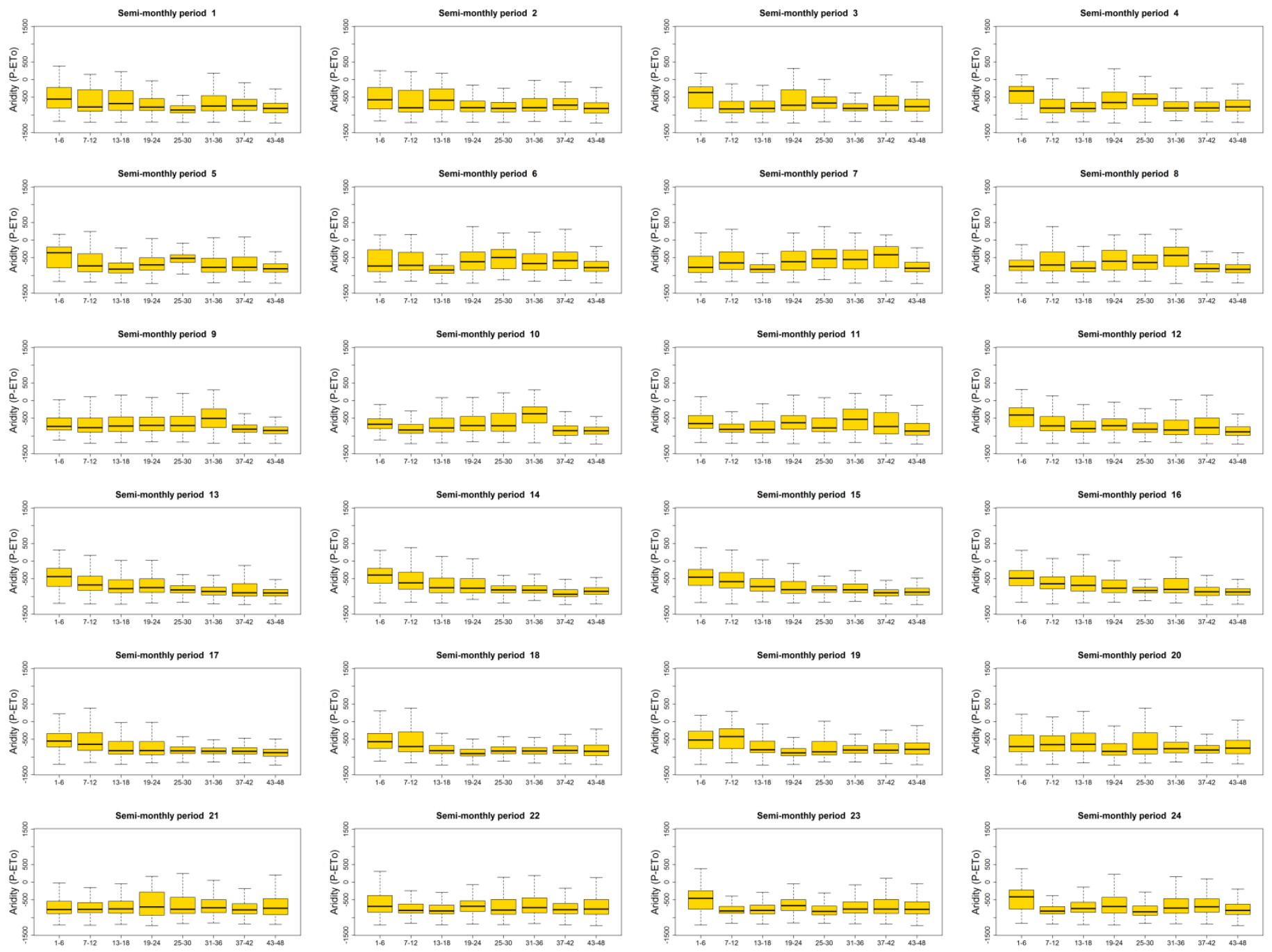

Supplementary Figure 46: Box-plots showing the values of aridity (P-AED) for areas showing maximum correlation between SPEI and sNDVI on different time scales. Coniferous forests. 

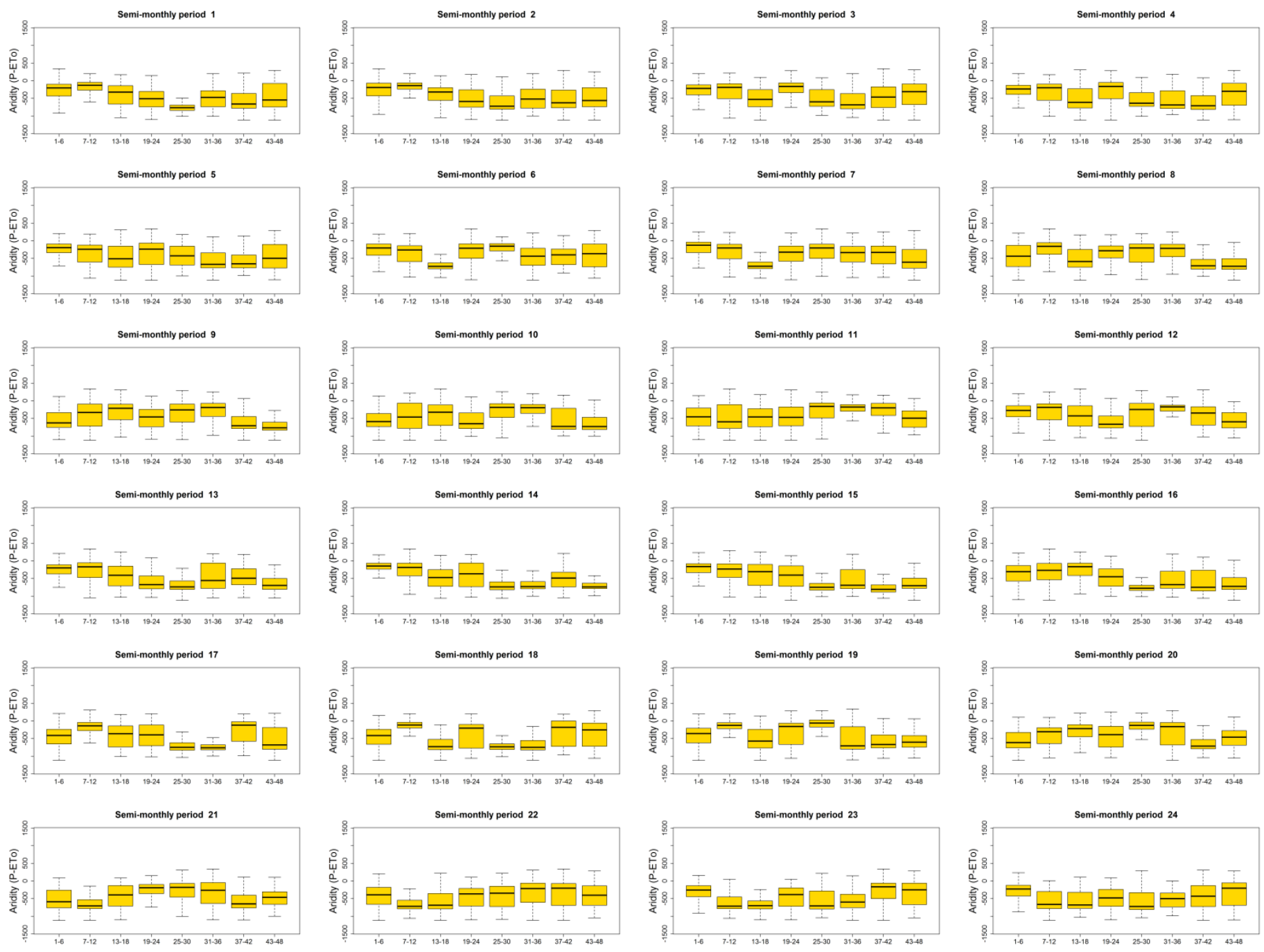

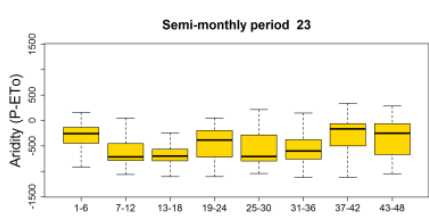

Supplementary Figure 47: Box-plots showing the values of aridity (P-AED) for areas showing maximum correlation between SPEI and sNDVI on different time scales. Mixed forests. 

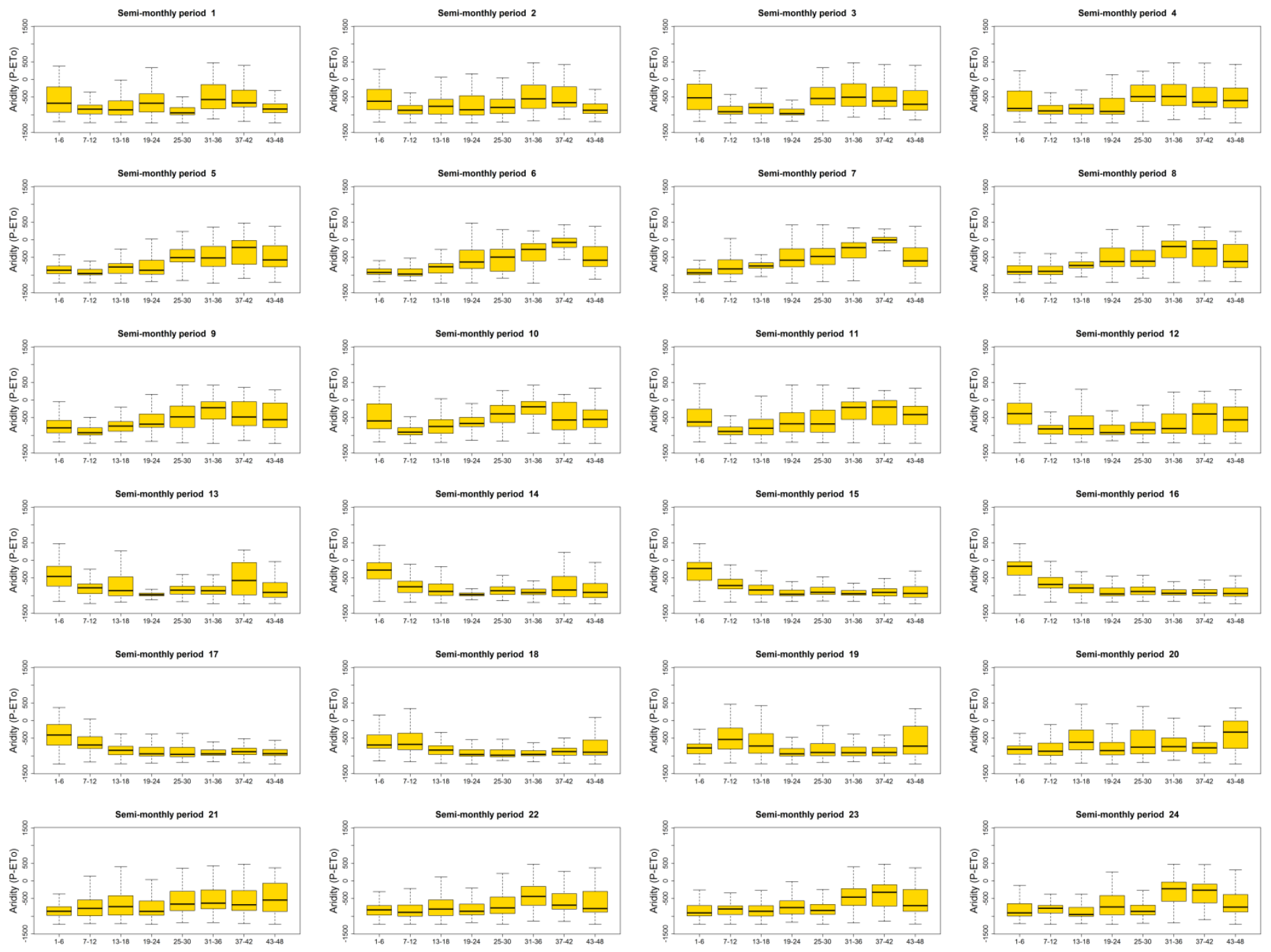

Supplementary Figure 48: Box-plots showing the values of aridity (P-AED) for areas showing maximum correlation between SPEI and sNDVI on different time scales. Natural grassland. 

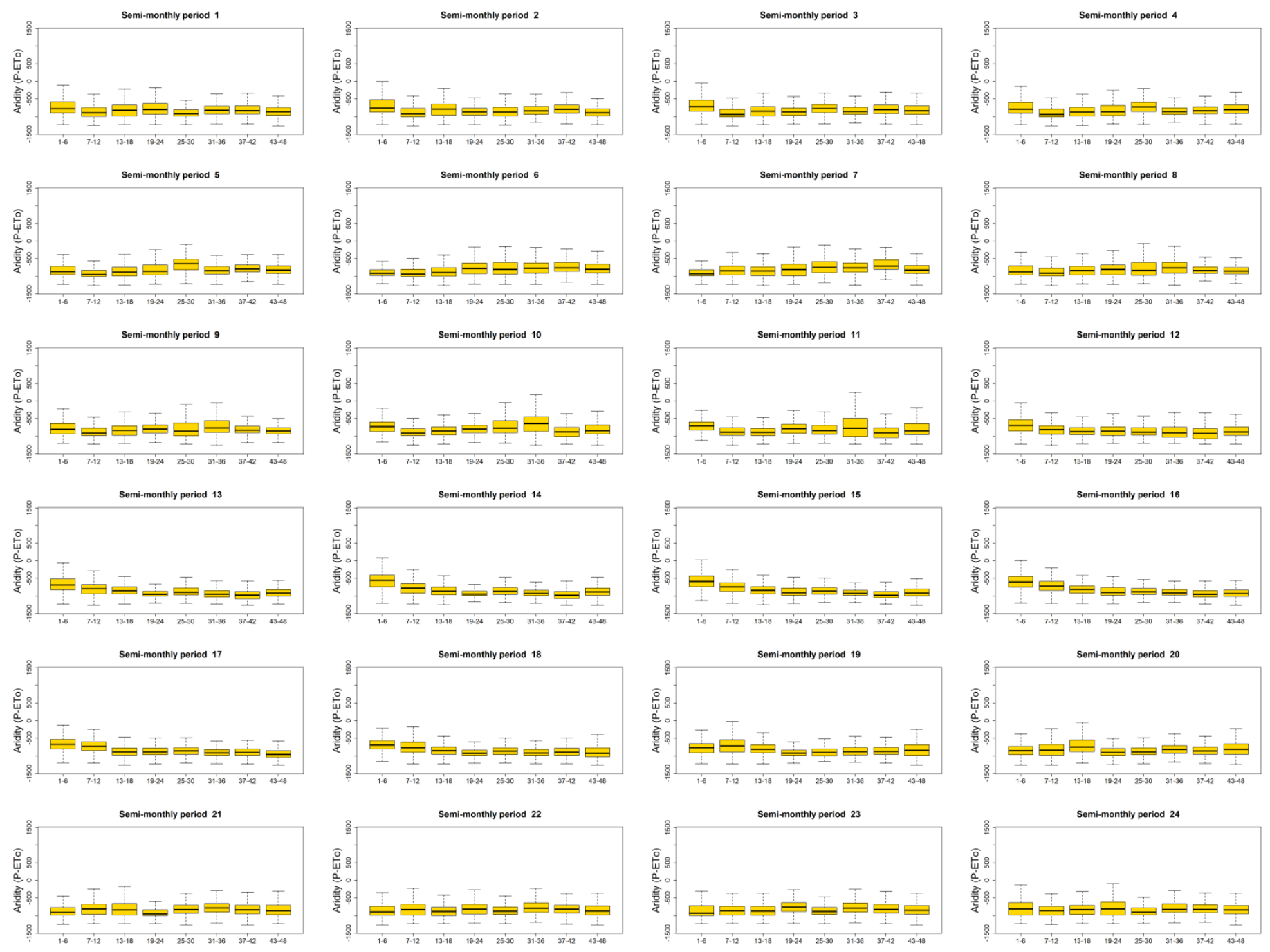

Supplementary Figure 49: Box-plots showing the values of aridity (P-AED) for areas showing maximum correlation between SPEI and sNDVI on different time scales. Sclerophillous vegetation. 

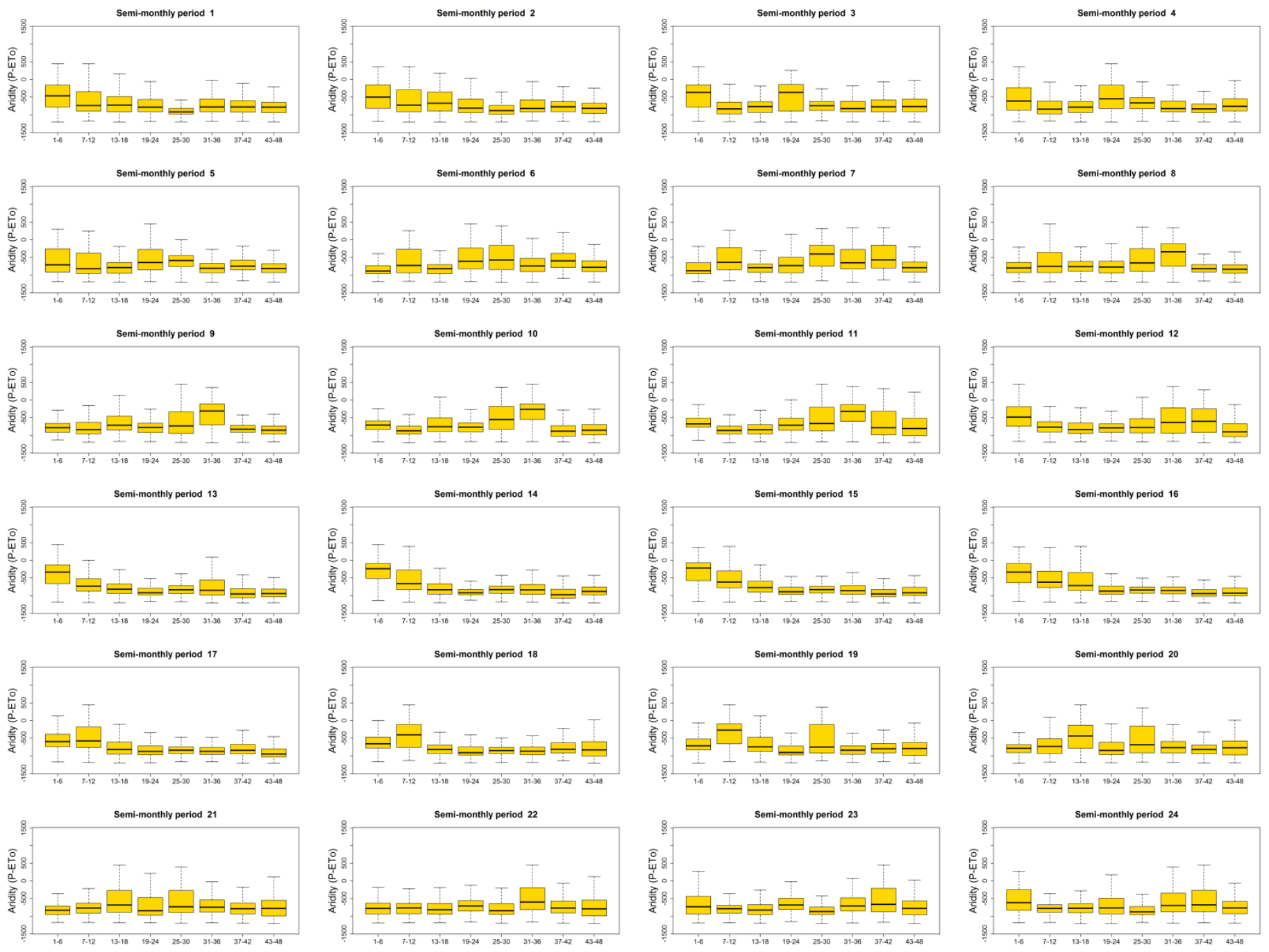

Supplementary Figure 50: Box-plots showing the values of aridity (P-AED) for areas showing maximum correlation between SPEI and sNDVI on different time scales. Transition wood-scrub. 


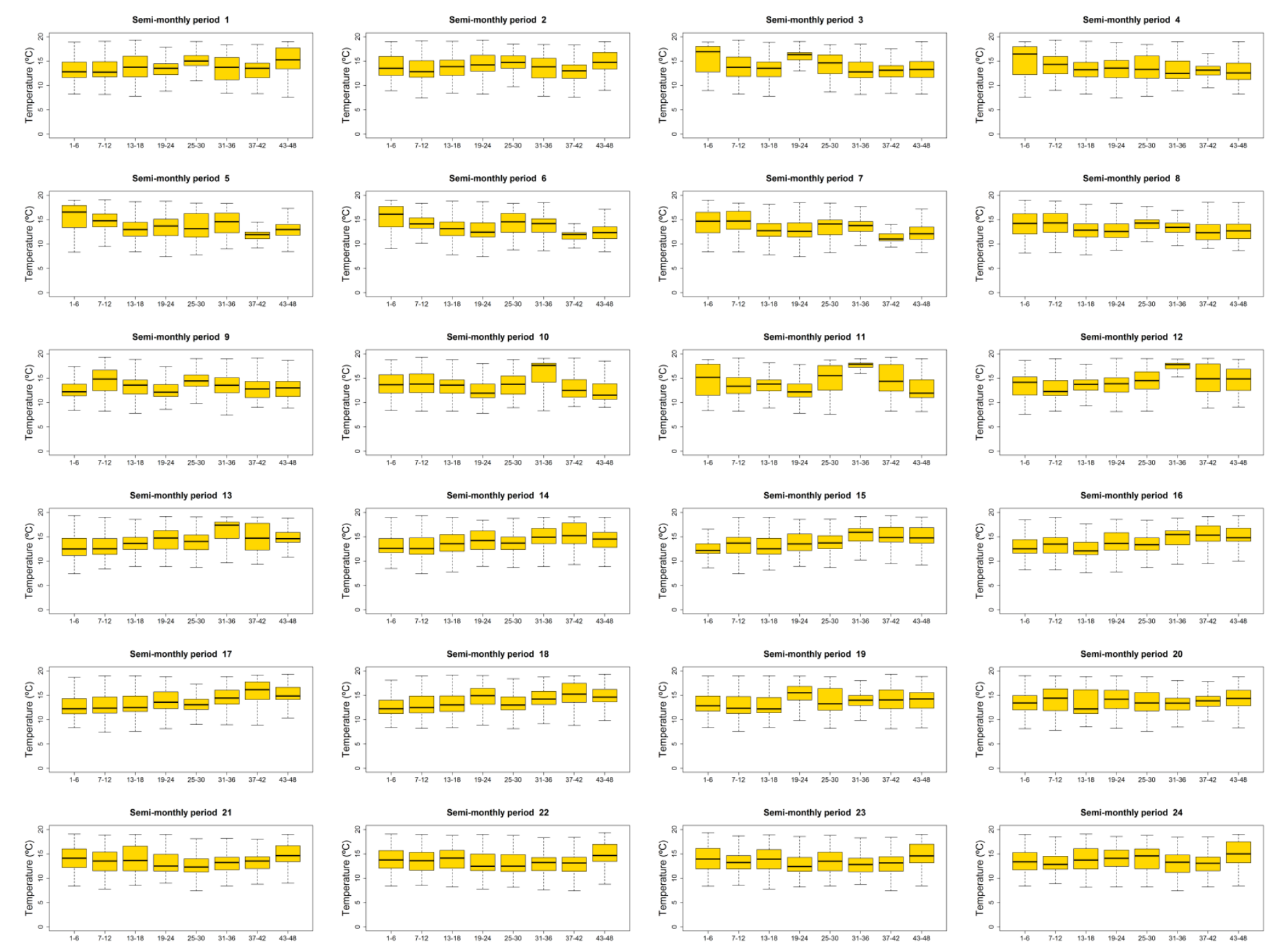

Supplementary Figure 51: Box-plots showing the values of average air temperature for areas showing maximum correlation between SPEI and sNDVI on different time scales. Non irrigated arable lands. 


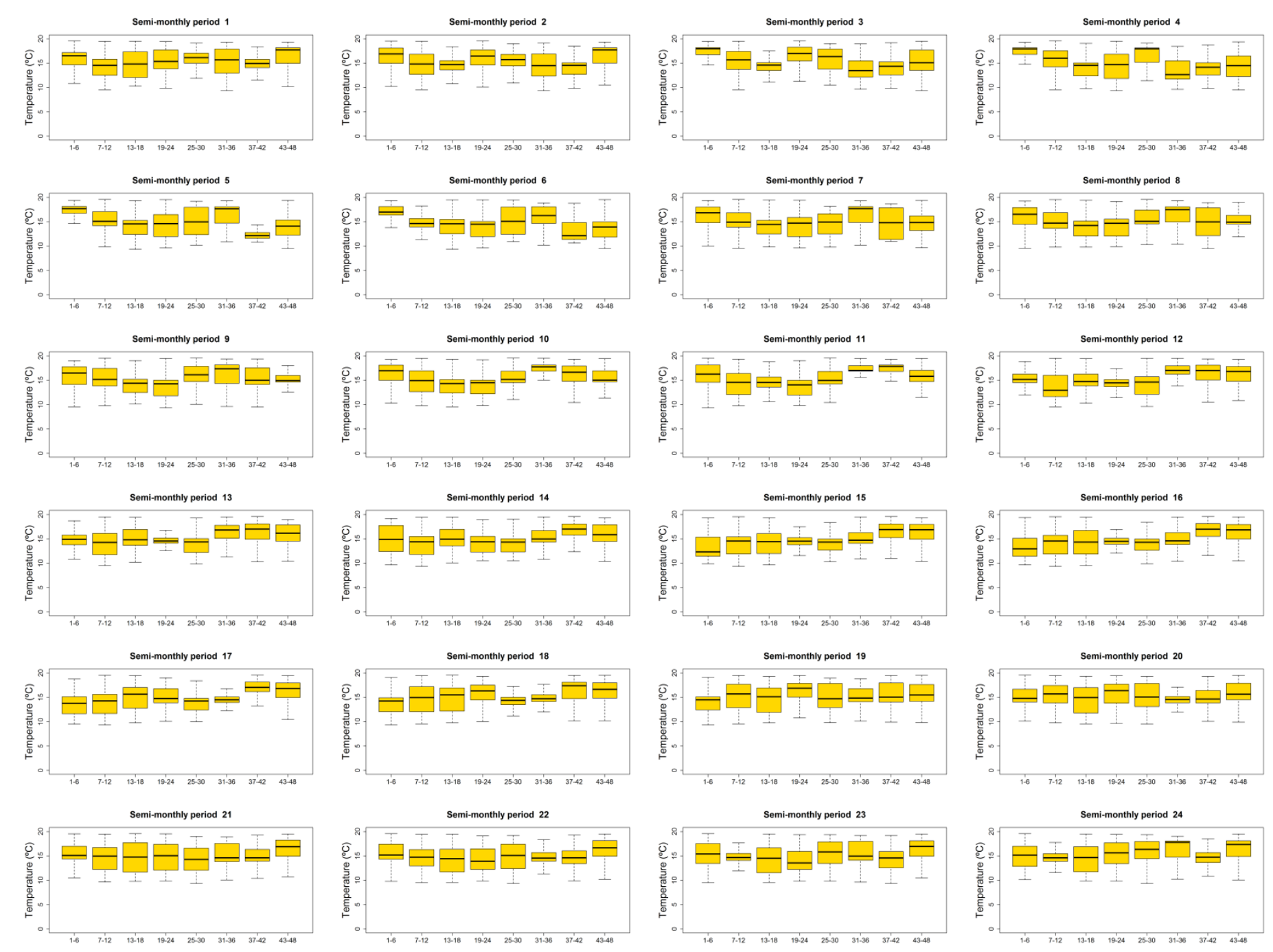

Supplementary Figure 52: Box-plots showing the values of average air temperature for areas showing maximum correlation between SPEI and sNDVI on different time scales. Irrigated lands. 


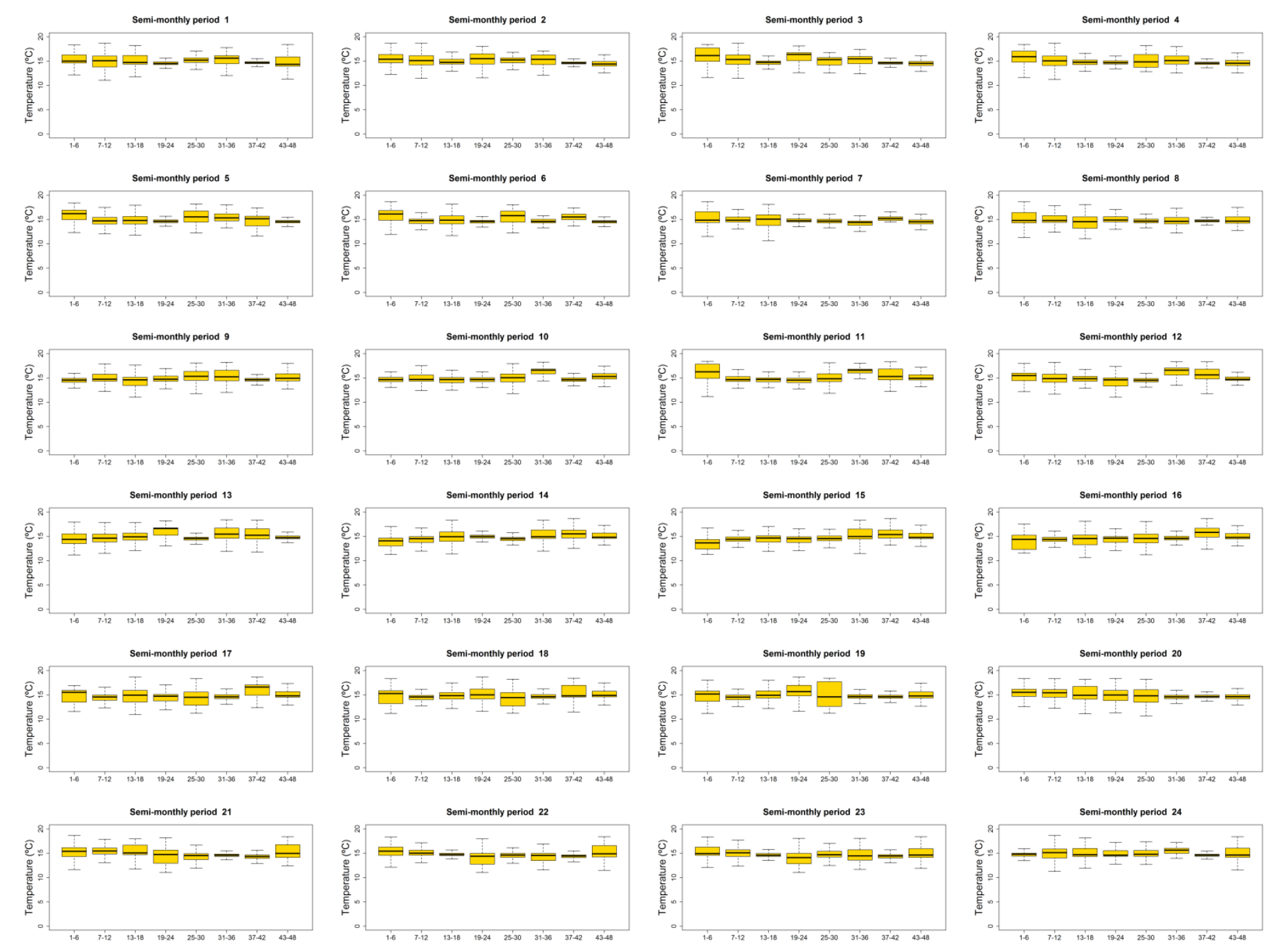

Supplementary Figure 53: Box-plots showing the values of average air temperature for areas showing maximum correlation between SPEI and sNDVI on different time scales. Vineyards. 


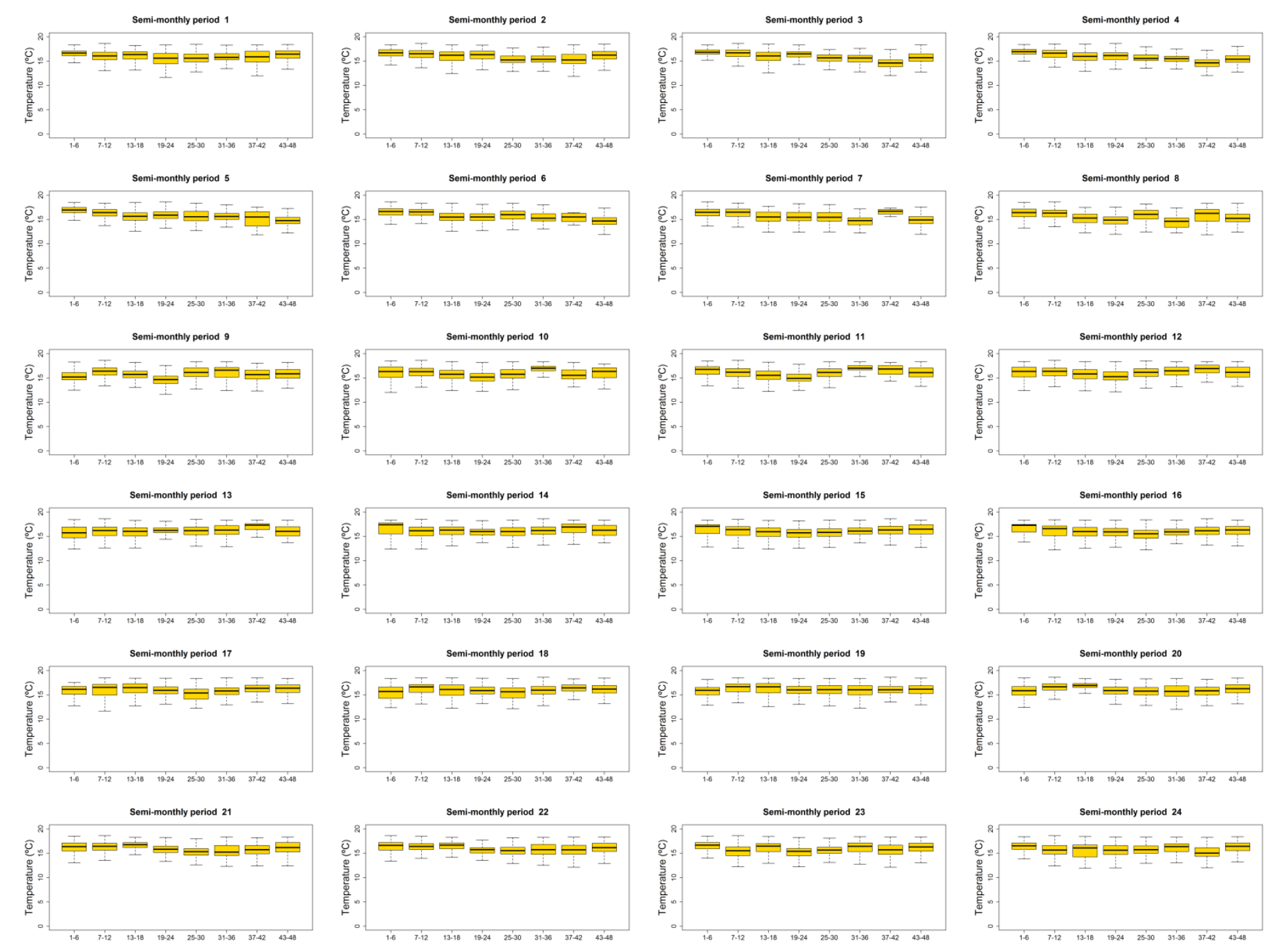

Supplementary Figure 54: Box-plots showing the values of average air temperature for areas showing maximum correlation between SPEI and sNDVI on different time scales. Olive groves. 


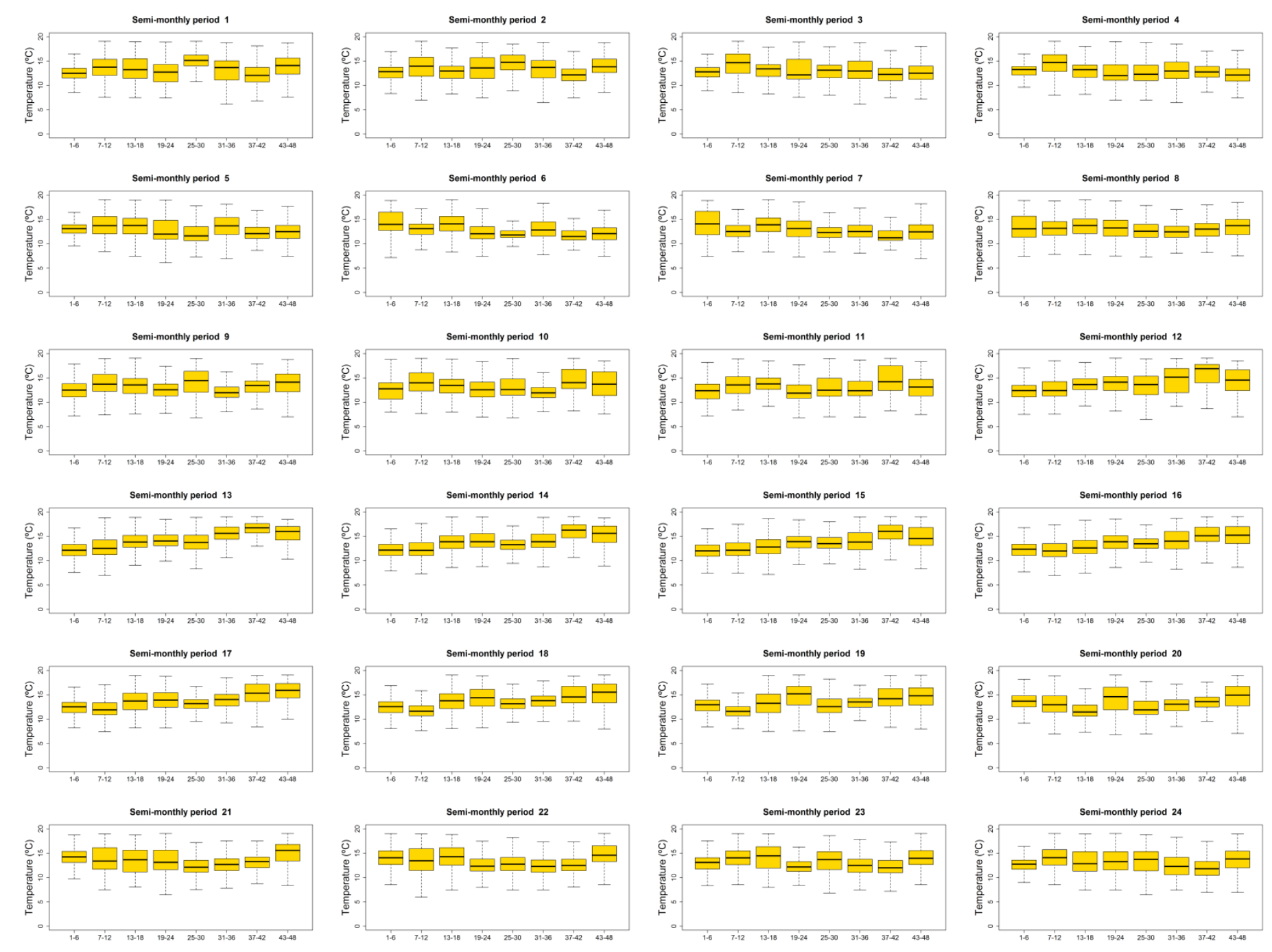

Supplementary Figure 55: Box-plots showing the values of average air temperature for areas showing maximum correlation between SPEI and sNDVI on different time scales. Mixed agriculture/natural vegetation. 


$$
\begin{aligned}
& \text { Semi-monthy period } 1 \\
& \text { Semi-monthy period } 5 \\
& \text { Semi-monthy period } 9 \\
& \text { Seml-monthly period } 10
\end{aligned}
$$

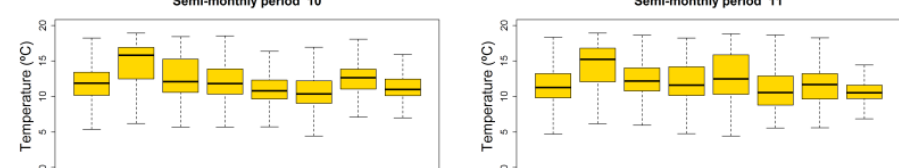

$$
\begin{aligned}
& \text { Semi-monthly period } 12 \\
& \text { Semi-monthly period } 13 \\
& \text { Semi-monthly period } 14 \\
& \text { Seni-monthly period } 15 \\
& \text { Semi-monthly period } 16 \\
& \text { Semi-monthly period } 17 \\
& \text { Semi-monthly period 18 } 18 \\
& \text { Semi-monthy period } 20 \\
& \text { Semi-monthly period } 21 \\
& \text { Semi-monthy period 22 } 22 \\
& \text { Semi-monthly period } 24
\end{aligned}
$$

Supplementary Figure 56: Box-plots showing the values of average air temperature for areas showing maximum correlation between SPEI and sNDVI on different time scales. Broad-leaved forests. 


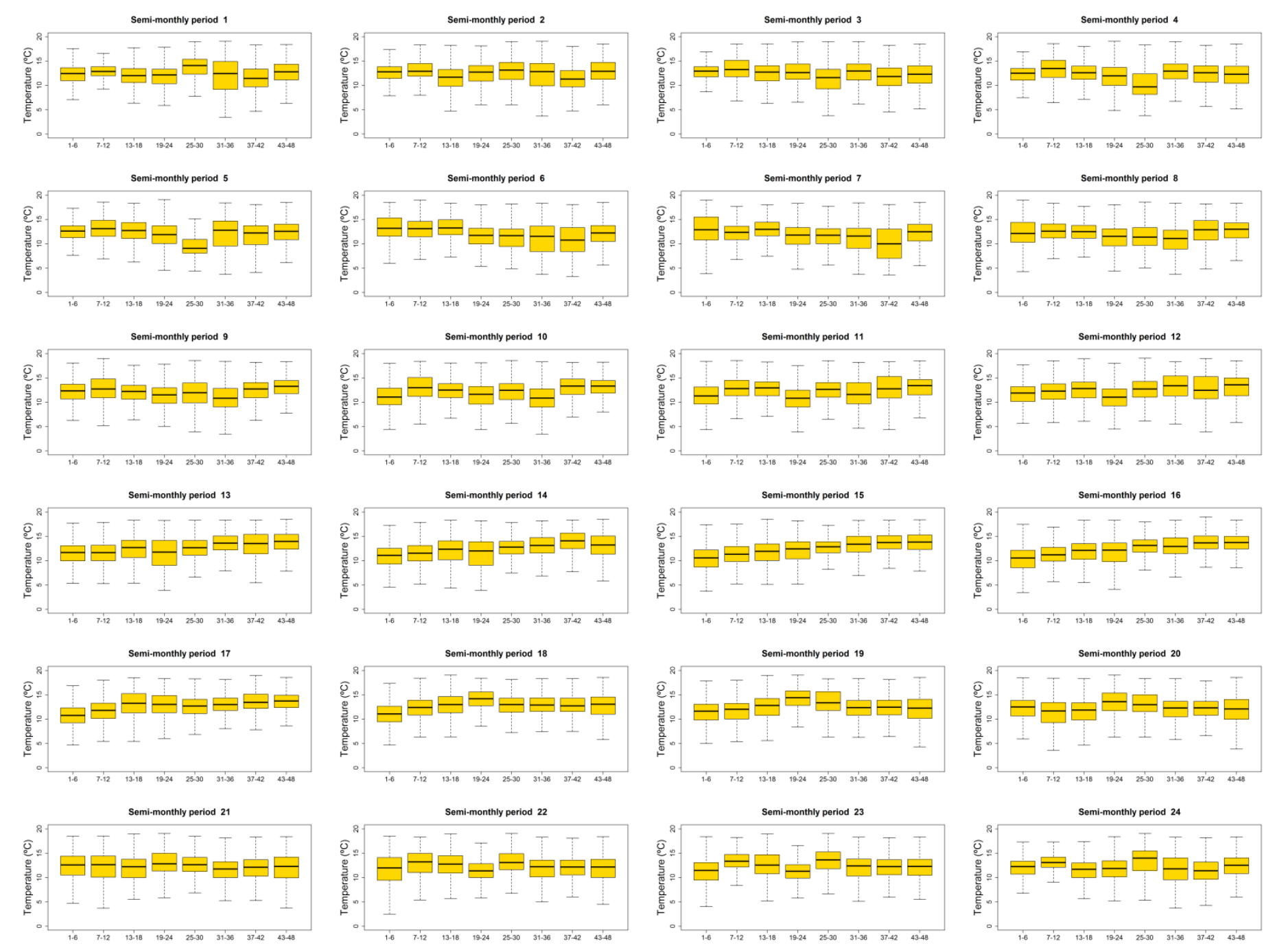

Supplementary Figure 57: Box-plots showing the values of average air temperature for areas showing maximum correlation between SPEI and sNDVI on different time scales. Coniferous forests. 


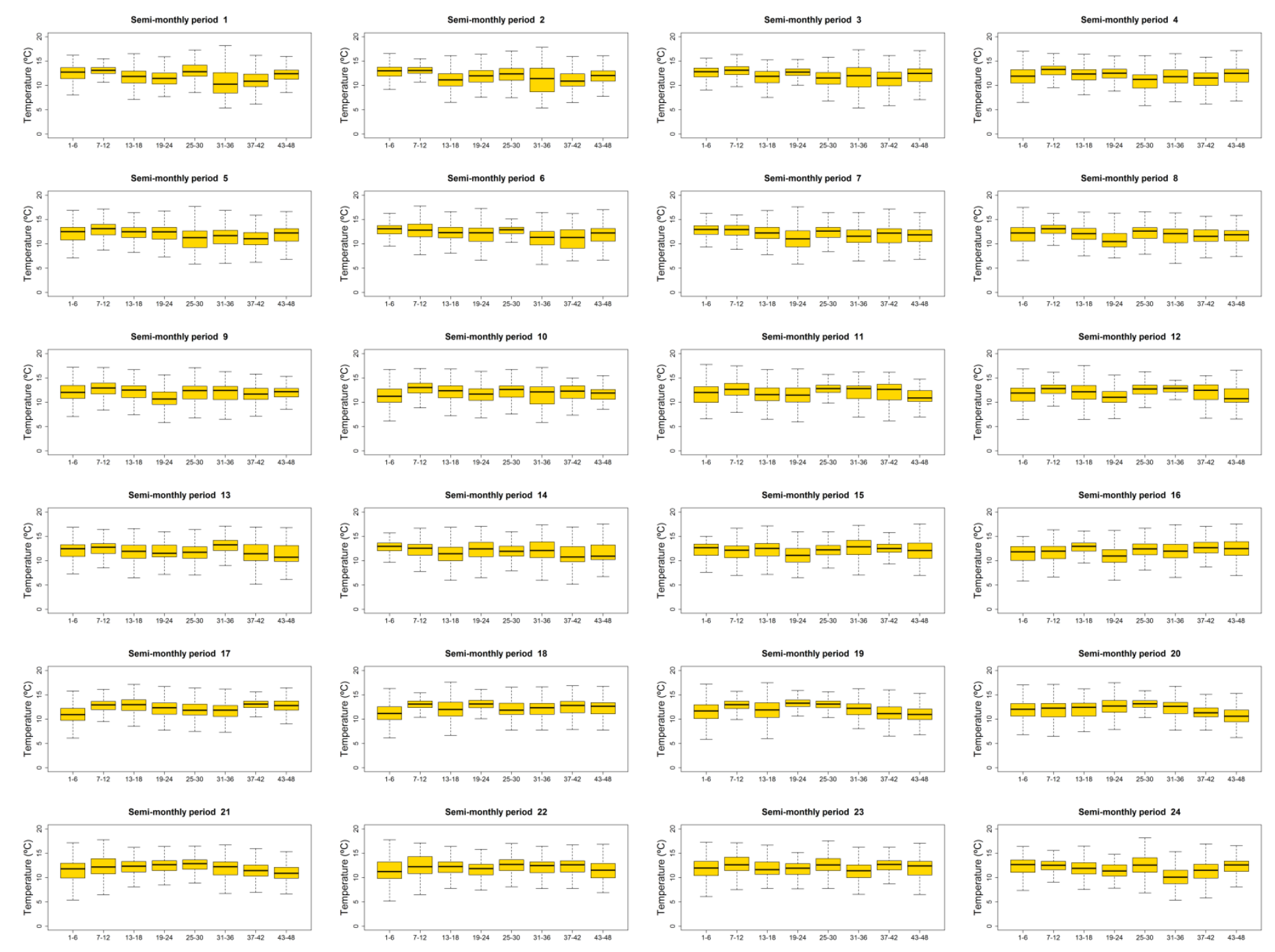

Supplementary Figure 58: Box-plots showing the values of average air temperature for areas showing maximum correlation between SPEI and sNDVI on different time scales. Mixed forests. 


$$
\begin{aligned}
& \text { Semi-monthy period } 1 \\
& \text { Semi-monthy period } 5 \\
& \text { Somi-monthy period } 9 \\
& \text { Semi-monthly period 10 } \\
& \text { Semi-monthy period } 12 \\
& \text { Semi-monthy period 13 } 13 \\
& \text { Semi-monthly period 14 } 14 \\
& \text { Semi-monthly period 15 } \\
& \text { Semi-monthly period } 16 \\
& \text { Semi-monthy period } 17 \\
& \text { Semi-monthly period } 18 \\
& \text { Semi-monthly period 19 } \\
& \text { Semi-monthly period } 20 \\
& \text { Semi-monthy period } 21 \\
& \text { Semi-monthly period } 22
\end{aligned}
$$
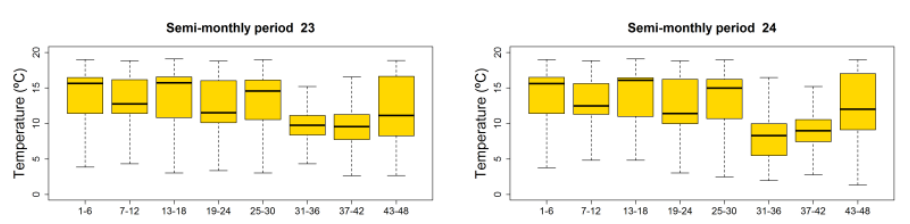

Supplementary Figure 59: Box-plots showing the values of average air temperature for areas showing maximum correlation between SPEI and sNDVI on different time scales. Natural grassland. 


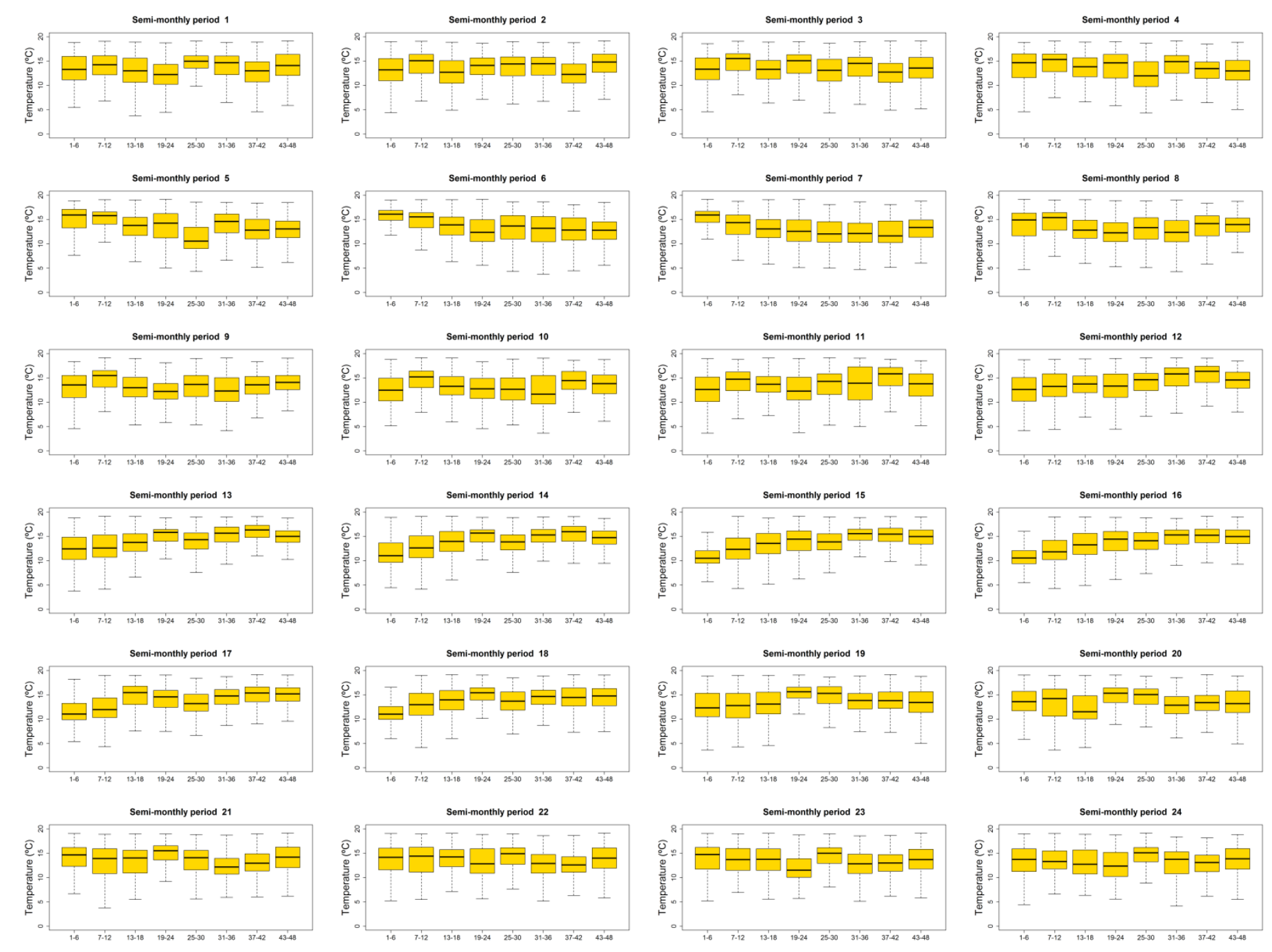

Supplementary Figure 60: Box-plots showing the values of average air temperature for areas showing maximum correlation between SPEI and sNDVI on different time scales. Sclerophillous vegetation. 


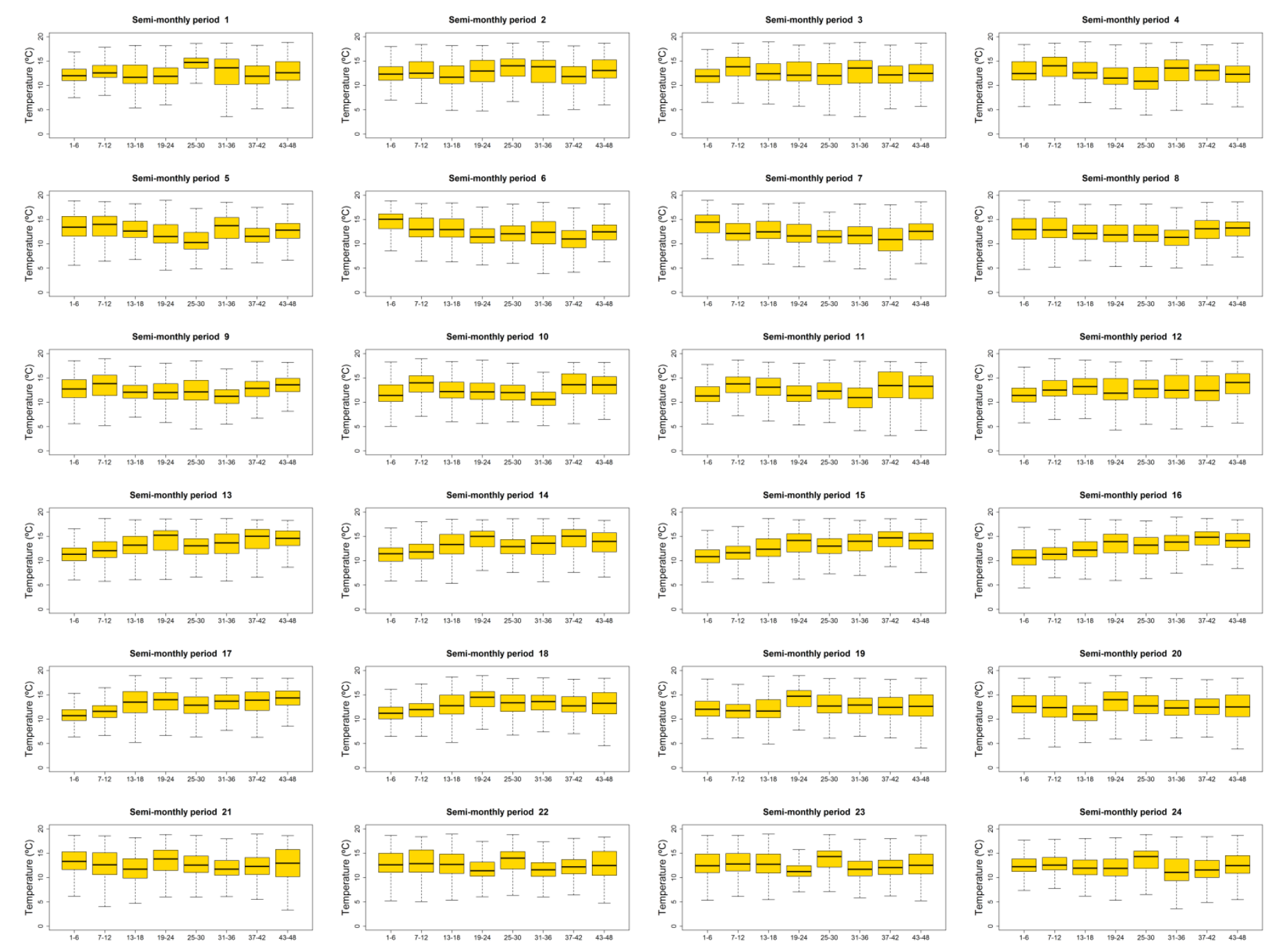

Supplementary Figure 61: Box-plots showing the values of average air temperature for areas showing maximum correlation between SPEI and sNDVI on different time scales. Transition wood-scrub. 